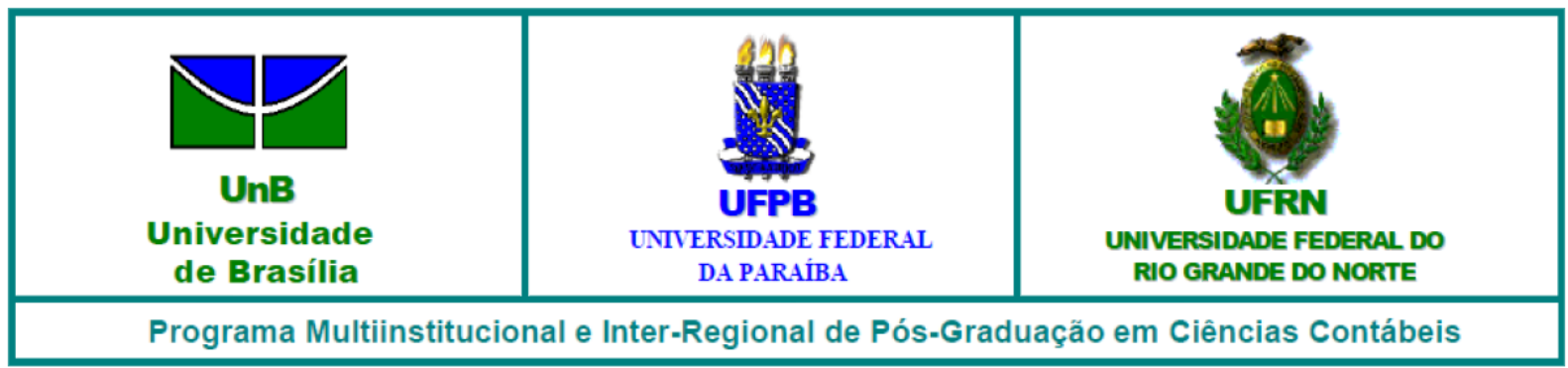

BIANCA GABRIEL FELLET

\title{
AVALIAÇÃO DE MODELOS DE PRECIFICAÇÃO DE ATIVOS NO MERCADO ACIONÁRIO BRASILEIRO
}

BRASÍLIA 


\section{UNIVERSIDADE DE BRASÍLIA - UnB}

\section{Reitor:}

Prof. Dr. Ivan Marques de Toledo Camargo

Vice-Reitor:

Prof. . Dra. Sonia Nair Báo

Decano de Pesquisa e Pós-graduação:

Prof. Dr. Jaime Martins de Santana

Diretor da Faculdade de Economia, Administração e Contabilidade:

Prof. Dr. Roberto de Goes Ellery Júnior

Chefe do Departamento de Ciências Contábeis e Atuariais:

Prof. Dr. José Antônio de França

Coordenador Geral do Programa Multiinsticucional e Inter-regional de Pós-

Graduação em Ciências Contábeis da UNB, UFPB e UFRN

Prof. Dr. Jorge Katsumi Niyama 


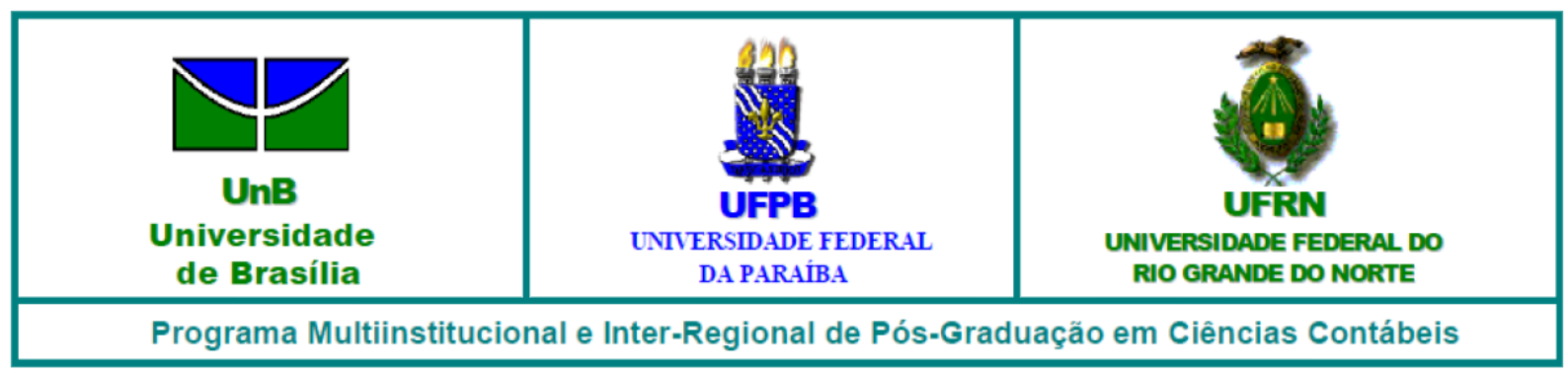

BIANCA GABRIEL FELLET

\section{AVALIAÇÃO DE MODELOS DE PRECIFICAÇÃO DE ATIVOS NO MERCADO ACIONÁRIO BRASILEIRO}

Dissertação apresentada como requisito parcial à obtenção do título de Mestre em Ciências Contábeis do Programa Multiinstitucional e InterRegional de Pós-Graduação em Ciências Contábeis da Universidade de Brasília, da Universidade Federal da Paraíba e da Universidade Federal do Rio Grande do Norte.

Linha de pesquisa: Contabilidade e Mercado Financeiro

Orientador: Prof. Otávio Ribeiro de Medeiros, $\mathrm{PhD}$ 
Fellet, Bianca Gabriel

Avaliação de Modelos de Precificação de Ativos no Mercado Acionário Brasileiro / Bianca Gabriel Fellet - Brasília, DF, 2016. 99 p.

Orientador: Prof. Otávio Ribeiro de Medeiros, $\mathrm{PhD}$

Dissertação (mestrado) - Universidade de Brasília. Faculdade de Economia, Administração e Ciências Contábeis e Atuariais - FACE. Programa Multiinstitucional e Inter-Regional de Pós-Graduação em Ciências Contábeis (UnB/UFPB/UFRN).

1. Modelos de Precificação de ativos 2. CAPM 3. CAPM Global 4.CAPM Local 5. Modelos de 3 Fatores 6. APT 7.Mercado acionário brasileiro 


\title{
AVALIAÇÃO DE MODELOS DE PRECIFICAÇÂO DE ATIVOS NO MERCADO ACIONÁRIO BRASILEIRO
}

\begin{abstract}
Dissertação apresentada como requisito parcial à obtenção do título de Mestre em Ciências Contábeis do Programa Multiinstitucional e InterRegional de Pós-Graduação em Ciências Contábeis da Universidade de Brasília, da Universidade Federal da Paraíba e da Universidade Federal do Rio Grande do Norte.
\end{abstract}

Comissão avaliadora:

Professor Otávio Ribeiro de Medeiros, $\mathrm{PhD}$

Programa Multiinstitucional e Inter-regional de Pós-graduação em Ciências

Contábeis da UNB/UFPB/UFRN

Presidente da Banca

Professor Dr. Cecílio Elias Daher

$\mathrm{ADM} / \mathrm{UnB}$

Membro Externo

Professor Dr. José Alves Dantas

PPGCont/UnB

Membro Interno

Brasília, 2016. 


\section{AGRADECIMENTO}

Agradeço primeiramente a Deus, que me permitiu chegar até aqui, sempre zelando pela minha vida e saúde. Aos meus pais, Renato e Suely, pela formação ética; pelos ricos ensinamentos de vida, amor e apoio incondicionais. À minha filha Luiza, por ser a origem de todas as minhas forças para lutar e por todo o amor que me dedicou neste período. Também à minha avó Rosa, que apesar de suas limitações não deixou um dia sequer de me querer bem ou perguntar por mim.

Ao meu querido orientador Prof. Otávio, que sempre será uma referência profissional e acadêmica. Muito mais que um orientador, o professor Otávio foi um amigo e um grande incentivador: sempre me inspirando e me fazendo ter garra para alcançar meus objetivos. Saiba o quão grande é minha admiração, tanto no âmbito profissional quanto pessoal. Não tenho palavras para agradecer seus ensinamentos, sua paciência e respeito.

Sou grata ao Departamento de Ciências Contábeis da Universidade de Brasília UnB, por ter me acolhido e estimulado ainda mais no caminho da docência e pesquisa. À equipe de professores do programa: Rodrigo, César Tibúrcio, Jorge Katsumi, Bruno, Fátima, Fernanda, Otávio e Paulo Lustosa. Aos professores José Alves Dantas e Bruno pelas contribuições ao projeto. Aos funcionários: Inez, Sara e Rodolfo, pelo apoio e força.

Aos colegas da Universidade agradeço a união, cumplicidade e convívio ao longo do curso. Em especial, aos amigos: Ricardo, Afonso, Keylla, Carlos e Eduardo, com quem partilhei inesquecíveis momentos de angústia, preocupação, alegria, esperança, amizade e que tenho como um grande legado desse mestrado.

A todos os meus amigos e familiares, especialmente aos que tiveram que se privar da minha companhia, mas que, com certeza, não deixaram de torcer por mim. Em especial a irmã que adquiri em Brasília: Thaís, Francisco que me acompanhou durante todo o tempo com estímulo, compreensão e paciência. Cecília e Lena que me apoiarem em todos os momentos, Cleide e Cícera pelas orações e apoio. Recebam todos vocês, com imenso carinho, essas palavras, que representam um registro sincero da minha gratidão! 


\section{RESUMO}

Diante da relevância da precificação de ativos no mercado acionário brasileiro, o presente estudo teve como objetivo testar e avaliar modelos de precificação de ações neste mercado. Dessa forma, buscou-se identificar o modelo que apresenta o melhor desempenho nesse mercado dentre os modelos testados: CAPM, CAPM Global, CAPM Local, APT e Modelo de 3 Fatores. Os modelos foram testados utilizando dados em painel, compostos por 132 ativos individuais (ações de empresas) e também por 60 portfólios, com dados mensais, durante o período compreendido entre 2010 e 2014. A avaliação dos modelos se deu através de análise de regressão e utilização dos critérios de Akaike e Schwarz. O modelo CAPM Global não apresentou resultados satisfatórios, enquanto que no modelo CAPM Local a inclusão do riscopaís não se mostrou significativa. Os modelos CAPM, APT e 3 Fatores se mostraram adequados à precificação de ativos no mercado em análise. Observou-se que o modelo de 3 Fatores apresentou um desempenho superior aos demais, tanto em carteiras como em ativos individuais. Entretanto, os modelos CAPM e APT também se apresentam adequados para a precificação de ativos no Brasil, e a inclusão de variáveis macroeconômicas proporcionou um melhor desempenho do modelo APT em comparação ao CAPM. Então, deve-se avaliar se o acréscimo marginal de desempenho dos modelos de 3 fatores e APT é compensatório, observando os custos operacionais da utilização de modelos mais complexos e tendo como alternativa a simplicidade da utilização do CAPM.

Palavra chave: Modelos de Precificação de ativos. CAPM. CAPM Global. CAPM Local. Modelo de 3 Fatores. APT. Mercado acionário brasileiro. 


\begin{abstract}
Having in mind the relevance of asset pricing in the Brazilian stock Market, this study is aimed at testing and assessing stock pricing models in that market. Accordingly, we attempted to identify the model with the best performance among the ones tested: CAPM, Global CAPM, Local CAPM, APT, and Fama and French's 3-Factor model. These models were tested by means of panel data regressions comprising 132 individual company stocks and also 60 portfolios using monthly data during the period from 2010 and 2014. Model assessment was carried out by means of regression analysis and the use of Akaike and Schwarz information criteria. The empiricals have shown that Global CAPM has not presented satisfactory results, while in Local CAPM the inclusion of country risk has not proved significant. CAPM, APT and 3-Factor models have shown to be appropriate for asset pricing in the market under analysis. We noticed that the 3-Factor model has shown a higher performance with respect to the others both when testing portfolios and individual assets as well. However, CAPM and APT have also shown to be adequate for asset pricing in Brazil, and the inclusion of macroeconomic variables has provided a better performance of APT with respect to CAPM. Nevertheless, one should assess whether the marginal improvement that can be obtained from using 3-Factor and APT is worthwhile, taking into account the operating costs of using models that are more complex when one has as an alternative the simplicity of CAPM.
\end{abstract}

Keywords:Asset Pricing Models. CAPM. Global CAPM. Local CAPM. 3-Factor Model. APT. Brazilian Stock Market. 


\section{LISTA DE ABREVIATURAS}

ADF

AIC

APT

BACEN

BIC

BM\&FBovespa

CAPM

CDI

DW

EMBI+

EUA

FIV

HME

HML

IBGE

IBOVESPA

IPCA

IPEA

LLC

MELNV

MQO

NYSE

PIB

PP

SMB

S\&P500

SUR

VM

VP

US CPI
Teste Dickey-Fuller Aumentado

Critério Informacional de Akaike

Arbitrage Pricing Theory

Banco Central do Brasil

Critério Informacional Bayesiano ou Schwarz

Bolsa de Valores, Mercadorias e Futuros de São Paulo

Capital Asset Pricing Model

Certificado de Depósito Interbancário

Teste de Durbin-Watson

Emerging Markets Bond Index Plus

Estados Unidos da América

Fator de Inflação da Variância

Hipótese do Mercado Eficiente

High Minus Low

Instituto Brasileiro de Geografia e Estatística

Índice BOVESPA

Índice de Preços ao Consumidor Amplo

Instituto de Pesquisa Econômica Aplicada

Teste de Levin, Lin, e Chu

Melhor Estimador Linear Não-Viesado

Método dos Mínimos Quadrados Ordinários

New York Stock Exchange

Produto Interno Bruto

Teste de Phillips-Perron

Small Minus Big

Standard \& Poor's 500

Seemingly Unrelated Regressions With Identical Regressors

Valor de Mercado

Valor Patrimonial

United States Consumer Price Index 


\section{ÍNDICE DE TABELAS}

Tabela 1 - Fatores macroeconômicos....................................................................... 56

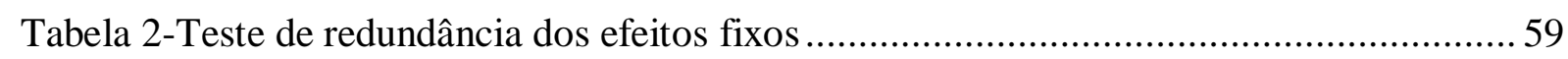

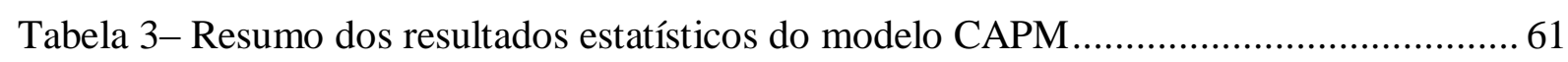

Tabela 4 - Resumo dos resultados estatísticos do modelo CAPM Global ........................... 61

Tabela 5- Resumo dos resultados estatísticos do modelo CAPM Local ................................62 62

Tabela 6 - Resumo dos resultados estatísticos do modelo de 3 Fatores ................................63

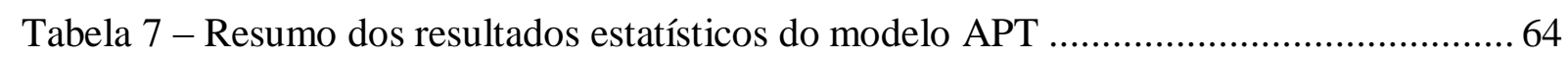

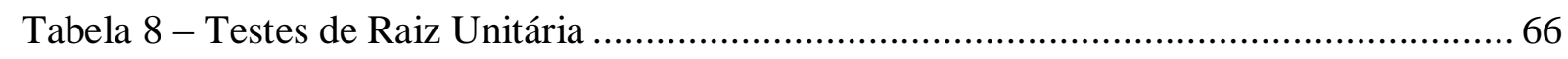

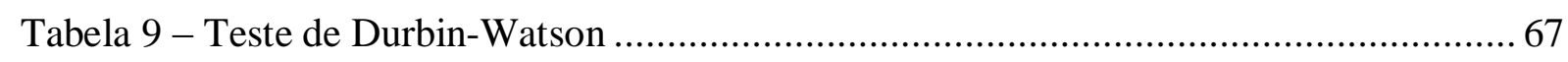

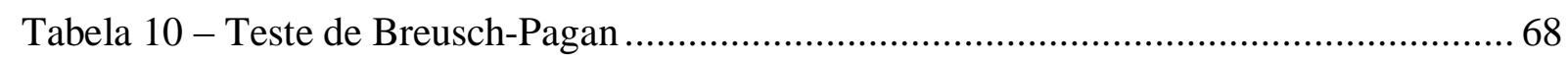

Tabela 11 - Resultados dos testes de normalidade dos resíduos....................................... 70

Tabela 12 - Resultados dos testes do Fator de inflação da variância (FIV) .......................... 71

Tabela 13- Resumo dos resultados estatísticos de todos os modelos................................... 72

Tabela 14- Critérios de comparação dos modelos ......................................................... 74 


\section{ÍNDICE DE QUADROS}

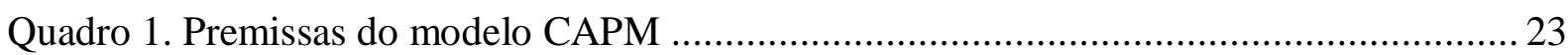

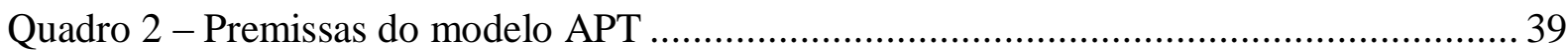

Quadro 3 - Vantagens, desvantagens e evidências empíricas dos métodos de estimação de

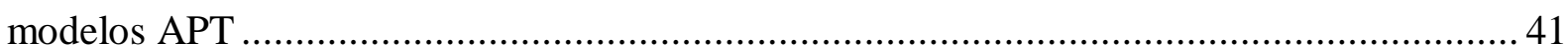

Quadro 4 - Estudos precursores sobre a relação entre o retorno das ações e outras variáveis. 43

Quadro 5 - Estudos realizados no mercado acionário brasileiro ........................................ 46

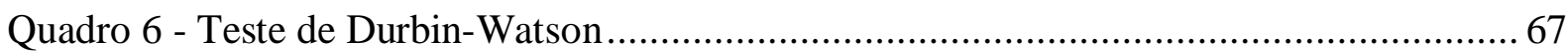




\section{SUMÁRIO}

1 INTRODUÇÃO

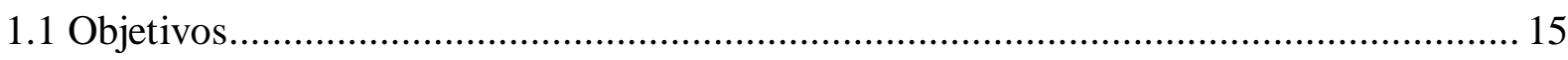

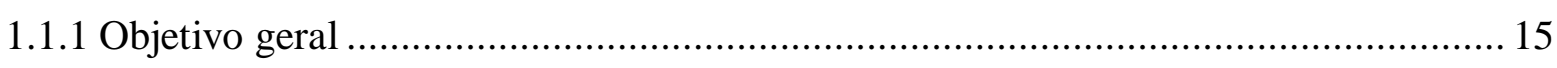

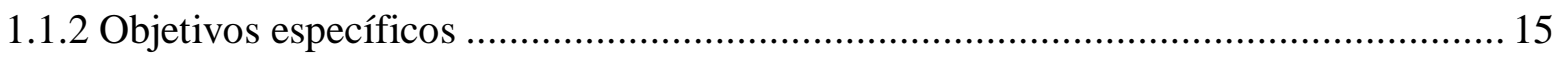

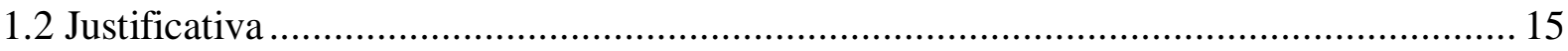

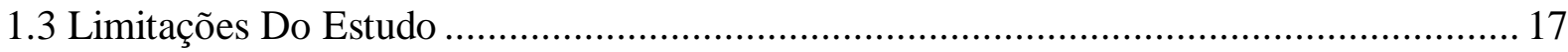

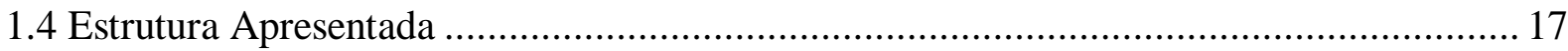

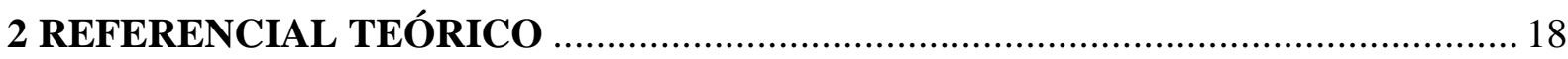

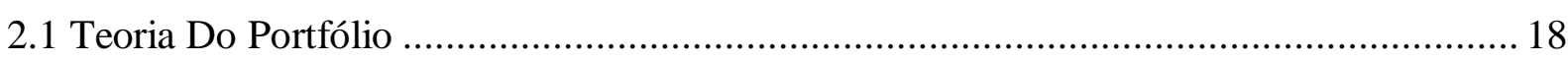

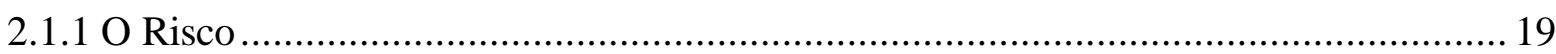

2.2 A Hipótese Do Mercado Eficiente (HME) ………………............................................ 20

2.3 Introdução Ao Desenvolvimento Teórico Do CAPM………………………………….... 22

2.4 O CAPM

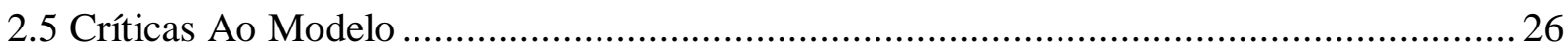

2.6 As prospostas de adaptação do CAPM aos mercados emergentes ..................................... 28

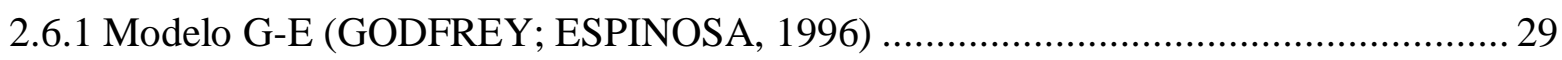

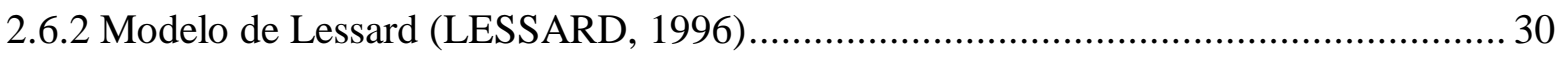

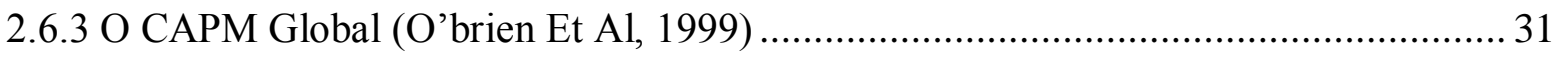

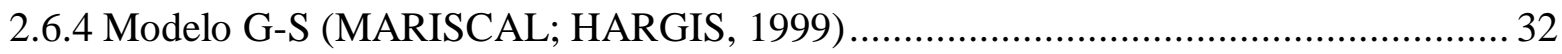

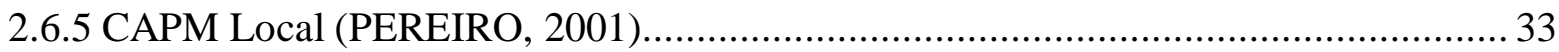

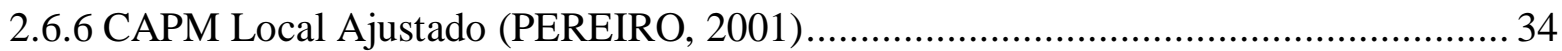

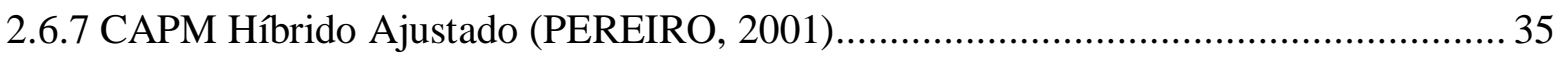

2.6.8 Modelo de Assaf Neto et al (ASSAF NETO et al, 2008) ............................................. 36

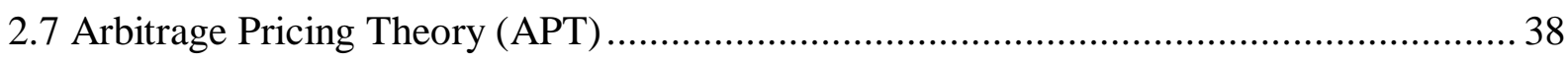

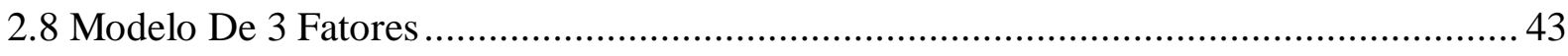

2.9 Testes Empíricos Dos Modelos De Precificação De Ativos Em Economias Emergentes . 46

2.10 Evidências Empíricas Dos Modelos De Precificação De Ativos No Brasil..................... 47

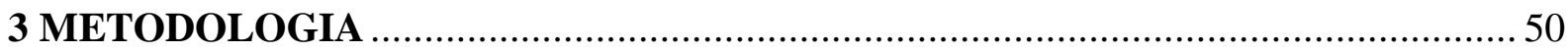

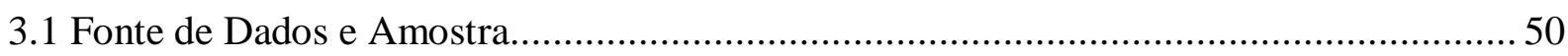

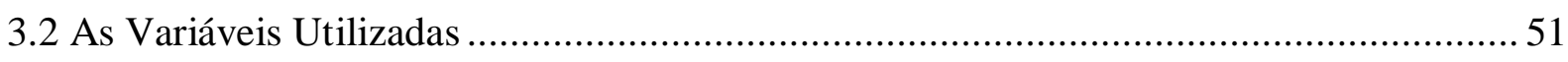

3.3 Descrição Dos Modelos Econométricos Utilizados............................................................ 53 
3.3.1 O Modelo CAPM (Sharpe, Lintner e Mossin, 1965) ............................................. 53

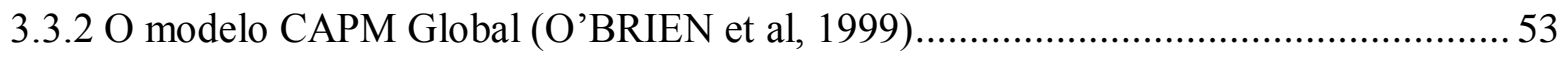

3.3.3 O modelo CAPM Local (PEREIRO, 2001) ......................................................... 54

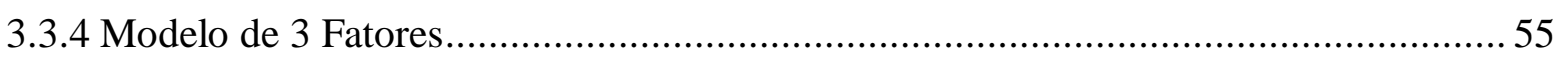

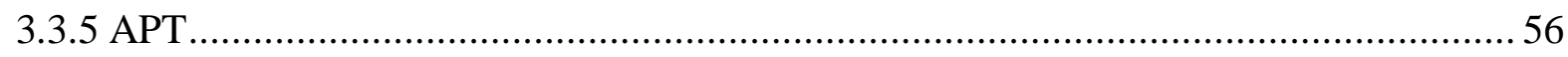

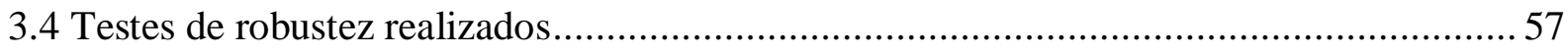

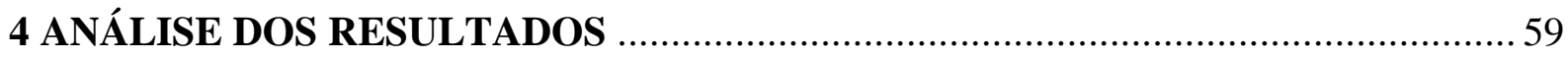

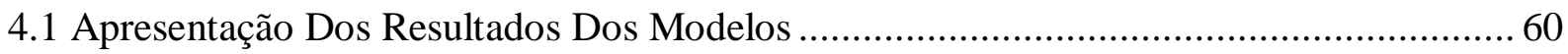

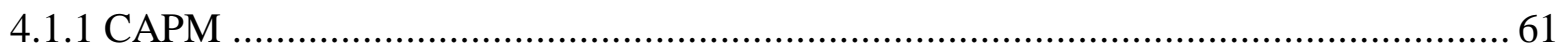

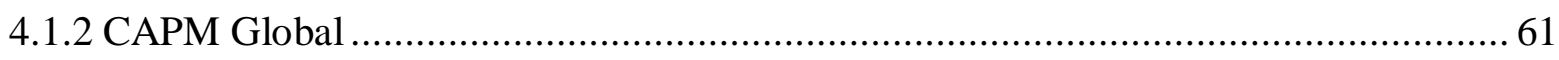

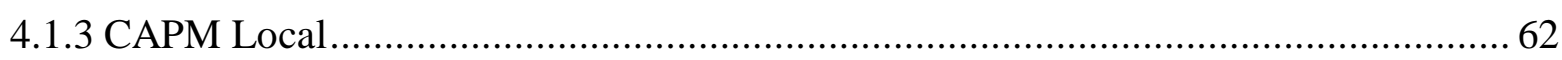

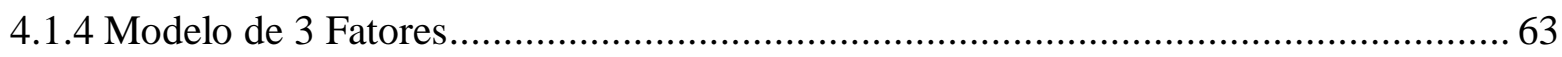

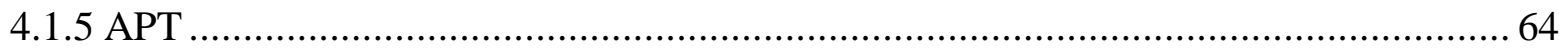

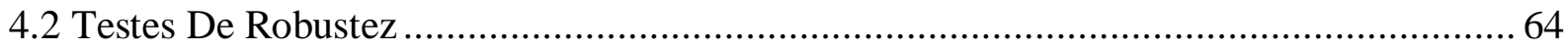

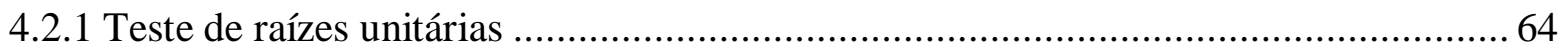

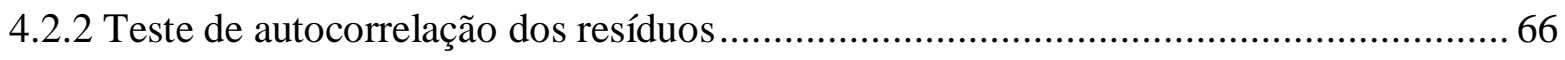

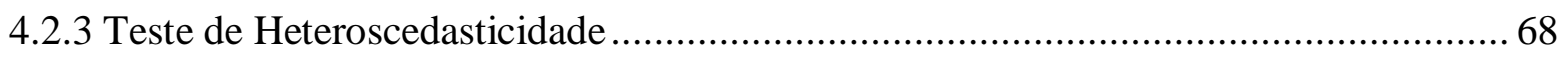

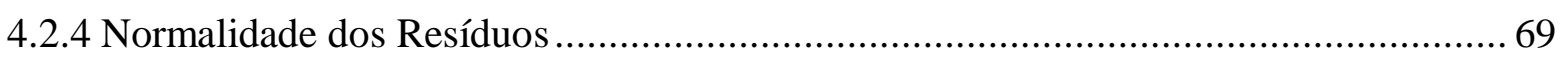

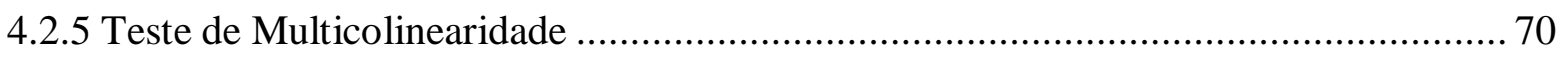

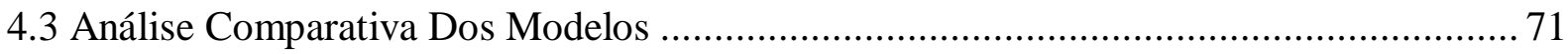

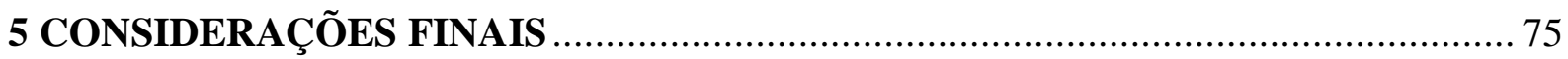

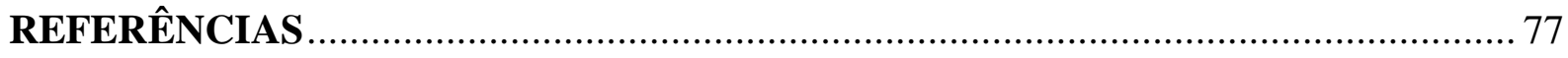

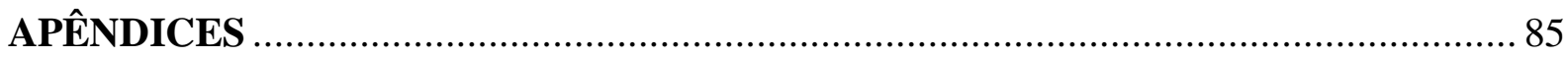




\section{INTRODUÇÃO}

O processo de globalização dos investimentos consiste em um desafio para os modelos de precificação de ativos, tendo em vista a exposição ao risco, inerente ao país no qual é realizado o investimento. De acordo com Damodaran (2006), a precificação pode ser considerada como o coração das finanças corporativas. Em finanças considera-se que a melhor forma de aumentar o valor da firma é aprimorando as decisões de investimentos, financiamentos e distribuição de dividendos. Na gestão de carteiras, procura-se encontrar papéis negociados por um valor inferior ao seu valor real para, em seguida, ter-se uma perspectiva de geração de lucros na convergência de preços e valor. Para saber se os mercados são eficientes, analisam se os preços de mercado e seus desvios em relação ao seu valor, e com que rapidez eles convergem. Entender os determinantes do valor, portanto é um prérequisito para a realização de decisões financeiras acertadas.

Dentre os modelos de precificação de ativos destaca-se o Capital Asset Pricing Model (CAPM) ou Modelo de Precificação de Ativos de Capital, desenvolvido por Sharpe (1964), Lintner (1965) e Mossin (1966), que proporciona a determinação do preço em função do relacionamento entre o retorno esperado e o risco para qualquer ativo financeiro, partindo do pressuposto de um mercado em equilíbrio, situação caracterizada pela existência de um preço relacionado ao desempenho esperado de cada ativo listado em bolsa.

Muitos são os estudos empíricos que analisam a capacidade preditiva e validade do CAPM na precificação de ativos no Brasil e em outras economias emergentes, questionando se as premissas nas quais o modelo se baseia são válidas nesses mercados. Uma das premissas questionadas é a eficiência do mercado de capitais brasileiro. Embora o modelo seja alvo de várias críticas, sua importância é reconhecida. Podem ser observadas também várias propostas de adaptação do modelo tradicional às economias emergentes. Apesar de serem vários os modelos que propõem adaptações mais complexas ao CAPM tradicional, os estudos acerca de sua validade no mercado brasileiro ainda são escassos e inconclusivos (GALDI; SECURATO, 2007; LINS; SILVA; MARQUES, 2007; ROGERS; SECURATO; 2008; CASOTTI; MOTTA; 2008; MACHADO; MEDEIROS, 2012; NODA; et al, 2015).

Apesar de todas as controvérsias existentes acerca do assunto, a utilização do modelo persiste no meio acadêmico, como pode ser constatado em diversos estudos, bem como na prática do mercado financeiro, pelos analistas das corretoras, bancos de investimento, 
empresas avaliadoras, etc (COPELAND, 2002; MACHADO, 2007; GÁRRAN; MARTELANC, 2007; ASSAF NETO. et al., 2008, CUNHA, 2011; LUCENA; et al, 2013).

Mesmo diante de críticas a respeito do seu desempenho no mercado brasileiro, Araújo e Silva (2012) analisaram os estudos sobre o CAPM no mercado brasileiro, constatando que em mais de $58 \%$ da amostra foi confirmada sua efetividade na precificação de ativos. Entretanto, o restante dos estudos não confirmou a eficácia do modelo, sendo que em quase $42 \%$ da amostra a sua capacidade preditiva do retorno para o acionista foi rejeitada. Diante do exposto, ressalta-se a ausência de consenso no que tange à precificação de ativos no mercado brasileiro e à utilização do CAPM.

Dentre os modelos alternativos ao CAPM, foram observadas diversas propostas de adaptação buscando melhorar o poder explicativo do CAPM tradicional, citando como exemplos: CAPM Intertemporal (MERTON, 1973), CAPM Global (O’BRIEN et al, 1999) CAPM Local (PEREIRO, 2001), CAPM Local Ajustado (PEREIRO, 2001), CAPM Híbrido Ajustado (PEREIRO, 2001), Modelo de Lessard (LESSARD, 1996), Modelo G-E (GODFREY; ESPINOSA, 1996), Modelo G-S (Mariscal; Hargis, 1999), Downside-CAPM (ESTRADA, 2002), CAPM Condicional (LEWELLEN; NEGEL, 2003) e Modelo de Assaf Neto et al (ASSAF NETO; et al, 2008).

Em decorrência de diversos testes empíricos realizados, foi questionada a capacidade de um modelo de um único fator explicar o retorno dos ativos. Dessa forma, iniciou-se a busca por outros fatores que pudessem aprimorar o poder explicativo do CAPM e capturar algumas anomalias encontradas no mercado (REIGANUM, 1981; BANZ, 1981; BASU, 1983; BHANDARI, 1988; ROSENBERG; REID; LANSTEIN,1985 e FAMA; FRENCH, 1993).

Como alternativa ao tradicional modelo CAPM e visando aumentar seu poder explicativo, foi desenvolvida por Ross (1976) a Arbitrage Pricing Theory ou Teoria de Formação de Preços por Arbitragem (APT), que, , inserindo variáveis macroeconômicas que possam explicar o retorno dos ativos, flexibiliza a ideia de que apenas um único fator (beta do prêmio de mercado) é capaz de explicar o retorno de ativos com risco. Entretanto, não são definidas no estudo original quais e quantas variáveis devem ser inseridas no modelo, e dessa forma as discussões ainda persistem.

Em 1992, Fama e French relatam em seus estudos as anomalias do mercado e consideram a capacidade de que outros fatores, além de um único fator, como preconiza o CAPM, possam afetar o retorno das ações. Então, Fama e French (1993) formularam o modelo de três fatores. Assim como no CAPM, um dos fatores de risco do modelo é o 
mercado, e são incluídos o efeito tamanho da empresa, definido pelo valor de mercado do patrimônio líquido, e o índice Book-to-Market, definido pela relação entre o valor patrimonial contábil e o valor de mercado do patrimônio líquido.

Diante do exposto nesse cenário e considerando o debate acerca da aplicabilidade e validade dos diversos modelos de precificação de ativos, este trabalho procura identificar entre algumas das alternativas de modelos propostos, aquele(s) que possui(em) uma maior capacidade de explicação dos retornos no mercado acionário brasileiro, já que apesar de já existirem alguns trabalhos nesta linha, ainda não se observa uma metodologia empírica consolidada a respeito da forma a se testar e são observados estudos com metodologias diferentes e resultados controversos.

Assim, define-se como problema de pesquisa: Qual entre os modelos de precificação de ativos: CAPM, CAPM Global, CAPM Local, APT e Modelo de 3 Fatores apresenta melhor desempenho na precificação de ações negociadas na Bolsa de Valores de São Paulo?

\subsection{Objetivos}

\subsubsection{Objetivo geral}

Testar e avaliar modelos de precificação de ações no mercado acionário brasileiro, aplicando-os às ações negociadas na Bolsa de Valores de São Paulo e identificando dentre os modelos testados aquele(s) que apresenta(m) desempenho superior.

\subsubsection{Objetivos específicos}

- Pesquisar na literatura existente os modelos de precificação de ativos

- Selecionar os modelos a serem testados

- Coletar os dados para testar os modelos selecionados

- Testar os modelos selecionados utilizando métodos de regressão

- Analisar o desempenho dos modelos no mercado acionário brasileiro

- Definir metodologia para comparação dos resultados obtidos

- Comparar os resultados obtidos e identificar dentre os modelos testados aquele que possui um melhor desempenho no mercado acionário brasileiro

\subsection{Justificativa}

A precificação de ativos tem sido amplamente discutida em função de sua relevância nas decisões de alocação de recursos, principalmente por considerar a relação entre o risco e o 
retorno requerido. Através dos modelos de precificação de ativos o custo de capital é determinado e projetos de viabilidade de investimentos são analisados em relação a tal variável. Dessa forma ressalta-se a importância dos modelos de precificação de ativos.

O questionamento acerca da validade do modelo CAPM de Sharpe, Lintner e Mossin é recorrente. Várias são as alternativas ao modelo como por exemplo o APT de Ross (1976) e o Modelo de três fatores de Fama e French (1993). Entretanto, não existe uma teoria consolidada que justifique tais modelos de modo pleno. No presente trabalho, pretende-se contribuir com a literatura acadêmica sobre precificação de ativos, utilizando o CAPM e suas adaptações, o APT de Ross (1976) e o modelo de três fatores de Fama e French (1992) e avaliando qual (ais) modelo(s) de precificação de ativos é (são) mais adequado (s) ao mercado brasileiro. Visto que o mercado de capitais das economias emergentes apresentam particularidades em relação ao mercado de capitais de países com economia plenamente desenvolvida.

A pesquisa em finanças no Brasil tem se desenvolvido muito nos últimos anos, mas ainda está aquém daquela realizada em países mais avançados. Dentre as razões para isso destacam-se a insuficiência e baixa disponibilidade de dados, e do reduzido número de pesquisadores em finanças no país (Mendes da Silva et al, 2013). Dessa forma, observam-se limitações que tornam a precificação de ativos um assunto com amplo espaço para pesquisa no Brasil.

Após o período de hiperinflação e a implantação do Plano Real, abriu-se um extenso campo de estudo e discussões sobre a validade de proxies de variáveis do mercado brasileiro para estimação dos modelos de precificação de ativos, já que passou a ocorrer uma maior estabilidade em seus preços. Assim, começou a ser disponibilizada uma base de dados mais confiável do mercado brasileiro, e também mais adequada às pesquisas acadêmicas na área de finanças, que pode ser utilizada na precificação de ações.

O presente estudo busca contribuir com testes empíricos acerca da precificação de ativos no mercado acionário brasileiro, identificando dentre os modelos estudados aquele(s) que apresenta(m) melhor desempenho na precificação de ações da BM\&FBovespa, colaborando com a discussão acadêmica acerca do assunto e também com a resolução de questões de ordem prática enfrentadas por analistas do mercado financeiro na precificação de ativos. 


\subsection{Limitações do Estudo}

Uma das principais limitações deste estudo consiste no fato de a análise ser realizada apenas com empresas brasileiras durante o período compreendido entre 2010 e 2014, dessa forma, não se podendo assim identificar o modelo mais adequado a períodos não contemplados neste estudo, visto que o mercado financeiro brasileiro apresenta diversas particularidades e mudanças ao longo do tempo.

O estudo não pretende abordar empresas do setor financeiro, visto que estas foram excluídas da amostra em função de suas particularidades, principalmente em relação a sua estrutura de capital. Assim, outra limitação do estudo refere-se às inferências sobre os setores de atuação das empresas, não sendo o objeto de estudo identificar o modelo mais adequado para cada setor.

Podem ser encontrados na literatura diversos outros modelos de precificação de ativos. Portanto de forma alguma se pretende esgotar o assunto, mas apenas contribuir com as discussões, visto que ainda existem muitos outros modelos que poderiam ser testados e outras metodologias empíricas que não foram contemplados neste estudo.

\subsection{Estrutura Apresentada}

Para o desenvolvimento do estudo apresentado nesta introdução, foram utilizadas quatro seções adicionais, além das referências. A Seção 2 apresenta o referencial teórico onde está presente a teoria de base sobre precificação de ativos, os modelos são apresentados e são relatados estudos anteriores que visam alicerçar o desenvolvimento deste trabalho. A Seção 3 discorre sobre a metodologia de pesquisa, que apresenta as etapas de coleta e tratamento dos dados e os modelos utilizados. A Seção 4 enfatiza os resultados e as análises para que, em seguida, na Seção 5, sejam apontadas as considerações finais deste estudo. 


\section{REFERENCIAL TEÓRICO}

O referencial teórico divide-se em dez partes. Nas três primeiras são apresentadas a fundamentação conceitual e teórica para os modelos de precificação de ativos. Em seguida o modelo CAPM de Sharpe (1964), Lintner (1965) e Mossin (1966) é apresentado, bem como os parâmetros que o compõe. Nas seções 2.5 e 2.6 apresentam-se as críticas, propostas alternativas e adaptações ao modelo. Nas seções 2.7 e 2.8 é feita uma apresentação sobre os modelos APT de Ross (1976) e o modelo de 3 Fatores de Fama e French (1992). Por fim, nas duas últimas seções, relatam-se os testes empíricos acerca dos modelos e suas adaptações no Brasil e demais economias emergentes.

\subsection{Teoria do Portfólio}

A teoria de seleção de portfólio de Markowitz (1952) parte da premissa de que o investidor considera o retorno como algo desejável e sua variabilidade um aspecto indesejável, sendo tais variáveis representadas pelo retorno esperado e o risco (variância desse retorno). Esses critérios seriam fundamentais para o investidor, uma vez que o retorno futuro não pode ser definido com absoluta certeza: ele deve ser "esperado" ou "antecipado" em forma de desconto a valor presente. A teoria da seleção do portfólio assume como regra que na escolha da carteira, o investidor deveria maximizar o retorno descontado, hipótese essa que deve ser rejeitada, sob a premissa de que as imperfeições do mercado devem ser ignoradas, já que regra anterior não implica na existência uma carteira diversificada que é preferível a todas as demais carteiras. Como os investidores estariam de acordo quanto à distribuição de probabilidades das taxas de retorno dos ativos, seria assegurada a existência de um conjunto de carteiras eficientes.

São premissas da teoria a racionalidade econômica dos investidores e sua aversão ao risco, de modo que, dentre opções de investimento com mesmo retorno, os investidores sempre escolheriam a opção de menor risco, e diante de opções de risco semelhantes os investidores sempre escolheriam a opção que conferisse maior retorno. Visando a simplificação das percepções dos investidores, assume-se que todos os estariam em acordo quanto à distribuição de probabilidades das taxas de retorno dos ativos (MARKOWITZ, 1952). 
O retorno da carteira como um todo é uma média ponderada do retorno dos ativos individuais (onde o investidor pode escolher os pesos). A carteira com o máximo retorno esperado não é necessariamente a carteira com variância mínima. O investidor pode obter maior retorno esperado assumindo um aumento no risco, ou reduzir a variância em detrimento do retorno esperado, ajustando-se às preferências individuais do investidor em relação ao risco a que está disposto a incorrer (MARKOWITZ, 1959).

A teoria de seleção de portfólio de Markowitz (1952) estabelece que o investidor deveria diversificar entre aqueles títulos com o máximo retorno esperado. A lei dos grandes números garantiria que o rendimento real da carteira será praticamente o mesmo que o rendimento previsto. Entretanto, observa-se a existência de correlações entre os títulos e a diversificação não pode eliminá-las. Supõe-se que exista uma carteira que oferece o máximo retorno esperado e mínima variância, sendo esse o melhor portfólio para o investidor.

No sentido de tornar a variância menor, não é suficiente investir em muitos títulos. É necessário desviar-se de investimentos em ativos com altas covariâncias entre si. Torna-se preferível a diversificação em títulos de empresas em diferentes setores, especialmente setores com diferentes características econômicas, já que essas apresentariam menor covariância, Markowitz (1959, p.3) afirma ainda que “um bom portfólio de ativos é mais que uma grande quantidade de títulos e de boas ações. É um conjunto balanceado, com objetivo de fornecer ao investidor proteção e oportunidades em um conjunto de situações adversas".

\subsubsection{O Risco}

Segundo Damodaran (2010), o risco surge a partir do desvio dos retornos reais e dos retornos esperados, podendo ocorrer por diversas razões, dividindo-se em dois tipos: os que são específicos para o investimento e aqueles que se aplicam a todos os investimentos, também chamado de risco de mercado. Avaliando a variância dos retornos reais em torno dos retornos esperados, conclui-se que maior variância é um indicativo de maior risco. Em investimentos com risco de inadimplência, o risco é medido pela probabilidade de que os fluxos de caixa esperados não aconteçam. Os investimentos com maior risco de inadimplência devem ser remunerados com taxas de juros mais elevadas, sendo adicionado um prêmio exigido sobre uma taxa considerada livre de risco de inadimplência.

Assaf Neto et al (2008) descrevem riscos conjunturais, tais como crise cambial, crise política, guerras, inflação, etc. Estes riscos permanecem na carteira, não sendo eliminados através da diversificação, já que atingem a carteira como um todo, devendo ser tratados como 
sendo relevantes para o investidor. O risco total de um ativo pode ser divido em duas partes: a parcela que é determinada por fatores conjunturais e de mercado que atingem todas as empresas, não podendo ser diversificado, a outra parcela de risco que é de fato diversificável, não devendo preocupar o investidor diversificado, sendo referente a um contexto específico da empresa, como por exemplo: o endividamento, entrada de concorrência no mercado, etc. Nesses casos a carteira como um todo não seria afetada. O risco específico de uma ação ou título pode ser mensurada pelo coeficiente beta, que é o coeficiente angular da reta de regressão linear entre os retornos do título e os retornos da carteira de mercado.

Pereiro (2001) trata o risco-país relacionado às economias emergentes como um dos componentes do risco idiossincrático. Nessas economias, podem ser observados: riscos derivados da turbulência social e política que podem afetar negativamente o desempenho da empresa, a possibilidade de expropriação de bens privados por parte do governo; chance de desvalorização da moeda ou de reavaliação do risco cambial; a possibilidade de o governo dar sinais de que não pode pagar seus credores alterando a classificação de crédito do país; o risco decorrente da inflação.

\subsection{A Hipótese Do Mercado Eficiente (HME)}

Segundo Fama (1970), a Hipótese do Mercado Eficiente (HME) tem como principais premissas: (1) não há custos de transação na comercialização dos títulos; (2) todas as informações disponíveis são gratuitas e disponíveis para todos os participantes do mercado; e (3) todos os participantes do mercado analisam as informações disponíveis de forma idêntica e a projetam da mesma maneira em distribuições futuras dos preços dos títulos. Um mercado onde os preços sempre "refletem completamente" a informação disponível seria chamado de eficiente.

Fama (1970) descreve os principais conceitos acerca da HME. A literatura empírica relaciona-se implicita ou explicitamente à suposição de que as condições de equilíbrio de mercado podem ser definidas em termos de retornos esperados. A relevância da HME vem da ideia de que o mercado pode precificar os ativos de três formas diferentes, baseando-se em informações disponíveis. A partir dessas formas novos estudos podem ser melhor modelados assumindo uma dessas três premissas: fraca, semi-forte e forte.

A forma fraca de eficiência mercado persistiu quase que indiscutivelmente até por volta de 1960, quando trabalhos utilizando o modelo do passeio aleatório começaram e ser desenvolvidos por autores como Samuelson (1965). A forma fraca de eficiência de mercado 
adotava como base estatística o modelo martingale. O modelo martingale implica que o retorno futuro de um título pode ser previsto com grande margem de segurança a partir dos retornos históricos. Desta forma, a expectativa de um retorno anormal, ou seja, um retorno acima do esperado com base na série histórica é igual a zero.

A forma semi-forte se relaciona com o fato de os preços atuais "refletirem completamente", todas as informações disponíveis publicamente. Cada teste individual se preocupa com o ajuste dos preços dos títulos para um tipo de evento que fornece informação: desdobramento de ações, divulgação de relatórios financeiros, fatos relevantes, novas emissões de ações, etc. Na forma semiforte, as informações disponíveis publicamente são refletidas nos preços dos títulos e desta forma os preços não refletem somente o histórico passado como na forma fraca, mas também todas as informações disponíveis publicamente. Portanto, nenhum investidor poderá obter retornos anormais baseados em informações publicamente disponíveis, sendo que diante da ocorrência de novas informações os preços se ajustam rapidamente.

Quanto à forma forte, a preocupação é se algum investidor ou grupos, tais como gestores de fundos, têm acesso monopolista a qualquer informação relevante para a formação de preços. De acordo com essa vertente, nenhum investidor pode obter retornos extraordinários, devido ao fato de todas as informações já estarem precificadas. Ocorre quando toda informação disponível e também as informações confidenciais estão refletidas nos preços das ações, ou seja, nenhum agente obtém retornos superiores aos normais ao negociar títulos com base em informações privilegiadas que detenham. Fama (1970) afirma ainda que não é esperado que esta situação seja uma descrição exata da realidade do mercado.

Os estudos iniciais acerca da HME estavam preocupados com os chamados testes de forma fraca em que são utilizadas informações de interesse é apenas histórico dos preços passados (ou retornos). Não há nenhuma evidência importante contra a hipótese de os testes forma fraca e semi-forte, e apenas evidência limitada contra a hipótese nos testes forma forte, como é o fato de alguns usuários terem acesso à informação monopolista (insiders) sobre os preços (FAMA, 1970).

De acordo com Silva et al (2014) muitos são os estudos que questionam a eficiência do mercado acionário brasileiro. Ressalta-se ainda que esse mercado é ainda pouco maduro, com um número restrito de empresas participantes se comparado a um mercado mais desenvolvido, e havendo o problema de existir um curto período de estabilidade monetária, iniciado em 1994. Em seu estudo, os mesmos autores tiveram como objetivo avaliar a eficiência do mercado de capitais brasileiro utilizando a metodologia descrita por Jegadeesh e 
Titman (1993). Utilizou-se uma amostra que compreendeu os ativos listados na BOVESPA, no período de 1994 a 2009, sendo possível a identificação de alguns períodos de baixa eficiência de mercado. Dessa forma evidenciou-se que o mercado de capitais brasileiro alterna períodos de baixa e alta eficiência. Entretanto existe a predominância dos períodos de alta eficiência de mercado.

\subsection{Introdução ao Desenvolvimento Teórico do CAPM}

O CAPM (Capital Asset Pricing Model) está embasado na Teoria do Portfólio de Harry Markowitz, desenvolvida entre os anos de 1952 e 1959, sendo que o desenvolvimento de tal modelo permitiu que as ideias de Markowitz fossem simplificadas (BROWN; WALTER, 2012).

O CAPM em sua forma tradicional foi desenvolvido conceitualmente por Sharpe (1964), Lintner (1965) e Mossin (1966). Ele descreve determinadas hipóteses restritivas, no sentido de proporcionar uma teoria sobre o prêmio de risco de mercado.

Lintner (1965) descreve as premissas nas quais o CAPM se baseia, como a aversão ao risco por parte dos investidores, que têm a alternativa de investimento em títulos sem risco que oferecem um retorno positivo (ou tomar emprestado à mesma taxa de juros), podendo vendê-los se assim o desejarem.

Fernandéz (2002) traz os seguintes pressupostos básicos do CAPM: (a) todos os investidores têm expectativas homogêneas; (b) os investidores podem tomar emprestado e investir na taxa livre de risco; (c) não há custos de transação; (d) os investidores têm aversão ao risco; (e) os investidores têm o mesmo horizonte de tempo.

Brown e Walter (2012) apresentam diversas pesquisas empíricas que demonstram que o CAPM continua sendo de grande relevância, seja para as firmas em seus orçamentos de capital, para as agências regulatórias na fixação de preços ou para os acadêmicos que continuam a estimar o prêmio pelo risco de mercado e a usar o CAPM no ensino de finanças corporativas.

\subsection{O CAPM}

O CAPM consiste em um modelo de equilíbrio parcial em que os agentes visualizam o retorno livre de risco $\left(\mathrm{R}_{\mathrm{f}}\right)$ e a distribuição de probabilidade do retorno futuro sobre os ativos de risco como variável exógena. Assim, o CAPM procura identificar o retorno em excesso de 
uma determinada empresa, considerando como variável o prêmio pelo risco de mercado. $\mathrm{O}$ CAPM é um modelo de precificação de ativos adequado a qualquer tipo de ativo financeiro sob condições de risco ou incerteza, sendo três os componentes nos quais o modelo se baseia: retorno do ativo livre de risco, o $\beta$ (beta) como medida de risco do ativo em relação a uma carteira de referência e o prêmio relativo ao risco de mercado (SHARPE, 1964; LINTNER, 1965; MOSSIN, 1966).

As principais premissas que permeiam o modelo CAPM são:

\section{Quadro 1. Premissas do modelo CAPM}

\begin{tabular}{|c|l|}
\hline \multirow{5}{*}{ Investidores } & $\begin{array}{l}\text { - maximizam o retorno ajustado ao risco ou o índice de Sharpe; } \\
\text { - fazem as mesmas previsões sobre retornos esperados, variâncias e covariâncias, no mesmo } \\
\text { horizonte de tempo e escolhem pesos para os ativos de risco (expectativas homogêneas); } \\
\text { - podem emprestar e tomar emprestado quantias ilimitadas à taxa livre de risco; } \\
\text { - podem ter dotações de riqueza diferentes; } \\
\text { - são tomadores de preços já que nenhum investidor tem o poder de afetar os preços do } \\
\text { mercado; } \\
\text { - têm diferentes graus de aversão ao risco. }\end{array}$ \\
\hline Mercado & $\begin{array}{l}\text { - não há custos de transação; } \\
\text { - todos os investimentos ocorrem em ativos financeiros negociados publicamente; } \\
\text { - existência de uma taxa livre de risco (conhecida e não-estocástica). }\end{array}$ \\
\hline
\end{tabular}

Fonte: adaptado de Cuthbertson e Nitzsche (2008, p. 268)

Segundo Assaf Neto (2010), para o desenvolvimento desse modelo, assume-se as seguintes hipóteses: (a) o mercado é eficiente; (b) os ativos possuem o comportamento de uma distribuição normal; (c) os investidores são avessos ao risco; (d) não há impostos, taxas, custos de transações ou qualquer restrição para os investimentos no mercado; (e) todos os investidores formam carteiras com base em expectativas idênticas; (f) existe uma taxa de juros de mercado definida como livre de risco. Dentro de um contexto de otimização por média variância, pode-se propor que: diante de opções de investimentos com riscos iguais, o investidor escolhe o de maior retorno; e diante de opções de investimentos de retornos iguais, o investidor escolhe de menor risco. A principal hipótese do modelo é a de que todos os investidores utilizam a otimização por média variância para alocação dos seus recursos.

A principal ideia subjacente ao CAPM é que um ativo livre de risco pode ser combinado com um nível de retorno mínimo a uma carteira formada por ativos com riscos. Esse modelo indica a relação linear existente entre o retorno do capital e o risco do ativo. $\mathrm{O}$ CAPM tem sido aplicado para se encontrar o custo de capital das empresas e para precificar ativos (ROGERS; SECURATO, 2009). 
O modelo foi formulado com base na teoria de seleção do portfólio de Markowitz (1952), onde a seleção de carteiras é feita através da relação entre risco e retorno esperado. A descrição do modelo CAPM é feita pela seguinte equação linear:

$$
\mathrm{R}_{i}=R_{f}+\beta\left(R_{m}-R_{f}\right)
$$

Onde:

$\mathrm{R}_{i}=$ retorno esperado de um ativo;

$R_{f}=$ retorno do ativo livre de risco;

$\beta=$ Medida de risco do ativo em relação a uma carteira de referência (coeficiente de risco sistemático da ação);

$R_{m}=$ taxa esperada de retorno sobre o portfólio geral do mercado;

$\left(R_{m}-R_{f}\right)=$ taxa de prêmio relativo ao risco de mercado.

O retorno aumenta de modo linear em função do risco sistemático ou não diversificável, risco este inerente ao mercado. O risco não-sistemático não é remunerado, pois ele pode ser eliminado por meio da diversificação do portfólio. O prêmio relativo ao risco de mercado é a diferença entre a taxa projetada de retorno sobre a carteira de mercado e a taxa livre de risco. O prêmio de risco é o prêmio oferecido pelo mercado por se assumir uma quantidade média de risco sistemático além do tempo de espera do dinheiro, que seria a taxa livre de risco: $\left(R_{m}-R_{f}\right)$. Desta forma, o prêmio "é definido como a diferença entre os retornos médios sobre as ações e os retornos médios sobre os títulos de risco zero para um longo período histórico" (DAMODARAN, 2011, p. 174).

O CAPM foi um avanço em relação à teoria das carteiras de Markowitz, sendo que um elemento diferencial foi a inclusão de um ativo livre de risco. A característica fundamental do ativo livre de risco é que o retorno esperado será sempre igual ao retorno real. A relação desses ativos com os ativos expostos ao risco é que a variância dos ativos livre de risco é não correlacionada com o retorno sobre qualquer ativo com risco (DAMODORAN, 2010).

Fama e French (2007, p.107) afirmam sobre o CAPM e seus testes empíricos que:

Os testes do CAPM se baseiam em três implicações da relação entre retorno esperado e beta de mercado, implícitas no modelo. Primeiro, os retornos esperados de todos os ativos apresentam relação linear com seus betas e nenhuma outra variável tem poder explicativo marginal. Segundo, o prêmio do beta é positivo, o que significa que o retorno esperado da carteira de mercado supera o de ativos cujos retornos não estejam correlacionados com o retorno do mercado. Terceiro, na versão Sharpe Lintner do modelo, os 
ativos não correlacionados com o mercado têm retornos esperados iguais à taxa de juros livre de risco, e o prêmio do beta é o retorno esperado do mercado menos a taxa livre de risco. A maioria dos testes dessas previsões usa regressões longitudinais ou de série temporal. As duas abordagens datam dos primeiros testes do modelo.

O coeficiente Beta indica o incremento necessário no retorno de um ativo de forma a remunerar seu risco sistemático e a forma como o ativo é impactado pelas variações do mercado de ações como um todo. Segundo a fórmula, o retorno esperado de um título está linearmente relacionado a seu beta, ou seja, se o $\beta$ for igual a zero, o retorno esperado do título é igual à taxa livre de risco, porém, se o $\beta$ for 1 , o retorno esperado do título é igual ao do mercado. Em outras palavras, os indivíduos aplicarão em um ativo com risco somente se o seu retorno esperado remunerar o risco incorrido (HILL; GRIFFITHS; JUDGE, 2010; DAMODARAN, 2011).

De acordo com Cuthbertson e Nitzsche (2008), o beta pode ser calculado e interpretado de acordo com seguinte equação:

$$
\beta_{i m}=\frac{\operatorname{Cov}\left(R_{i}, R_{m}\right)}{\sigma_{m}^{2}}
$$

Onde:

$\beta_{\text {im }}=$ Beta de um ativo

$\operatorname{Cov}\left(R_{i}, R_{m}\right)=$ covariância entre o retorno do ativo e o retorno do mercado de referência;

$\sigma_{m}^{2}=$ variância do mercado de referência.

Se:

$\beta=1$ o ativo tem o mesmo risco sistemático que o $\beta_{m}$ geral do mercado;

$\beta<1$ o ativo tem menos risco sistemático que o mercado;

$\beta>1$ o ativo tem mais risco sistemático que o mercado.

O coeficiente beta mede a sensibilidade do ativo em relação ao mercado, ou risco de uma ação (ou ativo) em relação ao retorno de um mercado de referência. Cabe relatar que os valores dos betas são dependentes do intervalo de tempo e da frequência dos dados adotados nos cálculos de retornos, sendo que a teoria não determina um intervalo o que pode gerar betas diferentes dependendo do intervalo e da frequência utilizada (COPELAND et al, 2002). 
Ao se realizar a regressão, além do Beta, também é encontrado o intercepto da regressão, conhecido como Alfa de Jensen. Berk (2010, p. 394) explica que "a distância de um grupo de ações acima ou abaixo da linha do mercado de títulos é o seu alfa". O alfa é igual a zero quando a carteira de mercado é eficiente, sendo que quando isto não ocorre o mercado não está no equilíbrio do CAPM. Nesse contexto, os investidores ainda podem aprimorar o desempenho da carteira de mercado através da compra de ações com alfas positivos e venda de ações com alfas negativos.

Cabe destacar alguns pressupostos que devem ser respeitados para a aplicação de testes empíricos com o CAPM, tais como: a) o intercepto não pode ser significativamente diferente de zero; b) o beta deve ser o único que explica a taxa de retorno do ativo com risco; c) o trade-off risco-retorno deve ser linear; e d) a carteira de mercado deve possuir maior retorno do que o ativo livre de risco, sendo que, no longo prazo, as estimativas de retorno devem seguir essa trajetória. E, particularmente no Brasil, as proxies mais utilizadas para os componentes do CAPM são o Ibovespa como a carteira de mercado e o CDI ou a SELIC como proxy do ativo livre de risco (ARAÚJO; OLIVEIRA; SILVA, 2012).

\subsection{Críticas ao Modelo}

Os problemas empíricos do CAPM podem refletir falhas teóricas resultantes de um grande número de importantes premissas simplificadoras. Observam-se também problemas que podem ser causados por dificuldades na implementação de testes válidos para o modelo. Ao observar o histórico dos trabalhos empíricos e as limitações do CAPM, surgem oportunidades de elaboração de modelos alternativos (FAMA; FRENCH, 2007).

Roll (1977) questiona a validade dos testes empíricos do modelo CAPM, em que é testada apenas uma proxy específica da carteira de mercado. Segundo o autor, seria possível concluir que o CAPM nunca foi testado efetivamente porque não seria possível incluir na carteira de mercado todos os ativos que podem ser negociados e essa seria a verdadeira carteira de mercado de referência.

A utilização do Ibovespa como carteira de mercado no Brasil, para cálculo do coeficiente beta, tem sido alvo de várias críticas, principalmente porque o Ibovespa representa um índice baseado na negociabilidade das ações e não no valor de mercado das empresas, como é sugerido pelo CAPM. Observa-se também que o Ibovespa é muito concentrado em uma pequena quantidade de ações (PAIVA, 2005; MACHADO; MEDEIROS, 2012). 
O estudo desenvolvido por Banz (1981) analisou a relação empírica entre o retorno e o valor de mercado total de ações ordinárias da NYSE (New York Stock Exchange). Verificouse que as empresas menores tiveram maiores retornos ajustados ao risco, em média, do que as empresas maiores. É relatado no estudo que o "efeito tamanho" tem existido por longo tempo. O estudo sugere que essa é uma evidência de que o modelo CAPM é mal especificado. O efeito tamanho não é linear ao valor de mercado. Constatou-se que o principal efeito ocorre para empresas muito pequenas, embora haja pouca diferença no retorno entre as empresas médias e grandes.

Reiganum (1981) documenta anomalias empíricas que sugerem que o CAPM é mal especificado ou que os mercados de capitais não são eficientes. Foi observado que carteiras com base no tamanho da empresa ou na razão entre lucro e preço apresentam retornos médios sistematicamente diferentes daqueles previstos pelo CAPM. Há persistência de pelo menos dois anos nos retornos "anormais", o que reduz a probabilidade de que estes resultados sejam gerados por uma ineficiência do mercado.

Destacam-se como críticas sobre as falhas empíricas do CAPM as de:

Fama e French (1992) atualizam e sintetizam as evidências sobre as falhas empíricas do CAPM. Usando a abordagem por regressão longitudinal, confirmam que o porte e os índices preço-lucro, dívida-patrimônio líquido e escritural-mercado somam-se à explicação dos retornos esperados das ações fornecida pelo beta de mercado. Fama e French (1996) chegam à mesma conclusão usando a abordagem por regressão de série temporal aplicada a carteiras de ações classificadas por índices de preço. Eles também concluem que diferentes índices de preço trazem, em grande medida, as mesmas informações sobre retornos esperados. Isso não surpreende, dado que o preço é o vetor comum dos índices de preço e os numeradores são meras variáveis de escala usadas para extrair as informações sobre retornos esperados que há no preço. (Fama e French, 2007, p.110)

O CAPM é muito utilizado por oferecer poderosas e intuitivas previsões sobre a medição do risco e a relação entre retorno esperado e risco. Porém, o registro empírico do modelo é pobre. Os problemas empíricos do CAPM podem refletir falhas teóricas, resultantes de muitas premissas simplificadoras ou causadas por dificuldades na implementação de testes válidos do modelo (FAMA; FRENCH, 2004).

Perlin e Cereta (2004) entendem que o motivo da exclusão de outros parâmetros estatísticos deve-se à afirmação feita dentro da teoria do CAPM de que os rendimentos de mercado possuem distribuição normal, o que levaria à caracterização das ações apenas com base nos desvios padrões e nas médias de rendimentos. Contudo, para esses pesquisadores, essa simplificação não corresponde ao comportamento estatístico do mercado acionário, uma 
vez que o mesmo não segue distribuições normais, apresentando, na grande maioria dos casos, valores significativos de curtose e assimetria.

Embora existam críticas ao CAPM, Benson e Faff (2012) afirmam que tais críticas estão relacionadas ao fato de que muitos estudos empíricos são naturalmente voltados para testes de curto prazo, podendo produzir resultados inconsistentes ou mesmo contrários às predições do modelo. Dessa forma, os autores constatam que o CAPM é um modelo de equilíbrio e que o conceito de equilíbrio é irrealista no curto prazo, funcionando muito melhor no longo prazo. A precificação de ativos deve ser considerada uma preocupação de longo prazo.

\subsection{As propostas de adaptação do CAPM aos mercados emergentes}

Com a globalização dos investimentos, ocorrida de forma contundente a partir da década de 1990, os mercados de capitais dos países de economias emergentes tem sido alvo de investimentos, tanto de investidores globais quanto locais. Dessa forma, adotar o modelo CAPM em sua forma tradicional na precificação de ações é passível de questionamentos tanto no Brasil quanto nos demais mercados emergentes. De acordo com Pereiro (2002) e Damodaran (2010), ajustes são necessários com a finalidade de adequar o modelo à realidade econômica dos países emergentes, que é expressivamente divergente de uma economia desenvolvida, para o qual o modelo em sua forma tradicional foi elaborado.

A literatura atual tem-se concentrado no pressuposto pleno da diversificação e desta forma são aplicadas uma série de modelos de precificação usando como base referências para o mercado global ou de um mercado de ações desenvolvido (como o norte-americano), o que dependendo do grau de diversificação do investidor tornam-se ajustes arbitrários. (MONGRUT, 2006)

Paiva (2005) sustenta que, em mercados emergentes, o CAPM torna-se mais complicado. Tomando-se o Brasil como exemplo, pode-se inferir que o CAPM tende a falhar na explicação das taxas de retornos dos ativos financeiros, em razão, principalmente, da baixa representatividade e expressividade do índice de mercado, no caso, o índice da Bolsa de Valores de São Paulo (Ibovespa), como proxy da carteira de mercado.

Os modelos Modelo G-E (GODFREY; ESPINOSA, 1996), Modelo de Lessard (LESSARD, 1996), CAPM Global (O’BRIEN et al, 1999), Modelo G-S (MARISCAL; HARGIS, 1999), CAPM Local (PEREIRO, 2001), CAPM Local Ajustado (PEREIRO, 2001), Modelo de Damodaran (DAMODARAN ,2002) e Modelo de Assaf Neto et al (Assaf Neto et 
al, 2008) são alguns dos modelos que tentam adaptar o modelo CAPM às particularidades das economias emergentes.

\subsubsection{Modelo G-E (GODFREY; ESPINOSA, 1996)}

O trabalho de Godfrey e Espinosa (1996) propõe um quadro prático que pode ser usado para determinar as taxas de desconto e precificação de ativos, na avaliação de oportunidades de investimento em mercados emergentes. Os autores argumentam que há três tipos principais de risco que afetam a maior parte dos países em desenvolvimento: riscos políticos ou risco soberano; risco comercial ou risco do negócio (reflexo da volatilidade do ambiente empresarial local); e risco da moeda local. São propostas medidas para a avaliação desses riscos. O risco soberano pode ser avaliado pela observação dos diferenciais de rendimento sobre títulos soberanos de mercados maduros e de mercados emergentes. O risco do negócio pode ser medido pela comparação entre o grau de volatilidade dos mercados de capitais locais à volatilidade do mercado norte-americano.

O modelo tenta contornar o problema através da aplicação de um fator de correção de 0,60 , com base no coeficiente médio de determinação da volatilidade contra a qualidade de crédito do país, sendo a forte suposição de que é aceitável usar um fator de correção constante em vez de um verdadeiro, que seja variável com o tempo. (PEREIRO, 2002)

O modelo desenvolvido por Godfrey e Espinosa (1996) é descrito como:

$\mathrm{R}_{\mathrm{i}}=\mathrm{R}_{\mathrm{f}, \mathrm{US}}+\mathrm{R}_{\mathrm{c}}+\left(\sigma_{\mathrm{L}} / \sigma_{\mathrm{US}}\right)\left(\mathrm{R}_{\mathrm{m}, \mathrm{US}}-\mathrm{R}_{\mathrm{f}, \mathrm{US}}\right) \mathrm{x} 0,60$

Onde:

$R_{i}=$ retorno esperado de um ativo;

$R_{f, U S}=$ Taxa livre de risco dos EUA;

$R_{c}=$ Prêmio de risco-país;

$\sigma_{L}=$ Desvio padrão do retorno do mercado local;

$\sigma_{U S}=$ Desvio padrão do retorno do mercado dos EUA;

$R_{m, U S}=$ Retorno de mercado dos EUA. 
2.6.2 Modelo de Lessard (LESSARD, 1996)

De acordo com Lessard (1996) projetos em economias emergentes são geralmente considerados como arriscados. Esses mercados são mais voláteis do que as economias dos países desenvolvidos e também apresentam uma maior variedade de riscos como câmbio, desordem civil e instabilidade institucional, uma vez que tais riscos são desconhecidos aos investidores. Um prêmio suplementar é atribuído aos mercados emergentes, muitas vezes de forma arbitrária, já que tais ajustes podem não refletir adequadamente as informações sobre a natureza desses riscos, ou a capacidade de gerenciamento desses riscos. Visto que, podem ser tomadas ações para reduzí-los, sendo capazes de transferir algumas das exposições a riscos específicos, como operações de hedge de câmbio, ou seguro contra risco político. Esse risco político se relaciona tanto à incerteza econômica dos governos locais como às políticas de regulação locais.

Diante das incertezas ocorridas nos mercados emergentes, poderia ocorrer qualquer uma das três violações das premissas que permeiam o CAPM: (1) a informação não está igualmente disponível para todos os investidores; (2) os investidores podem ter diferentes graus de influência sobre os resultados; e (3) os investidores podem diferir em sua capacidade de diversificar os riscos. Os riscos, em teoria, deveriam ser refletidos como ajustes de fluxos de caixa, embora em determinadas circunstâncias também possam ser refletidas em adaptações na taxa de desconto (MONGRUT, 2006).

O beta captura o efeito dos riscos de mercado dos países-alvo, mas eles não refletem os impactos potenciais sobre fluxos de caixa esperados, riscos como ação expropriatória, inadimplência e assim por diante. O ideal é que o impacto de tais riscos seja estimado por combinar avaliações de especialistas de possíveis eventos e cenários com as estimativas do fluxo de caixa os impactos de cada um destes e não obrigatoriamente por meio de sua inclusão na taxa (LESSARD, 1996; PEREIRO, 2002).

De acordo com Lessard (1996), são utilizadas premissas do mercado norteamericano, acrescidas do beta que captura o efeito dos riscos de mercado dos países-alvo, mas eles não refletem os impactos potenciais sobre fluxos de caixa esperados, riscos como ação expropriatória e inadimplência. Dessa forma é incluído o risco-país como é apresentado no modelo: 
$R_{i}=R_{f, U S}+R_{c}+\beta C_{L, U S} \beta_{U S}\left(R_{m, U S}-R_{f, U S}\right)$

Onde:

$R_{i}=$ retorno esperado de um ativo;

$R_{f, U S}=$ Taxa livre de risco dos EUA;

$R_{c}=$ Prêmio de risco-país;

$\beta C_{L, U S}=$ Beta do país e o retorno do mercado dos EUA;

$\beta_{U S}=$ Beta dos EUA;

$R_{m, U S}=$ Retorno de mercado dos EUA

\subsubsection{O CAPM Global (O’BRIEN et al, 1999)}

Stulz (1999) apresenta uma versão simples do CAPM Global, e Schramm e Wang (1999) apresentam um modelo que reflete risco cambial, mas à custa da simplicidade. Então, O’Brien (1999) incorpora também a incerteza cambial no custo do capital. Por exemplo: é uma tendência natural pensar que a relação entre risco/retorno expressa em dólares dos Estados Unidos só se aplica a ativos dos Estados Unidos, enquanto que o risco/retorno relacionado em libras esterlinas só se aplica a ativos no Reino Unido. Esta ideia está baseada em um pressuposto implícito de que os mercados são segmentados. O modelo CAPM Global baseia-se na ideia de integração entre os mercados. No CAPM Global deve-se pensar em termos de risco e retorno, como um trade-off de todos os ativos, independentemente da sua nacionalidade ou qualquer outra moeda que se deseje utilizar.

De acordo com o modelo, a taxa de retorno requerida em qualquer ativo, expressa em dólares, depende de três fatores, e a interpretação de alguns fatores no contexto do modelo CAPM Global requer cuidados. Dado que a volatilidade de um índice global é menor do que a de um índice nacional, uma empresa com uma maior correlação com o índice global que com o índice nacional terá um aumento do beta global. Essa estimativa representa o risco sistemático da empresa, dentro de uma carteira de títulos globalmente diversificada. O termo "livre de risco" é considerado como a taxa nominal de juros sobre um ativo que está livre de ambos os riscos, "risco soberano" e "risco de câmbio". (O’BRIEN, 1999; STULZ, 1999).

De acordo com O’Brien (1999), premissas advindas no mercado financeiro global que compõem o modelo global apresentam uma lógica superior à estimativa do CAPM 
tradicional com premissas advindas do mercado local. O modelo CAPM Global baseia-se na ideia de integração entre os mercados e pode ser especificado como:

$R_{i}=R_{f G}+\beta_{L G}\left(R_{m, G}-R_{f, G}\right)$

Onde:

$R_{i}=$ retorno esperado de um ativo;

$R_{f G}=$ Taxa livre de risco global;

$\beta_{L G}=$ Beta local em relação ao índice do mercado global;

$R_{m G}=$ Retorno de mercado global.

\subsubsection{Modelo G-S (MARISCAL; HARGIS, 1999)}

Mariscal e Hargis (1999) relatam a relevância do risco na precificação dentro do mercado de ações. Entretanto, definir medidas do nível de risco associado não é simples em mercados emergentes. Os elevados níveis de volatilidade do mercado tornam medidas com base em indicadores de mercado contemporâneos altamente instáveis e o histórico limitado faz com que seja impossível determinar tendências a longo prazo.

Assim é desenvolvido um modelo com base em variáveis fundamentais do local e do mercado global. O estudo de Mariscal e Hargis (1999) contribui com estimativas de longo prazo de taxas de desconto para 23 mercados emergentes. A metodologia pode ser usada em qualquer país, sendo o requisito básicos: um conjunto de âmbito nacional e global de indicadores financeiros e econômicos. Entre os resultados da análise de risco em longo prazo observa-se uma tendência de queda nos mercados emergentes das taxas de desconto desde o início da década de 1980.

Devido a sua alta dependência de financiamento externo, o custo de capital nos mercados emergentes é muito suscetível à demanda e oferta global de dinheiro. As proxies para esta variável poderiam incluir o nível de taxas de juros dos EUA como referência. $\mathrm{O}$ modelo foi usado em 23 países de mercados emergentes por 25 anos. Um alto grau de correlação encontrado entre as taxas de desconto e o comportamento real dos mercados sugere que as estimativas são uma medida histórica adequada de risco (MARISCAL, HARGIS 1999; PEREIRO, 2002 e MONGRUT, 2006).

Mariscal e Hargis (1999) relatam em seu estudo a relevância do risco na precificação, utilizando como uma medida do nível de risco a volatilidade do mercado. Então 
foi desenvolvido um modelo com base em variáveis fundamentais do local e do mercado global. As proxies para cada variável podem incluir o mercado dos EUA como referência. O modelo foi especificado como:

$R_{i}=R_{f, U S}+R_{C}+\left(\sigma_{L} / \sigma_{U S}\right)+\beta_{L L}\left(R_{m, U S}-R_{f, U S}\right)(1-R)+R_{i d}$

Onde:

$R_{i}=$ retorno esperado de um ativo;

$R_{f, U S}=$ Taxa livre de risco dos EUA;

$R_{c}=$ Prêmio de risco-país;

$\sigma_{L}=$ Desvio padrão do retorno do mercado local;

$\sigma_{U S}=$ Desvio padrão do retorno do mercado dos EUA

$\beta_{L L}=$ Beta local em relação ao índice do mercado local;

$R_{m, U S}=$ Retorno de mercado dos EUA

$R=$ é a correlação entre o retorno do mercado local e o título de dívida do governo usado para medir o risco-país;

$R_{i d}=$ é o prêmio de risco exclusivo da empresa-alvo.

\subsubsection{CAPM Local (PEREIRO, 2001)}

No desenvolvimento deste modelo, Pereiro (2001) assume a segmentação das economias emergentes, partindo da premissa de que com a integração entre os mercados financeiros o risco-país torna-se irrelevante, já que este seria eliminado através de uma diversificação em um portfólio geograficamente variado. Se o investidor tem seus investimentos concentrados em mercados de países específicos, ele vem a assumir riscos relacionados com esses países. Em caso de segmentação, é recomendada a utilização do CAPM Local, com premissas da economia local e a adição do prêmio pelo risco país, justificado por meio de estudos empíricos que têm mostrado o seu efeito sobre os retornos das ações, argumentando ainda que o desempenho das ações possui relacionamento com a volatilidade da economia local. Do ponto de vista teórico, a adição de um prêmio de risco país implica o uso de um modelo de risco-retorno com mais fatores, em que o prêmio corresponde ao risco idiossincrático do país local.

No desenvolvimento do modelo, Pereiro (2001) assume a segmentação das economias emergentes e justifica a adoção de premissas da economia local e a adição do 
prêmio pelo risco país, justificado por meio de estudos empíricos que têm mostrado o seu efeito sobre os retornos das ações, argumentando ainda a relevância do relacionamento do desempenho das ações e a volatilidade da economia. O modelo tem a seguinte especificação:

$R_{i}=R_{f G}+R_{c}+\beta_{L L}\left(R_{m L}-R_{f L}\right)$

Onde:

$R_{i}=$ retorno esperado de um ativo;

$R_{f G}=$ Taxa livre de risco global;

$R_{c}=$ Prêmio de risco-país;

$\beta_{L L}=$ Beta local em relação ao índice do mercado local;

$R_{m L}=$ Retorno do mercado local;

$R_{f L}=$ Taxa livre de risco local.

\subsubsection{CAPM Local Ajustado (PEREIRO, 2001)}

O problema com o CAPM local é que ele tende a superestimar o risco em função da inclusão de um prêmio de risco país na equação do CAPM, apresentando um problema de dupla contagem, uma vez que parte dela pode estar presente no prêmio pelo risco de mercado. (Godfrey; Espinosa, 1996). Já Erb et al. (1995) mostraram que o risco de mercado inclui um componente de risco macroeconômico. Eles confirmaram que o risco-país explica aproximadamente $40 \%$ da variação da volatilidade dos retornos do mercado; e o risco do mercado de ações, os restantes $60 \%$. Nessa mesma linha de raciocínio, o modelo procura corrigir o prêmio de risco sistemático com a inclusão do coeficiente de determinação da regressão entre a volatilidade dos retornos da empresa local e da variação do risco-país. Esse fator de correção na equação diminui prêmio de risco para combater o problema superestimação.

De acordo com Pereiro (2001), para resolver o problema do CAPM local, que tende a superestimar o risco em função da inclusão de um prêmio de risco país, acarretando um possível problema de dupla contagem, é proposto um ajuste. O modelo procura corrigir o prêmio de risco sistemático por meio da inclusão do coeficiente de determinação da regressão entre a volatilidade dos retornos da empresa local e da variação do risco-país. Esse fator de correção na equação diminui o prêmio de risco, buscando resolver o problema superestimação. A especificação para este modelo é: 
$R_{i}=R_{f G}+R_{c}+\beta_{L L}\left(R_{m L}-R_{f L}\right)\left(1-R_{i}^{2}\right)$

Onde:

$R_{i}=$ retorno esperado de um ativo;

$R_{f G}=$ Taxa livre de risco global;

$R_{c}=$ Prêmio de risco-país;

$\beta_{L L}=$ Beta local em relação ao índice do mercado local;

$R_{m L}=$ Retorno do mercado local;

$R_{f L}=$ Taxa livre de risco local.

$R_{i}{ }^{2}=$ é o coeficiente de determinação da regressão entre a volatilidade da empresa em relação à variação do risco-país.

\subsubsection{CAPM Híbrido Ajustado (PEREIRO, 2001)}

A alta volatilidade dos mercados emergentes torna o cálculo dos prêmios de mercado em longo prazo e betas bastante complicado, uma vez que ambos são altamente instáveis ao longo do tempo, e as médias históricas tendem a não ser confiáveis ou simplesmente indisponíveis (PEREIRO, 2002; ASSAF NETO et al, 2008; DAMODARAN, 2010).

O modelo CAPM híbrido ajustado, combina ambos os parâmetros de risco locais e globais. A vantagem do modelo é que ele inclui dados facilmente disponíveis no mercado global. Assume-se, no entanto, a estabilidade entre um padrão de empresa global ou betas da indústria, e os betas do mercado local, um fato que ainda é em grande parte não comprovado. Se os mercados financeiros são integrados, o risco de investir em um país é irrelevante dada a diversificação de cada portfólio de investimentos em outros países. Contudo, quando um investidor deseja realizar investimentos em um determinado país, ainda mais em países em desenvolvimento, este investidor pode se sentir segmentado, isto é, ter uma percepção de que os riscos envolvidos em investir em um país são maiores (PEREIRO, 2001).

O modelo CAPM híbrido ajustado combina parâmetros de risco locais e globais, Assume-se a estabilidade entre um padrão de betas extraídos da indústria global, e os betas do mercado local. Se os mercados financeiros são integrados, o risco de investir em um país é irrelevante, dada a diversificação do portfólio de investimento em outros países. Sua especificação é a seguinte: 
$R_{i}=R_{f G}+R_{c}+\beta C_{L G}\left[\beta_{G G}\left(R_{m G}-R_{f G}\right)\right]\left(1-R^{2}\right)$

Onde:

$R_{i}=$ retorno esperado de um ativo;

$R_{f G}=$ Taxa livre de risco global;

$R_{c}=$ Prêmio de risco-país;

$\beta C_{L G}=$ é o beta país (coeficiente angular da regressão entre o índice de mercado local e o índice de mercado global);

$\beta_{G G}=$ o beta não alavancado médio de empresas comparáveis no mercado global;

$R_{m G}=$ Retorno de mercado global.

$\mathrm{R}^{2}=$ é o coeficiente de determinação da regressão entre a volatilidade do mercado local em relação à variação do risco-país.

2.6.8 Modelo de Assaf Neto et al (ASSAF NETO; et al, 2008)

Segundo Assaf Neto et al (2008), o CAPM é uma metodologia a ser utilizada em mercados estáveis, e as conclusões favoráveis ao CAPM deveriam ser reavaliadas em mercados emergentes como é o caso do mercado brasileiro. Seu estudo descreve um modelo que utiliza padrões de benchmark, e descreve os ajustes necessários às empresas brasileiras, incorporando ao cálculo o risco-país e utilizando valores de referência extraídos de uma economia mais estável como a dos Estados Unidos. A inconsistência dos parâmetros oferecidos dentro do contexto dos mercados emergentes é discutida, questionando se esses parâmetros realmente refletem as condições de incerteza associadas. Concluindo por meio dos cálculos apresentados, utilizando principalmente medidas estatísticas de dispersão e volatilidade, a baixa confiabilidade dos parâmetros.

No estudo questiona-se a dificuldade de identificação de um título no Brasil que possa efetivamente ser tratado como isento de risco de inadimplência, já que nem todo título público pode ser considerado como sem risco, gerando assim um problema de escolha da taxa livre de risco em algumas economias, principalmente as classificadas como emergentes. Uma média histórica desses títulos no Brasil teria pouca validade diante da enorme dispersão e amplitude nos períodos observados. Dessa forma, a taxa livre de risco utilizada seria melhor mensurada por meio de uma referência às taxas de juros pagas pelos melhores títulos de dívida do mundo. O benchmark seria feito com papéis emitidos pelo Tesouro do Governo dos Estados Unidos (ASSAF NETO et al, 2008; DAMODARAN, 2010). 
O cálculo do prêmio de risco de mercado com base em dados históricos em países emergentes como o Brasil apresenta problemas referentes à confiabilidade das informações e volatilidade. Alguns fatores são críticos, como o longo período de altas taxas de inflação, a dispersão da rentabilidade da carteira de mercado de ações e sua concentração em poucas ações. No modelo proposto, o prêmio pelo risco de mercado refere-se à economia dos Estados Unidos, acrescido de uma medida do risco-país. O risco-país procura refletir o risco da economia do país, cuja proxy é a diferença entre as taxas de remuneração do bônus do governo norte-americano (T-Bond) e o bônus do governo brasileiro (C-Bond) e pode ser entendido como um spread pelo risco de inadimplência (ASSAF NETO et al, 2008).

Assaf Neto et al (2008) descrevem um modelo que utiliza padrões de benchmark, e os ajustes necessários às empresas brasileiras, incorporando o risco-país e utilizando valores de referência extraídos de uma economia mais estável como a dos Estados Unidos partindo de questionamentos acerca da validade de dados obtidos na economia brasileira e demais países emergentes como apresentado na equação a seguir:

$$
R_{i}=R_{f, U S}+\beta_{u}\left(R_{m, U S^{-}} R_{f, U S}\right)+R_{c}
$$

Onde:

$R_{i}=$ retorno esperado de um ativo;

$R_{f, U S}=$ Taxa livre de risco dos EUA;

$\beta_{u}=$ Beta médio desalavancado de empresas do mesmo setor dos EUA, alavancado com a estrutura de capital média do setor no Brasil.

$\left(R_{m, U S}-R_{f, U S}\right)=$ Prêmio de Mercado dos EUA

$R_{c}=$ Prêmio de risco-país

Mongrut (2006) faz uma crítica relacionada à inclusão do risco-país, ou seja, do total do risco assumido em investir em economias emergentes, produto do risco político, econômico e financeiro, bem como os riscos de força maior (por exemplo, o terrorismo) não seriam imputáveis ao projeto. Este talvez não seja o melhor caminho para fazê-lo em todos os casos, já que uma parte desse risco pode ser excluída por ser diversificável, ao realizar investimentos em outros países.

Há uma diversidade de estudos que testam a validade do CAPM e também criticam e propõem alterações e complementações que visam incrementar o poder explicativo do modelo. Entretanto a maior parte dos modelos alternativos ao modelo CAPM tradicional não 
considera um possível efeito de variáveis macroeconômicas sobre o retorno de qualquer ativo, mas apenas tomam como benchmark variáveis extraídas de outras economias e dessa forma, o impacto de variáveis exógenas ao mercado não é avaliado (MILANI e CERETTA, 2014).

\subsection{Arbitrage Pricing Theory (APT)}

A literatura sobre precificação de ativos foi por muito tempo baseada unicamente no modelo CAPM. Entretanto, em 1976, foi desenvolvido por Stephen Ross a teoria conhecida como Arbitrage Pricing Theory ou Teoria de Formação de Preços por Arbitragem (APT), que envolve um modelo alternativo à análise de média variância utilizada pelo modelo CAPM. Ao observar as principais críticas ao modelo CAPM, que se baseiam em premissas como a distribuição normal do retorno dos ativos, entre outras, pode-se constatar que todas elas são premissas muito fortes e restritivas e que dificilmente refletem a verdadeira realidade dos mercados acionários, sendo sempre questionada a capacidade de um único fator ser capaz de explicar o retorno dos ativos (ROSS, 1976).

A explicação das contradições empíricas do CAPM indica a necessidade de um modelo mais complexo de precificação de ativos. O CAPM se baseia em muitas premissas irreais. Por exemplo, a de que os investidores somente se preocupam com a média e a variância do retorno da carteira em um período é bastante exagerada. É razoável que eles também se importem com a maneira que o retorno de sua carteira é afetado e com oportunidades futuras de investimento, de modo que a variância do retorno de uma carteira deixa escapar importantes dimensões do risco (FAMA; FRENCH, 2007).

A abordagem APT exige que sejam especificadas quais variáveis macroeconômicas são fatores de risco relevantes. Então, busca-se escolher fatores de risco aos quais os investidores devem exigir prêmios de risco significativos para suportar a exposição a essas fontes de risco. De forma alternativa à especificação utilizando fatores macroeconômicos, utilizam-se também características das empresas baseadas em evidências empíricas (BODIE; KANE; MARCUS, 2001).

A Teoria de Formação de Preços por Arbitragem (APT) tem como premissa a lei de preço único, ou seja: dois ativos semelhantes não podem ser vendidos por diferentes preços. As premissas do CAPM referente às preferências dos investidores e a descrição de equilíbrio nos modelos APT são mais relaxadas, visto que a formação de preços pode ser afetada por outros fatores, além do Beta referente ao prêmio de mercado. As evidências empíricas sobre os modelos APT sugerem que o retorno dos ativos responde sistematicamente a determinadas 
variáveis macroeconômicas como: inflação, taxas de juros, taxa de câmbio, produção industrial, PIB, etc. Também se relaciona com variáveis especificas de cada empresa, tais como tamanho, desempenho, índice book-to-market, índice preço / lucro etc., que são vistas como muito relevantes para explicar retornos esperados (ROGERS; SECURATTO, 2009).

O modelo resultante da APT é derivado do modelo CAPM em sua forma tradicional admitindo que outros fatores, além do Beta relativo ao prêmio de mercado, possuem a capacidade de melhorar o poder explicativo do modelo. Dessa forma o CAPM é um caso específico do APT, onde é utilizado apenas um fator explicativo. Segundo Ross (2008), a taxa de retorno $\left(R_{i}\right)$ de qualquer ativo negociado no mercado financeiro é formada por duas partes e está embasado na teoria de que, em equilíbrio, não é possível haver arbitragem no mercado. Sendo assim, não há obtenção de retorno positivo sem utilizar riqueza e sem incorrer em risco. O APT requer menos premissas e mais realistas que o modelo CAPM, conforme visto no Quadro 2:

Quadro 2 - Premissas do modelo APT

\begin{tabular}{|c|l|}
\hline Investidores & $\begin{array}{l}\text { Têm expectativas homogêneas em relação ao retorno dos ativos explicado pelo } \\
\text { modelo de k fatores. }\end{array}$ \\
\hline Mercado & É perfeitamente competitivo e não existem custos de transação. \\
\hline Ativos & $\begin{array}{l}\text { Número de ativos } n \text { deve ser muito superior ao número de fatores } \lambda . \\
\text { O erro } \varepsilon_{i} \text { deve ser o risco não sistemático do ativo i. } \\
\text { Os erros } \varepsilon_{i} \text { de cada ativo devem ser independentes dos fatores } \\
\text { Os erros } \varepsilon_{i} \text { de cada ativo devem ser independentes entre si }\end{array}$ \\
\hline
\end{tabular}

Fonte: Adaptado de Cuthbertson e Nitzsche (2008).

Assume-se, então, que o retorno pode ser descrito por um modelo de fatores e não existem oportunidades de arbitragem. Entretanto, o risco associado ao retorno dos ativos pode ser dividido em duas fontes de risco: uma parcela sistemática, chamada de risco sistemático, que afeta com maior ou menor intensidade grande número de ativos; uma parcela específica, chamada de risco não sistemático, que afeta particularmente um único ativo ou pequeno grupo de ativos. O risco referente à parcela sistemática é comum a todos os ativos, e dois pontos cruciais nos modelos APT são: encontrar o número de fatores comuns que influenciam os ativos em questão; e mensurar a sensibilidade dos ativos em relação a esses fatores (ROSS, WESTERFIELD; JAFFE, 2008; ROGERS; SECURATO, 2009).

O retorno de qualquer ativo é composto por uma parte que já esperada, mas também possui uma parte inesperada resultante de novos acontecimentos e informações que constitui o 
risco, ou seja, o nível de incerteza associado Admitindo a racionalidade do investidor, o retorno esperado deve compensar qualquer tipo de risco associado ao investimento. Sendo o retorno esperado um somatório da taxa livre de risco mais uma compensação atribuída a cada tipo de risco, justifica-se que fatores associados a um nível de incerteza como o crescimento da produção industrial, variação da inflação esperada, variação da taxa livre de risco, mudança no retorno dos títulos do governo de longo prazo e de curto prazo, entre outros podem afetar diretamente o retorno de um investimento (ROSS; WESTERFIELD; JORDAN, 2013).

Cada fator incluído no modelo representa um risco de que não pode ser diversificado. O beta mais elevado significa uma maior sensibilidade a um determinado fator. Assume como exemplo, que um evento relacionado à inflação que não é esperado será capaz de exercer influência sobre praticamente todas as empresas de alguma forma. Se o retorno aumenta em função do aumento imprevisto da inflação, pode-se dizer que esse retorno é positivamente relacionado, e há uma relação negativa se o retorno diminui quando a inflação supera as expectativas. Raramente observa-se que o retorno não é correlacionado com surpresas de inflação, ou seja que a inflação não tenha nenhum efeito sobre o retorno de um determinado ativo. Pode-se capturar a influência de um risco sistemático como a inflação sobre um ativo através do coeficiente beta. O coeficiente beta, $\beta$, associado a cada fator inserido no modelo APT mede a capacidade de resposta do retorno de um ativo ou carteira associado a um fator de risco específico (GRINBLATT; TITMAN, 2005; ROSS; WESTERFIELD; JAFFE, 2008).

O APT prevê que o retorno dos ativos possa ser explicado pela combinação linear de diversos fatores e não apenas um, como previsto pelo CAPM, sendo representado pela equação:

$$
\mathrm{R}_{i}=R_{f}+\beta_{1} \lambda_{1}+\beta_{2} \lambda_{2}+\beta_{3} \lambda_{3}+\ldots+\beta_{N} \lambda_{N}
$$

Onde:

$\mathrm{R}_{i}=$ retorno esperado de um ativo;

$R_{f}=$ retorno do ativo livre de risco;

$\beta=$ coeficiente de sensibilidade do ativo $i$ a cada um dos fatores explicativos $\lambda$;

$\lambda_{N}=\mathrm{N}$ fatores explicativos para o retorno do ativo $i$

Ross (1976) não define quais nem quantos fatores devem ser utilizados e a literatura de modo geral sugere que sejam entre 3 e 5 . As sensibilidades aos fatores são representadas 
por cada um dos coeficientes betas $\left(\beta_{N}\right)$ associados a cada um dos fatores. Também não há na literatura sinal esperado para os fatores, que são difíceis de interpretar porque não há uma teoria econômica por trás da inclusão de cada fator no modelo.

Dessa forma, vale ressaltar a importância da construção dos modelos APT de forma empírica, pois observa-se que um determinado ativo pode-se ser mais sensível às variações de alguns tipos de fatores macroeconômicos. Já para outro ativo, outros fatores como indicadores de rentabilidade podem ser mais relevantes. Então, busca-se identificar os fatores que exercem influência sobre o maior número de ativos. Para minimizar essas diferenças, se dá importância a uma carteira bem diversificada. Nos modelos APT observa-se necessidade de que esteja disponível uma grande quantidade de ações, de modo que seja possível formar carteiras que diversifiquem o risco não sistemático, assumindo assim que não existe risco específico de cada empresa (GRINBLATT; TITMAN, 2005; CUTHBERTSON; NITZSCHE, 2008; ROGERS; SECURATO, 2009).

No Quadro 3 são apresentados os métodos utilizados para determinação do modelo e evidências empíricas.

Quadro 3 - Vantagens, desvantagens e evidências empíricas dos métodos de estimação de modelos APT

\begin{tabular}{|c|c|c|c|}
\hline Método de estimação & Vantagens & Desvantagens & Evidências empíricas \\
\hline $\begin{array}{l}\text { A Análise fatorial: } \\
\text { Trata-se de um } \\
\text { procedimento totalmente } \\
\text { estatístico a fim de estimar } \\
\text { fatores e a sensibilidade dos } \\
\text { retornos a eles. }\end{array}$ & $\begin{array}{l}\text { Fornece a melhor } \\
\text { estimativa dos } \\
\text { fatores, dados os } \\
\text { seus pressupostos. }\end{array}$ & $\begin{array}{l}\text { A pressuposição de que as } \\
\text { covariâncias são constantes } \\
\text { é crucial e provavelmente } \\
\text { será violada na realidade; } \\
\text { não "nomeia" efetivamente } \\
\text { os fatores }\end{array}$ & $\begin{array}{l}\text { Roll e Ross (1980); } \\
\text { Connor e Korajczyk } \\
(1986) ; \text { Elton e Gruber } \\
\text { (1988); Neves (2001); } \\
\text { Berenice (1998); Samanez } \\
(1999) .\end{array}$ \\
\hline $\begin{array}{l}\text { Variáveis } \\
\text { macroeconômicas: } \\
\text { Utiliza séries temporais } \\
\text { macroeconômicas para que } \\
\text { atuem como aproximações } \\
\text { para os fatores que geram } \\
\text { retornos acionários. }\end{array}$ & $\begin{array}{l}\text { Fornece } \\
\text { Interpretações } \\
\text { mais intuitivas } \\
\text { dos fatores. }\end{array}$ & $\begin{array}{l}\text { Implica que os fatores } \\
\text { apropriados sejam as } \\
\text { alterações não antecipadas } \\
\text { das macrovariáveis. Pode ser } \\
\text { difícil medir na prática } \\
\text { alterações não antecipadas } \\
\text { nas variáveis. }\end{array}$ & $\begin{array}{l}\text { Chan, Chen e Hsieh } \\
\text { (1985); Chen, Roll e Ross } \\
\text { (1986); Burmeister e } \\
\text { McElroy (1988); } \\
\text { Jagannathan e Wang } \\
\text { (1996); Neves (2001). }\end{array}$ \\
\hline $\begin{array}{l}\text { Características da empresa: } \\
\text { Utiliza características da } \\
\text { empresa, sabendo de seu } \\
\text { relacionamento com os } \\
\text { retornos acionários, para } \\
\text { formar carteiras de fator. }\end{array}$ & $\begin{array}{l}\text { Mais intuitiva que } \\
\text { as carteiras } \\
\text { formadas pela } \\
\text { análise fatorial; } \\
\text { sua formação não } \\
\text { requer } \\
\text { covariâncias } \\
\text { constantes. }\end{array}$ & $\begin{array}{l}\text { Carteiras selecionadas com } \\
\text { base nas anomalias de } \\
\text { retorno do passado, que só } \\
\text { são fatores porque explicam } \\
\text { "acidentes" históricos, e } \\
\text { podem não ser boas para } \\
\text { explicar retornos esperados } \\
\text { no futuro. }\end{array}$ & $\begin{array}{l}\text { Fama e French (1993, } \\
\text { 1996) e Hong, Lim e Stein } \\
\text { (2000); Costa e Neves } \\
\text { (1998); Mellone } \\
\text { (1999); Rodrigues 2000); } \\
\text { Rodrigues e Leal(2003); } \\
\text { Malaga e Securato (2004); } \\
\text { Lucena e Pinto (2005). }\end{array}$ \\
\hline
\end{tabular}

Fonte: Adaptado Grinblatt e Titman (2005); Rogers e Securato (2009).

A partir do quadro 3, ao tratar das vantagens e desvantagens dos métodos de estimação de modelos APT, pode ser observado que não há consenso sobre uma metodologia 
empírica, o que aliado à ausência de uma teoria econômica que sustente a inclusão de cada fator no modelo tornam-se então as principais críticas a respeito desse modelo de precificação de ativos (ROSS; WESTERFIELD; JAFFE, 2008; CUTHBERTSON; NITZSCHE, 2008).

Diversos estudos foram realizados com o intuito de solucionar esses questionamentos. Roll e Ross (1980) testaram empiricamente o modelo APT com a proposta de estimar quantos fatores seriam necessários para explicar o retorno das ações no mercado norte americano entre 1962 e 1972. Foi feita aplicação da análise de fatorial utilizando dados diários de 42 grupos de 30 ações. Nas primeiras regressões, eles constataram que para a maioria dos grupos, cerca de cinco fatores eram capazes de fornecer uma explicação suficientemente boa. Em um segundo momento, apenas três fatores seriam suficientes. Contudo, não se pode afirmar nada a respeito de quais seriam esses fatores.

Dhrymes et al (1982) encontraram evidências do relacionamento entre o número de fatores e o número de ativos a serem avaliados. Ao utilizar a análise de fatorial, sua interpretação sugere que o número de fatores estatisticamente significantes aumenta à medida que são incluídos mais ativos na análise. Ao utilizar fatores que são resultantes de combinações lineares de variáveis econômicas, estes tornam-se difíceis de interpretar. No Brasil, Mello (1999) realizou um estudo semelhante e sugere que são necessários seis fatores explicativos para justificar o retorno das ações. Seu estudo foi realizado no período entre janeiro de 1989 e agosto de 1995.

Outra forma de se estimar o modelo APT é através da utilização de fatores prédeterminados. Esses fatores podem ser relacionados especificamente aos ativos como, por exemplo, indicadores de rentabilidade da própria empresa, dividendos pagos, tamanho da empresa ou fatores macroeconômicos como PIB, taxa de câmbio, inflação, produção industrial, entre outros. De acordo com Ross, Westerfield e Jaffe (2008), o modelo APT tem o potencial para medir retornos esperados com mais precisão do que o CAPM. No entanto, apresenta como desvantagem a dificuldade em determinar quais são os fatores apropriados. Os fatores geralmente são incluídos por razões de senso comum e conveniência, não sendo derivados de uma teoria, e as principais críticas sobre o modelo giram em torno desse fato. $\mathrm{O}$ modelo de Três Fatores apresentado por Fama e French (1993) é um exemplo de um caso particular do APT, onde os autores tentam consolidar os fatores a serem incluídos sendo apresentado a seguir. 


\subsection{Modelo de 3 Fatores}

Os estudos da década de 1990 de Fama e French concluem que a relação entre o retorno médio dos ativos e o beta é fraca durante o período compreendido entre 1941 e 1990 e praticamente inexistente de 1963 a 1990, com base no retorno das ações da NYSE (New York Stock Exchange). Documentam, ainda, a existência de relação do retorno médio a outros fatores, o que contradiz o CAPM que indica que os retornos esperados sobre as ações devem estar unicamente relacionadas ao beta. Entretanto, não é rejeitada a hipótese de que os retornos médios são completamente independentes do beta do prêmio de mercado (FAMA; FRENCH, 2007)

Fama e French (1992), usando a consolidada metodologia de Fama e Macbeth (1973), confirmam a existência de relações já observadas na literatura, ao adicionar outros fatores à explicação dos retornos esperados das ações do que as fornecidas somente pelo beta de mercado. O beta de mercado não é uma descrição completa do risco de um ativo, e observa-se que as diferenças de retorno esperado não são plenamente explicadas pelas diferenças de beta. Estudos anteriores destacavam importantes relações entre o retorno das ações com outras variáveis, conforme o quadro 4:

Quadro 4 - Estudos precursores sobre a relação entre o retorno das ações e outras variáveis

\begin{tabular}{|c|c|}
\hline Variáveis & Estudos anteriores \\
\hline Tamanho da empresa & Banz (1981); Reiganum (1981); Keim (1983) \\
\hline Alavancagem & Bhandari (1988) \\
\hline Lucro /Preço & $\begin{array}{c}\text { Basu (1977); Banz (1981); } \\
\text { Jaffe, Keim e Westerfield (1989) }\end{array}$ \\
\hline Indicador valor patrimonial/ valor de mercado & $\begin{array}{c}\text { Statnan (1980); Bondt e Thaler (1985) } \\
\text { Rosenberg, Reid e Lanstein (1985); Chan, Hamao e } \\
\text { Lakonishok (1991). }\end{array}$ \\
\hline
\end{tabular}

Fonte: Elaborado pela autora

Com base nesse cenário, Fama e French (1992) publicaram um estudo em que, além do fator mercado, investigaram o poder de explicação dos retornos de alguns fatores associados a características das empresas, tais como: tamanho, representado pelo valor de mercado (VM), índice book-to-market ou relação valor patrimonial/valor de mercado (VP/VM), alavancagem, relação lucro/preço por ação. Eles constataram que tais variáveis conseguiam capturar parcela relevante do retorno das carteiras não explicada pelo beta do 
CAPM. Entretanto não há necessidade de usar todas as variáveis em conjunto, já que algumas delas são correlacionadas (FAMA e FRENCH, 2007).

Os principais resultados de Fama e French (1993) indicam que o beta sozinho tem pouco poder explanatório sobre o retorno médio das ações, contrariando as premissas do CAPM. Segundo Machado (2009), se os ativos são racionalmente precificados, seus resultados sugerem que os riscos das ações são multidimensionais.

Fama e French (1993) adotam uma abordagem mais próxima da teoria da precificação por arbitragem de Ross (1976), argumentando que o efeito tamanho e índice book-to-market produzem riscos não diversificáveis (covariâncias) em retornos que não são captados pelo retorno do mercado e são precificados separadamente do beta de mercado. Os autores sustentam esse argumento com base na maior covariância entre os retornos das ações de pequenas empresas do que com os retornos de ações de empresas de grande porte. Isso também pode ser verificado com o índice book-to-market, as de elevado índice apresentam maior covariância entre si, assim como as de menores índices (FAMA e FRENCH, 2007).

Baseados nesses resultados, Fama e French (1993) propuseram o uso de um modelo de três fatores para explicar o retorno das ações. O primeiro fator trata do excesso de retorno da carteira de mercado de referência em relação ao ativo livre de risco denominado fator mercado, sendo similar ao utilizado no CAPM. São acrescidos mais dois fatores: o fator tamanho que é a diferença entre o retorno da carteira de ações de empresas pequenas (baixo valor de mercado) e grandes (alto valor de mercado). O fator tamanho é conhecido como Small Minus Big (SMB), o outro fator trata da diferença entre os retornos da carteira de ações de empresas de alta capitalização e da carteira composta por empresas de baixa capitalização. Sendo representada pelo índice book-to-market, ou seja, a razão entre o valor contábil e o valor de mercado) conhecido como High Minus Low (HML). A equação do modelo é apresentada a seguir:

$R_{i}=R_{f}+\beta\left(R_{m}-R_{f}\right)+s(\mathrm{SMB})+h(\mathrm{HML})$

Onde:

$R_{i}=$ retorno esperado de um ativo;

$R_{f}=$ retorno do ativo livre de risco;

$R_{m}=$ taxa esperada de retorno sobre o portfólio geral do mercado;

$\left(R_{m}-R_{f}\right)=$ taxa de prêmio relativo ao risco de mercado.

SMB: prêmio pelo fator tamanho; 
HML: prêmio pelo fator book-to-market;

$\beta$, s e $h=$ representam as sensibilidades em relação aos fatores mercado, tamanho e valor contábil /valor de mercado, respectivamente.

Note-se que neste modelo o índice de mercado tem o papel esperado de capturar uma parcela de risco proveniente de fatores macroeconômicos. Fama e French (1993) apontam que empresas com altos índices book-to-market são mais prováveis de estarem em dificuldades financeiras e que as pequenas empresas podem ser mais sensíveis a mudanças nas condições da economia. Assim, essa variável também tende a captar a sensibilidade a fatores de risco macroeconômicos (BODIE; KANE; MARCUS, 2001).

A inclusão do efeito tamanho foi documentada originalmente por Banz (1981), que constatou que o desempenho histórico de carteiras formadas por ações de acordo com o tamanho da empresa, sendo medido pelo valor de mercado é diferenciado. As carteiras formadas por empresas de baixo valor de mercado apresentam retornos médios maiores que as carteiras formadas por empresas de alto valor de mercado.

É apresentado como justificativa para isso que empresas de baixo valor de mercado tendem a sofrer efeitos de liquidez, o disclosure das informações contábeis e a disponibilidade sobre outros tipos de informações tendem a ser menores em empresas de baixo valor de mercado. A deficiência de informação faria com que as empresas menores se tornem investimentos mais arriscados e que justifiquem retornos mais elevados (BODIE; KANE; MARCUS, 2001).

Para Fama e French (2007), a principal desvantagem do modelo de três fatores reside em sua motivação empírica. Segundo eles, as variáveis explicativas do modelo (fator tamanho e índice book-to-market) não são motivadas por variáveis que refletem a preocupação dos investidores, mas sim por constructos brutos destinados a capturar padrões não cobertos pelos trabalhos anteriores em como os retornos acionários variam com o tamanho e o índice bookto-market. Alguns dos estudos realizados para o mercado acionário brasileiro apresentam resultados descritos no Quadro 5: 
Quadro 5 - Estudos realizados no mercado acionário brasileiro

\begin{tabular}{|c|c|c|}
\hline Mello (1999) & Janeiro/1989 - agosto/1995 & $\begin{array}{l}\text { Resultados sugerem que o modelo três fatores não } \\
\text { foi representativo para o mercado brasileiro. Os } \\
\text { resultados apresentados mostraram que em } 65 \% \\
\text { das carteiras observadas o fator SMB não foi } \\
\text { estatisticamente diferente de zero, e em } 70 \% \text { dos } \\
\text { casos para o fator HML. }\end{array}$ \\
\hline $\begin{array}{l}\text { Málaga e Securato } \\
\qquad(2004)\end{array}$ & Janeiro/1995 a junho/2003 & $\begin{array}{l}\text { Foram obtidos pelos autores resultados semelhantes } \\
\text { ao de Fama e French: superioridade do modelo de } \\
\text { três fatores em relação ao CAPM em sua forma } \\
\text { tradicional. Contudo, o retorno médio das empresas } \\
\text { de pequeno porte não supera o retorno médio das } \\
\text { empresas de grande porte, como era esperado. O } \\
\text { prêmio médio do fator SMB foi de }-0,32 \% \text { ao mês. } \\
\text { O prêmio negativo é contrário ao esperado. }\end{array}$ \\
\hline Lucena e Pinto (2005) & 1994 a 2004 & $\begin{array}{l}\text { Os autores incorporaram dois modelos de variância } \\
\text { condicionada e os resultados evidenciaram que a } \\
\text { modelagem utilizada mostrou-se adequada ao } \\
\text { modelo de três fatores. }\end{array}$ \\
\hline Mussa (2007) & Junho/1995 a junho/2007 & $\begin{array}{l}\text { O autor não encontrou prêmio de risco para as } \\
\text { empresas de menor porte no Brasil e também } \\
\text { concluiu que o modelo de três fatores é superior ao } \\
\text { CAPM para estimar o retorno das ações. }\end{array}$ \\
\hline
\end{tabular}

Fonte: elaborado pela autora

\subsection{Testes Empíricos dos Modelos de Precificação de Ativos em Economias Emergentes}

Bruner et al. (2008) realizaram testes empíricos com os modelos CAPM Global e CAPM Local, e constataram que em mercados de capitais de economias emergentes da utilização do modelo Local é preferível ao modelo Global, enquanto nos mercados desenvolvidos ambos os modelos conferem resultados praticamente idênticos. Estes resultados foram obtidos a partir de um conjunto de dados que abrangeu o período de Janeiro de 1994 a julho de 2004.

White (2011) comparou 3 modelos de precificação de ativos no mercado acionário indiano, o CAPM, o CAPM Global e o APT, usando 312 empresas, e confirmando a teoria proposta por Stulz (1995), de que o custo de capital próprio é mais baixo nos mercados globais do que nos mercados emergentes. Existem diferenças significativas nos betas entre os modelos utilizados, corroborando a ideia da relevância da escolha do modelo adequado, o CAPM e CAPM Global apresentaram resultados superiores para empresas indianas.

Barclay et al. (2010) testaram o CAPM Global e o CAPM Local, inserindo algumas modificações, adicionando vários fatores para esses modelos. A amostra incluiu dados de 20 mercados emergentes, dividido em dois sub-períodos: pré-crise (que inclui o período de crise) e pós-crise. Os resultados dos testes mostraram que os diferentes sub-períodos se mostraram diferenciados, apontando resultados favoráveis aos dois modelos, em situações diferentes. No primeiro momento (pré-crise e crise) o CAPM Local fornece melhores resultados do que o 
modelo global em mercados emergentes e no período pós-crise CAPM Global apresentou melhores resultados.

Também foram encontradas evidências na Turquia de que modelos com premissas locais não são recomendados para aquele país. No mercado turco os modelos que levam em conta o nível de integração do mercado produzem resultados mais realistas do que outros. Foram testados diversos modelos que se baseiam no modelo CAPM. Dentre os modelos testados estão o CAPM Local, CAPM Global, e o modelo de Damodaran, dentre outros. Os resultados de modelos usando dados locais foram comparados aos resultados de modelos usando dados globais. Foram utilizados dados do período de junho de 2008 a junho de 2013. Os resultados são favoráveis ao CAPM Global (DEMIR e KADERLI, 2015).

Entretanto, Sanvicente (2015) critica o uso de dados trazidos de mercados internacionais sob a ótica de que o mercado local pode ser desenvolvido o suficiente para que os preços correntes das ações incorporem informação a respeito de riscos relevantes, recomendando o uso dados do mercado local, especialmente quando o objetivo é precificar ativos locais, no lugar dos modelos que utilizam dados do mercado norte-americano.

\subsection{Evidências Empíricas Dos Modelos De Precificação De Ativos No Brasil}

Rogers e Securato (2009) testam e comparam três modelos de precificação para a predição de retornos esperados no mercado de capitais brasileiro, são comparados os modelos: CAPM; o modelo 3-Fatores de Fama e French; e o Reward Beta Model, proposto por Bornholt (2007). Foram realizadas regressões em séries temporais com o intuito de estimar os

parâmetros, e em seguida os parâmetros são usados em regressões cross-section. Foram utilizadas carteiras e a amostra foi dividida em duas subamostras referentes a períodos distintos onde primeiro são estimados os parâmetros e em seguida são realizadas as projeções para o período de 2001 a 2006. Os resultados encontrados tendem a apoiar o modelo 3 Fatores de Fama e French para explicar retornos futuros, entretanto o fator book-to-market não foi significativo.

Veras e Reis (2014) buscaram explicar as variações dos retornos das ações no mercado acionário brasileiro. Foi comparado o desempenho do CAPM com o modelo de três fatores de Fama e French (1993) e modelo de dois fatores desenvolvido por Liu (2006), investigando se o modelo é robusto às estratégias baseadas nos efeitos tamanho da empresa, book-to-market, estratégia momento, lucro/preço, liquidez e alavancagem, denominadas de anomalias de valor. Para o desenvolvimento do estudo foram empregados portfólios com 
dados no período de 1995 a 2008. Nos resultados apresentados, percebeu-se uma melhora no poder explicativo do modelo de dois fatores em relação ao CAPM e um desempenho muito próximo ao modelo de três fatores.

De acordo com Argolo, Leal e Almeida (2012) embora o modelo de três fatores de Fama e French tenha sido aplicado com sucesso em diversos países, seu uso no Brasil é questionável, apesar de testes indicarem a existência de prêmios e do modelo apresenta maior poder explicativo em relação ao modelo de fator único. Ao observar as médias históricas dos prêmios HML e SMB, estas se apresentam muito elevadas e não obstante expõem instabilidade em diversos momentos, gerando dúvidas sobre sua capacidade de gerar estimativas razoáveis para o cálculo do custo de capital acionário de empresas brasileiras. $\mathrm{O}$ beta apresenta-se significativo em todos os testes realizados e apresenta maior estabilidade. Dessa forma, as estimativas obtidas apenas com um único fator (prêmio de risco de mercado) aparentam ser mais razoáveis, do ponto de vista financeiro, do que as oferecidas pelo modelo de três fatores, cuja parametrização parece ser difícil para aplicação no Brasil.

No mercado acionário brasileiro, existem resultados, como os de Rayes et al (2012) que testaram o modelo de 3 fatores de Fama e French (1993) no mercado acionário brasileiro. Com o objetivo de identificar se os fatores prêmio de mercado, SMB e HML ainda explicam os retornos das ações no Brasil no período de 2000 até 2008, foram utilizadas regressões com os retornos mensais de carteiras e de ações individuais com as quarenta empresas de maior liquidez na bolsa de valores de São Paulo. Seus coeficientes não foram estatisticamente diferentes de zero tanto para as ações individuais como para as carteiras, contrariando a maior parte da literatura existente até o estudo, levantando como possível causa uma quebra estrutural ocorrida em meados de 2006, que é sinalizada por um aumento da liquidez no mercado. O prêmio de risco de mercado é significativo e é questionada a existência de outros possíveis fatores capazes de explicar o retorno acionário no mercado brasileiro.

Levando em consideração as particularidades do mercado acionário brasileiro, ressalta-se que o Brasil tem uma taxa de inflação mais elevada, se comparada a outras economias mais desenvolvidas. Podendo apresentar como consequência o fato do poder explicativo do fator de risco relacionado ao índice book-to-market do modelo de três fatores de Fama e French pode ser menor, uma vez que os valores contábeis podem ser seriamente influenciados pela idade dos ativos. Com isso, os índices book-to-market tornam-se menos significativos. Tais resultados são diferentes dos obtidos em mercados mais desenvolvidos, podendo se assemelhar as demais economias emergentes (NODA et al,2015). 
Com o objetivo de testar a capacidade preditiva dos modelos de precificação de ativos no mercado acionário brasileiro, Mussa et al (2009) utilizaram a metodologia proposta por Fama e MacBeth (1973) que consiste na realização de regressões em série temporal e em seguida utilizar os parâmetros obtidos como variável independente em regressões crosssection. Segundo os autores foram identificados interceptos significativos e tanto o modelo CAPM como modelo de três fatores não foram capazes de prever os retornos de ações brasileiras. 


\section{METODOLOGIA}

O plano da pesquisa se dirigiu a um estudo exploratório, empírico, analítico, com a utilização de técnicas de coleta, tratamento, e análise de dados baseado em métodos quantitativos e buscou-se identificar a relação entre as variáveis (MARTINS, 2002).

Foram realizados testes estatísticos com o objetivo de validação dos modelos adotados e por meio do $\mathrm{R}^{2}$ obtido nas regressões da metodologia proposta, e dessa forma se deu a identificação do modelo com maior poder explicativo. Através dos Critérios de Akaike, Schwarz pode ser determinado o modelo de melhor ajuste ao mercado acionário brasileiro.

\subsection{Fonte de Dados e Amostra}

O processo de amostragem adotado foi não probabilística por conveniência, onde as ações foram selecionadas de acordo com o atendimento aos requisitos necessários. Foram selecionados os ativos que possuem dados suficientes para o cálculo do retorno, facilitando a formação de portfólios, com a cotação de fechamento das ações ajustada por proventos e preços ajustados pela inflação do respectivo período sendo utilizado o IPCA para dados brasileiros e o CPI US para dados norte-americanos.

Dentre as empresas listadas na Bovespa, foram excluídas as que fizeram sua oferta pública inicial depois de $1^{\circ}$ de janeiro de 2009; foram excluídas também as empresas que não apresentaram cotação de fechamento na data de encerramento de cada mês, ao longo de todo o período analisado (do primeiro dia de 2010 ao último dia de 2014). Esses papéis que foram excluídos não apresentam a liquidez necessária para o desenvolvimento do estudo. O período foi definido de modo a incluir a quantidade mínima recomendada de observações temporais para a realização de testes econométricos.

A amostra é composta por todas as empresas listadas na Bovespa que abriram seu capital antes de 2009, sendo selecionadas as que apresentaram:

a) Cotação de fechamento no último dia útil de cada mês em todo o período compreendido entre dezembro de 2009 e dezembro de 2014, com tolerância definida na base de dados Economática ${ }^{\circledR}$ de cotação dentro da mesma semana de fechamento. Caso uma empresa apresentasse ações de mais de uma classe, foi usada na amostra a ação de maior liquidez no período. No cálculo do retorno foram considerados os ajustes de inflação feitos 
pela própria Economática ${ }^{\circledR}$, pelo IPCA, sendo também realizado o ajuste por pagamento de proventos e dividendos no período.

b) Valor patrimonial positivo no período requerido para a construção das carteiras.

c) Valor de mercado para o período requerido para a construção das carteiras, com tolerância definida no sistema Economática ${ }^{\circledR}$ de cotação dentro da mesma semana de fechamento. $\mathrm{O}$ valor de mercado foi calculado com base na cotação de fechamento das ações ON e PN considerando a tolerância relatada de existência de dados dentro da mesma semana.

De acordo com Araújo et al (2012), a maioria dos estudos, totalizando cerca de 70\%, com testes do CAPM e demais modelos de precificação em portfólios de ativos obtiveram resultados significantes, corroborando a efetividade do modelo. Dessa forma, foram realizados testes com a formação de portfólios e também com ativos individuais.

Dentre os modelos estudados foram escolhidos para a realização dos testes empíricos aqueles modelos que possuem adequação para utilização com ativos individuais e com carteiras, sendo escolhidos os modelos: CAPM, CAPM Global, CAPM Local, modelo de 3 Fatores e APT.

As empresas inicialmente incluídas na amostra totalizaram 146, mas as 14 do setor financeiro acabaram sendo excluídas, como no estudo de Fama e French (1993), por apresentarem uma estrutura de capital diferenciada das demais. A partir das 132 empresas restantes foram formadas 60 carteiras de forma aleatória, todas as carteiras possuindo 22 ações, que foram ponderadas igualmente. Assume-se que, pela construção aleatória e pela quantidade de ativos, tais carteiras estejam bem diversificadas, pois se o portfólio tem muitos ativos, os retornos específicos das ações tendem a anular-se mutuamente. A diversificação é condição relevante para os testes empíricos dos modelos de precificação de ativos. De acordo com Brito (1989), Oda et al (1998), Martins e Gava (2009), Farias e Moura (2014) e Santiago (2015), uma carteira com mais de 19 papéis no mercado acionário brasileiro contêm um número adequado de ações que atende à condição de diversificação.

Os dados utilizados para elaboração do presente estudo foram extraídos basicamente das bases de dados da Economática®, Reuters, Banco Central, IBGE e IPEA (Ipeadata).

\subsection{As Variáveis Utilizadas}

De acordo com Brooks (2002), quando o objeto de análise é uma série de preços, por diversas razões estatísticas relacionadas à estacionariedade, tais séries devem ser convertidas em séries de retornos. Existem dois métodos para o cálculo do retorno das séries de preços, o 
que pressupõe a escolha entre a forma de capitalização discreta ou capitalização contínua, conforme as equações, respectivamente:

$$
\begin{aligned}
& R_{i, t}=\frac{P_{i, t}-P_{i, t-1}}{P_{i, t-1}} \\
& R_{i, t}=\ln \left(\frac{P_{i, t}}{P_{i, t-1}}\right)=\ln P_{i, t}-\ln P_{i, t-1}
\end{aligned}
$$

Onde:

$R_{i, t}=$ o retorno da ação $i$ no período $t$;

$P_{i, t}=$ o preço da ação $i$, no período $t$, e

$P_{i, t-1}=$ Preço da ação $i$, no período $t-1$.

De acordo com Brooks (2002, p.7), a literatura acadêmica de finanças emprega geralmente o processo de capitalização contínua. Segundo Soares, Rostagno e Soares (2002), essa preferência pode ser justificada em função das consequências estatísticas quanto à distribuição de frequências dos retornos. Segundo esses autores, a fórmula de cálculo do retorno pela capitalização discreta, pressupõe que não será obtida uma série de retorno simétrica, já que os resultados se distribuirão à direita.

No caso do cálculo pela capitalização contínua, a curva representativa da distribuição de frequência torna-se simétrica. Soares, Rostagno e Soares (2002) concluem que a fórmula logarítmica de cálculo mostra-se mais adequada, pois os testes estatísticos paramétricos exigem que se utilize uma distribuição normal. Então, primeiramente todas as cotações de fechamento das ações foram deflacionadas adotando o IPCA sendo então convertidas em séries de retornos de ações e retornos de portfólios.

Os dados adotados para composição dos modelos seguem descritos, para a taxa livre de risco $\left(R_{f G}\right)$, bem como a taxa livre de risco dos EUA $\left(R_{f, U S}\right)$ foi utilizado o T-bonds de 10 anos, conforme Leal (2002). Foi utilizado o CDI deflacionado como taxa de risco local $\left(R_{f L}\right)$. Como retorno do mercado global $\left(R_{m G}\right)$ foi adotado o norte-americano, sendo a proxy escolhida o retorno logarítmico do S\&P500. O retorno do mercado local $\left(R_{m L}\right)$ foi obtido através do retorno logarítmico do IBOVESPA. Uma proxy de risco país pode ser obtida por meio da diferença entre a taxa livre de risco global e a taxa livre de risco local, e dessa forma foi adotada como medida de risco-país o EMBI+, que é calculado com base na média ponderada do spread de títulos americanos e brasileiros de diversos prazos. Todas as variáveis 
extraídas do mercado brasileiro foram deflacionadas pelo IPCA e deflacionadas pelo CPI US os dados do mercado norte-americano.

\subsection{Descrição Dos Modelos Econométricos Utilizados}

Dentre os modelos apresentados nesse estudo, foi feita a opção pelos modelos que pudessem ser testados empiricamente por meio de ativos individuais e também com a utilização de carteiras, sendo selecionados os modelos: CAPM, CAPM Local, CAPM Global, Modelo de 3 Fatores e APT, que seguem descritos.

\subsubsection{O Modelo CAPM (SHARPE, LINTNER E MOSSIN, 1965)}

O modelo CAPM tradicional foi testado tanto em ativos individuais como em carteiras conforme modelo descrito e amplamente testado. Como proxy da carteira de mercado local foi utilizado o índice IBOVESPA, como ativo livre de risco do mercado brasileiro foi usado o CDI (taxa real). Foi realizada a regressão do excesso do retorno das carteiras em relação ao ativo livre de risco e o excesso de retorno do mercado em relação ao ativo livre de risco, A mesma regressão também foi realizada utilizando o retorno dos ativos individuais no lugar do retorno das carteiras, dando origem a duas regressões distintas, o que também foi feitos para todos os outros modelos. O modelo segue descrito a seguir:

$\mathrm{R}_{i, t}-R_{f L, t}=\alpha+\beta\left(R_{m L, t}-R_{f L, t}\right)+\varepsilon_{i, t}$,

Onde:

$\mathrm{R}_{i, t}=$ retorno do portfólio e retorno dos ativos individuais em cada mês;

$R_{f L, t}=$ retorno do ativo livre de risco local em cada mês;

$\alpha=$ intercepto da regressão

$\beta=$ coeficiente angular da reta de regressão;

$R_{m L, t}=$ retorno da carteira de mercado local em cada mês;

$\varepsilon_{i, t}=$ resíduos da regressão

\subsubsection{O modelo CAPM Global (O’BRIEN et al, 1999)}

O modelo CAPM Global foi testado conforme modelo descrito na equação 16, Como proxy da carteira de mercado global foi utilizado o índice S\&P500, e como ativo livre de risco 
global foram usados os títulos americanos de 10 anos, os T-Bonds 10 years (taxa real). Foram estimadas as regressões do excesso do retorno das carteiras e do excesso dos retornos dos ativos individuais em relação ao ativo livre de risco global e o excesso de retorno do mercado global em relação ao ativo livre de risco global, como segue descrito a seguir:

$$
\mathrm{R}_{i, t}-R_{f G, t}=\alpha+\beta\left(R_{m G, t}-R_{f G, t}\right)+\varepsilon_{i, t},
$$

Onde:

$\mathrm{R}_{i, t}=$ retorno do portfólio e retorno dos ativos individuais em cada mês;

$R_{f G, t}=$ retorno do ativo livre de risco global em cada mês;

$\alpha=$ intercepto da regressão

$\beta=$ coeficiente angular da reta de regressão;

$R_{m G, t}=$ Retorno de mercado global em cada mês.

$\varepsilon_{i, t}=$ resíduos da regressão

\subsubsection{O modelo CAPM Local (PEREIRO, 2001)}

O modelo CAPM Local adotou as mesmas proxies dos modelos anteriores. Como proxy da carteira de mercado local foi utilizado o índice IBOVESPA, como ativo livre de risco do mercado brasileiro foi usado o CDI deflacionado, e como ativo livre de risco global foram usados os títulos americanos de 10 anos, T-Bonds 10 years. Como medida de risco-país foi utilizado o EMBI+, que é calculado com base na média ponderada do spread de títulos americanos e brasileiros de diversos prazos. Foram realizadas as regressões do excesso do retorno das carteiras e do excesso dos retornos dos ativos individuais em relação ao ativo livre de risco global e o excesso de retorno do mercado local em relação ao ativo livre de risco local e a medida de risco-país (EMBI+) como segue descrito a seguir:

$$
\mathrm{R}_{i, t}-R_{f G, t}=\alpha+\beta\left(R_{m L, t}-R_{f L, t}\right)+\gamma R_{c, t}+\varepsilon_{i, t},:
$$

Onde:

$\mathrm{R}_{i, t}=$ retorno do portfólio e retorno dos ativos individuais em cada mês;

$R_{f G, t}=$ retorno do ativo livre de risco global em cada mês;

$\alpha=$ intercepto da regressão;

$\beta=$ coeficiente angular da reta de regressão; 
$R_{m L, t}=$ retorno da carteira de mercado local em cada mês;

$R_{f L, t}=$ retorno do ativo livre de risco local em cada mês;

$\gamma=$ coeficiente angular da reta de regressão;

$R_{c, t}=$ Prêmio de risco-país em cada mês;

$\varepsilon_{i, t}=$ resíduos da regressão

\subsubsection{Modelo de 3 Fatores}

Para o cálculo dos fatores adicionais do Modelo de Três Fatores de Fama e French foram usados dados para o período compreendido entre junho de 2009 e dezembro de 2014. Assim como o estudo de Fama e French (1993) foram excluídas no cálculo dos fatores adicionais as empresas do setor financeiro, em função das peculiaridades do setor no que diz respeito a sua estrutura de capital, podendo causar viés no índice Book-to-Market, tendo em vista apresentarem diferente nível de alavancagem. Para o cálculo do índice Book-to-Market é utilizado o valor patrimonial referente ao semestre anterior dividido pelo valor de mercado

A metodologia para a elaboração das carteiras e cálculo dos fatores seguiu a metodologia original utilizada por Fama e French (1993). As carteiras foram rebalanceadas anualmente, dividindo-se as empresas de acordo com o seu valor de mercado, sendo chamadas de Big as que apresentaram valor superior a mediana e Small as empresas que apresentaram valor de mercado inferior a mediana.

Em seguida as empresas foram ordenadas em função do índice Book-to-Market apresentado, sendo separadas da seguinte forma:

-Low: $30 \%$ das ações de empresas com índices mais baixos;

-Medium: 40\% das ações de empresas com valores intermediários;

-High: $30 \%$ das ações de empresas com índices mais altos.

Assim divide-se a amostra em seis diferentes carteiras de investimento para o cálculo dos fatores adicionais: Big/Low, Big/Medium, Big/High, Small/Low, Small /Medium e Small/High. O retorno das carteiras foi ponderado em função do valor de mercado de cada empresa em relação ao valor de mercado total da carteira.

Após a divisão da amostra e as devidas ponderações, calculou-se o fator Small-Big (SMB), usando a média do retorno das carteiras das empresas classificadas como Small menos a média do retorno das carteiras das empresas classificadas com Big. Calculou-se também dessa forma o fator High-Low (HML), usando a média do retorno das carteiras das empresas High menos a média do retorno das carteiras Low. 
A composição do índice Ibovespa foi utilizada como carteira de mercado e para a taxa livre de risco utilizou-se o CDI deflacionado.

$\mathrm{R}_{i, t}-R_{f L, t}=\alpha+\beta\left(R_{m L, t}-R_{f L, t}\right)+s\left(\mathrm{SMB}_{t}\right)+h\left(\mathrm{HML}_{t}\right)+\varepsilon_{i, t}$,

Onde:

$\mathrm{R}_{i, t}=$ retorno do portfólio e retorno dos ativos individuais em cada mês;

$R_{f L, t}=$ retorno do ativo livre de risco local em cada mês;

$\alpha=$ intercepto da regressão

$\beta=$ coeficiente angular da reta de regressão;

$R_{m L, t}=$ retorno da carteira de mercado local em cada mês;

$s=$ coeficiente angular da reta de regressão;

$\mathrm{SMB}_{t}=$ prêmio pelo fator tamanho, no mês $t$;

$h=$ coeficiente angular da reta de regressão;

$\mathrm{HML}_{t}=$ prêmio pelo fator índice book-to-market, no mês $t$;

$\varepsilon_{i, t}=$ resíduos da regressão

\subsubsection{APT}

A estimação do modelo APT foi realizada com a utilização de fatores macroeconômicos pré-determinados. Em função da utilização de ativos individuais e também de carteiras foram buscados fatores macroeconômicos que seriam relevantes ao modelo como: PIB, taxa de câmbio, inflação, produção industrial, entre outros. Conforme a tabela a seguir:

Tabela 1 - Fatores macroeconômicos

\begin{tabular}{lll}
\hline \multicolumn{1}{c}{ Variável } & \multicolumn{1}{c}{ Fonte } & \multicolumn{1}{c}{ Nome } \\
\hline Índice de Atividade Econômica & BACEN & IBC \\
\hline Índice de Atividade Econômica dessazonalizado & BACEN & IBCd \\
\hline Produção industrial & IBGE & PI \\
\hline Produção industrial -dessazonalizado & IBGE & Pid \\
\hline Taxa de câmbio efetiva real IPEA & IPEA & TCE \\
\hline Dólar comercial - rendimento real & BACEN & DOLAR \\
\hline Ouro - rendimento real & BACEN & OURO \\
\hline Taxa de câmbio & BACEN & TC \\
\hline Importações & IPEA & I \\
\hline Exportações & IPEA & E \\
\hline PIB & BACEN & PIB \\
\hline Commodities - petróleo & IPEA & PET
\end{tabular}




\begin{tabular}{lll}
\hline Inflação - IPCA & BACEN & IPCA \\
\hline Risco-país-EMBI+ & BACEN & RC \\
\hline Retorno de mercado dos EUA-S\&P500 & ECONOMÁTICA & SP500 \\
\hline Divida Pública total & IPEA & DP \\
\hline Fonte: Elaborado pela autora & &
\end{tabular}

Fonte: Elaborado pela autora

As variáveis apresentadas na tabela foram testadas na composição do modelo APT, e através do critério informacional de Akaike, foi identificado o melhor modelo possível que segue descrito a seguir:

$$
\begin{aligned}
& \mathrm{R}_{i, t}-R_{f L, t}=\alpha+\beta_{1}\left(R_{m L, t}-R_{f L, t}\right)+\beta_{2}\left(\mathrm{PIB}_{t}\right)+\beta_{3}\left(\mathrm{PET}_{t}\right)+\beta_{4}\left(\mathrm{IPCA}_{t}\right)+\beta_{5}\left(\mathrm{E}_{t}\right)+ \\
& \varepsilon_{i, t},
\end{aligned}
$$

Onde:

$\mathrm{R}_{i, t}=$ retorno do portfólio e retorno dos ativos individuais em cada mês;

$R_{f L, t}=$ retorno do ativo livre de risco local em cada mês;

$\alpha=$ intercepto da regressão

$\beta=$ coeficiente angular da reta de regressão;

$R_{m L, t}=$ retorno da carteira de mercado local em cada mês;

$\mathrm{PIB}_{t}=$ variação percentual do PIB, no mês $t$;

$\mathrm{PET}_{t}=$ variação percentual do preço do Petróleo, no mês $t$;

IPCA $_{t}=$ variação do IPCA, no mês $t$;

$\mathrm{E}_{t}=$ variação percentual das exportações, no mês $t$;

$\varepsilon_{i, t}=$ resíduos da regressão

\subsection{Testes de robustez realizados}

Os dados em painel apresentam a dimensão tanto de séries temporais quanto de dados em cross-section (BROOKS, 2008). Na utilização de dados em painel, é necessário escolher o modelo mais adequado: pooled, modelo de efeito fixos ou de efeito aleatórios. Dessa forma, foram realizados os testes de redundância dos efeitos para a escolha entre pooled (dados agrupados) e efeitos fixos e o teste de Hausman para escolha entre o de efeitos fixos e o de efeitos aleatórios.

Para verificar se os resíduos são independentes entre si, ou seja, a inexistência de autocorrelação dos resíduos foi realizado o teste de Durbin-Watson. 
Apesar de todas as variáveis já se apresentarem em primeira diferença foram realizados os testes de raiz unitária para verificar se as séries são realmente estacionárias e não incorrer o risco de obtenção de regressões espúrias.

Também foram realizados o teste de Breusch-Pagan para detecção de heteroscedasticidade e Bera-Jarque para verificar a normalidade dos resíduos das regressões. Nos modelos com mais de um fator foram realizados os testes do Fator de Inflação da Variância (FIV) para identificar a existência de multicolinearidade. 


\section{ANÁLISE DOS RESULTADOS}

$\mathrm{Na}$ situação em que se busca analisar dados que compreendem séries temporais e elementos em corte transversal, trata-se de um conjunto de dados conhecido como um painel de dados. Os painéis de dados do estudo são composto por ativos individuais (132 ações de empresas) e também por portfólios (60 conjuntos aleatórios de 22 ativos dessas mesmas empresas) sendo estudados durante o período compreendido entre 2010 e 2014, totalizando 60 meses.

Observa-se que usualmente existem 3 formas de realizar as regressões com dados em painel. A maneira mais simples de tratar dados seria como regressão agrupada (pooled), que envolve a estimar uma equação simples com todas as observações temporais sendo empilhadas em uma única coluna de dados, o que pressupõe que o valores médios das variáveis e as relações entre eles são constantes ao longo do tempo e através de todas as unidades transversais na amostra. O modelo de efeitos fixos admite que as relações possam afetar de forma diferente os indivíduos e/ou ao longo do tempo variações essas que observadas nos interceptos da regressão. Uma alternativa para o modelo de efeitos fixos descrito acima é modelo de efeitos aleatório. Assim como acontece com efeitos fixos, o modelo de efeitos aleatórios propõe diferentes interceptos para cada unidade de corte transversal mas que são obtidos a partir de um intercepto comum mais um componente aleatório (BROOKS, 2008).

Com o objetivo de identificar o melhor modelo, foram realizados os testes de redundância dos efeitos fixos, que verifica se os efeitos fixos são necessários. São apresentados a seguir os resultado do teste de Redundância dos efeitos fixos:

Tabela 2-Teste de redundância dos efeitos fixos

\begin{tabular}{|c|c|c|c|c|c|c|c|}
\hline & & \multicolumn{2}{|c|}{ Cross-section F } & \multicolumn{3}{|c|}{ Cross-section Chi-square } & \\
\hline & & Estatística & Prob. & Estatística & d.f. & Prob. & \\
\hline \multirow{5}{*}{ Ativos Individuais } & CAPM & 2.449251 & 0.0000 & 319.788 & 131 & 0.0000 & Efeitos fixos \\
\hline & CAPM Global & 2.299687 & 0.0000 & 300.626 & 131 & 0.0000 & Efeitos fixos \\
\hline & CAPM Local & 2.453413 & 0.0000 & 320.361 & 131 & 0.0000 & Efeitos fixos \\
\hline & 3 Fatores & 2.506873 & 0.0000 & 327.241 & 131 & 0.0000 & Efeitos fixos \\
\hline & $\mathrm{APT}$ & 2.471468 & 0.0000 & 322.834 & 131 & 0.0000 & Efeitos fixos \\
\hline \multirow{5}{*}{ Carteiras } & CAPM & 1.004315 & 0.4669 & 59.7769 & 59 & 0.4473 & Agrupado \\
\hline & CAPM Global & 0.555355 & 0.9977 & 33.1774 & 59 & 0.9974 & Agrupado \\
\hline & CAPM Local & 1.032339 & 0.4083 & 61.4479 & 59 & 0.3884 & Agrupado \\
\hline & 3 Fatores & 1.353663 & 0.0381 & 80.3845 & 59 & 0.0336 & Efeitos fixos \\
\hline & APT & 1.137559 & 0.2212 & 67.7283 & 59 & 0.2039 & Agrupado \\
\hline
\end{tabular}


Em todas as regressões utilizando ativos individuais, verificou-se que o modelo de efeitos fixos é preferível. Entretanto observou-se que com as carteiras o modelo agrupado foi preferível na maioria dos casos, com exceção do Modelo de 3 Fatores.

De acordo com Brooks (2008) o modelo de efeitos aleatórios só é válido diante da verificação do pressuposto de que o termo de erro não está correlacionado com as variáveis explicativas, pois neste caso a estimativa dos parâmetros será viesada e inconsistente. . O teste de Hausman tem como objetivo verificar se esse pressuposto é válido, caso contrário o modelo de efeitos fixos é preferível. Ao realizar o teste de Hausman constatou-se que o modelo de efeitos aleatórios não seria adequado em nenhum dos casos.

De acordo com Greene (2012), o caso onde os regressores são idênticos é bastante comum principalmente na precificação de ativos. O modelo SUR (Seemingly Unrelated Regressions With Identical Regressors) é recomendado quando os regressores são os mesmos, entretanto os estimadores são não-viesados e eficientes. A principal vantagem da especificação SUR é seu tratamento da correlação entre as observações em um determinado ponto no tempo que ocorre frequentemente quando são utilizados dados em painel. O modelo SUR pode suportar heteroscedasticidade e autocorrelação. Dessa forma, todos os modelos foram estimados utilizando o método SUR.

\subsection{Apresentação dos Resultados dos Modelos}

De acordo com Gujarati (2006), o teste F é utilizado na regressão em substituição do teste t para verificar a hipótese conjunta de que os verdadeiros coeficientes parciais angulares são simultaneamente iguais a zero. A hipótese nula do teste é que os coeficientes $\left(\beta_{1}, \beta_{2}, \beta_{3}\right.$, etc.) conjuntamente são iguais a zero. Se a hipótese nula for verdadeira, significa que a relação entre a variável dependente e as independentes deve-se a efeitos aleatórios representados pelo termo de erro. Caso haja a rejeição da hipótese nula, as variáveis independentes exercem de fato influência sobre a dependente. 


\subsubsection{CAPM}

Tabela 3- Resumo dos resultados estatísticos do modelo CAPM

\begin{tabular}{ccccccccc}
\hline & Coeficiente & $\begin{array}{c}\text { Erro } \\
\text { padrão }\end{array}$ & $\begin{array}{c}\text { Estatística } \\
\mathrm{t}\end{array}$ & Prob. & $\begin{array}{c}\mathrm{n}^{\mathrm{o}} \mathrm{de} \\
\text { observações }\end{array}$ & $\mathrm{R}^{2}$ & $\begin{array}{c}\text { Prob. } \\
\text { Teste } \mathrm{F}\end{array}$ \\
\hline $\begin{array}{c}\text { Ativos } \\
\text { Individuais }\end{array}$ & $\boldsymbol{\alpha}$ & -0.005862 & 0.0031 & -1.856 & 0.0634 & \multirow{2}{*}{7920} & 0.1272 & 0.0000 \\
\cline { 2 - 6 } Carteiras & $\boldsymbol{\beta}\left(R_{m L}-R_{f L}\right)$ & 0.643287 & 0.0576 & 11.167 & 0.0000 & & & \\
\cline { 2 - 7 } & $\boldsymbol{\beta}\left(R_{m L}-R_{f L}\right)$ & -0.004500 & 0.0031 & -1.478 & 0.1394 & \multirow{2}{*}{3600} & 0.5611 & 0.0000 \\
\hline
\end{tabular}

Fonte: Elaborado pela autora

$\mathrm{O}$ resultado do teste $\mathrm{F}$ (Tabela 3 ) apresenta um p-valor do teste $\mathrm{F}$ significante ao nível $1 \%$ tanto para carteiras quanto para ativos individuais. Observa-se, ainda, que os interceptos não são significativamente diferentes de zero ao nível de confiança de $5 \%$, sugerindo ser um modelo consistente para explicar os retornos, visto que a suposta eficiência do mercado requer que os interceptos não sejam significativos. Analisando a regressão constata-se que o coeficiente do intercepto é não significativo, pois o p-valor $(0,063)$ para ativos individuais e $(0,139)$ para as carteiras, sendo maiores que o nível de significância requerido $(0,05)$, sendo obtidos resultados alinhados com a hipótese do mercado eficiente.

Quanto ao coeficiente do prêmio de mercado, verifica-se que este é significativo ao nível de 5\%, pois o p-valor (0,0000) para ativos individuais e carteiras são ambos significantes a $1 \%$. Estes resultados demonstram um alinhamento com a teoria do CAPM. São corroborados os resultados de Araújo et al (2004), Alves (2007), Castro et al (2009) e Brandão (2013). Araújo e Silva (2012), que analisaram os estudos sobre o CAPM no mercado brasileiro, constataram que mais da metade (58\%) dos estudos que fazem parte da amostra confirmam a efetividade do modelo CAPM na precificação de ativos.

\subsubsection{CAPM Global}

Tabela 4 - Resumo dos resultados estatísticos do modelo CAPM Global

\begin{tabular}{ccccccccc}
\hline & & Coeficiente & $\begin{array}{c}\text { Erro } \\
\text { padrão }\end{array}$ & $\begin{array}{c}\text { Estatística } \\
\mathrm{t}\end{array}$ & Prob. & $\begin{array}{c}\mathrm{n}^{\mathbf{o}} \text { de } \\
\text { observações }\end{array}$ & $\mathrm{R}^{2}$ & $\begin{array}{c}\text { Prob. } \\
\text { Teste } \mathrm{F}\end{array}$ \\
\hline $\begin{array}{c}\text { Ativos } \\
\text { Individuais }\end{array}$ & $\boldsymbol{\alpha}$ & -0.015596 & 0.0047 & -3.288 & 0.0010 & 7920 & 0.0706 & 0.0000 \\
\cline { 2 - 7 } Carteiras & $\boldsymbol{\beta}\left(R_{m G}-R_{f G}\right)$ & 0.560229 & 0.1239 & 4.521 & 0.0000 & & & \\
\cline { 2 - 7 } & $\boldsymbol{\beta}\left(R_{m G}-R_{f G}\right)$ & -0.014107 & 0.0046 & -3.055 & 0.0023 & \multirow{2}{*}{3600} & 0.2127 & 0.0000 \\
\hline
\end{tabular}

Fonte: Elaborado pela autora 
Observa-se nos resultados do modelo CAPM Global, que utilizando carteiras e também ativos individuais, foram obtidos interceptos significativamente diferentes de zero ao nível de confiança de $1 \%$, sugerindo inadequação do modelo na explicação dos retornos no mercado acionário brasileiro. Assim, sugere-se que outros fatores, não absorvidos pelo prêmio de mercado com dados globais, podem estar influenciando a variação dos retornos. Estes resultados estão alinhados com Mongrut (2006) e Sanvicente (2015) que criticam a utilização de dados provenientes de mercados internacionais alegando que o mercado local pode estar suficientemente desenvolvido para incorporar informações relevantes sobre os riscos.

\subsubsection{CAPM Local}

Tabela 5- Resumo dos resultados estatísticos do modelo CAPM Local

\begin{tabular}{|c|c|c|c|c|c|c|c|c|}
\hline & & Coeficiente & $\begin{array}{c}\text { Erro } \\
\text { padrão }\end{array}$ & $\begin{array}{c}\text { Estatística } \\
\mathrm{t}\end{array}$ & Prob. & $\begin{array}{c}\mathrm{n}^{\mathbf{o}} \text { de } \\
\text { observações }\end{array}$ & $\mathrm{R}^{2}$ & $\begin{array}{c}\text { Prob. } \\
\text { Teste F }\end{array}$ \\
\hline \multirow{3}{*}{$\begin{array}{c}\text { Ativos } \\
\text { Individuais }\end{array}$} & $\alpha$ & 0.023407 & 0.020259 & 1.155 & 0.2480 & \multirow{3}{*}{7920} & \multirow{3}{*}{0.1289} & \multirow{3}{*}{0.0000} \\
\hline & $\boldsymbol{\beta}\left(R_{m L}-R_{f L}\right)$ & 0.629024 & 0.057783 & 10.886 & 0.0000 & & & \\
\hline & $\gamma R_{c}$ & -15.911 & 11.860 & -1.341 & 0.1798 & & & \\
\hline \multirow{3}{*}{ Carteiras } & $\alpha$ & 0.027008 & 0.019436 & 1.389 & 0.1647 & \multirow{3}{*}{3600} & \multirow{3}{*}{0.5732} & \multirow{3}{*}{0.0000} \\
\hline & $\boldsymbol{\beta}\left(R_{m L}-R_{f L}\right)$ & 0.62104 & 0.055433 & 11.203 & 0.0000 & & & \\
\hline & $\gamma R_{c}$ & -17.237 & 11.378 & -1.514 & 0.1299 & & & \\
\hline
\end{tabular}

Fonte: Elaborado pela autora

Nos resultados apresentados na Tabela 5 observa-se que os interceptos não são significativamente diferentes de zero em um nível de confiança de 5\%, assim como o coeficiente da variável Risco-país $\left(R_{c}\right)$ inserida não se mostrou significativa, os coeficiente apresentam p-valor de $(0,1798)$ para ativos individuais e $(0,1299)$ para as carteiras, sendo maiores que o nível de significância requerido $(0,05)$. Os resultados obtidos estão alinhados com os resultados de Mongrut (2006) e Sanvicente (2015) que não recomendam a inclusão do risco-país no modelo de precificação de ativos.

Os coeficientes relativos ao prêmio de mercado com dados locais se apresentam significativos, pois o p-valor $(0,0000)$ para ativos individuais e carteiras, ambos significantes a $1 \%$. 
Tabela 6 - Resumo dos resultados estatísticos do modelo de 3 Fatores

\begin{tabular}{|c|c|c|c|c|c|c|c|c|}
\hline & & Coeficiente & $\begin{array}{c}\text { Erro } \\
\text { padrão }\end{array}$ & $\begin{array}{c}\text { Estatística } \\
\mathrm{t}\end{array}$ & Prob. & $\begin{array}{c}\mathrm{n}^{\mathrm{o}} \mathrm{de} \\
\text { observações }\end{array}$ & $\mathrm{R}^{2}$ & $\begin{array}{c}\text { Prob. } \\
\text { Teste F }\end{array}$ \\
\hline \multirow{4}{*}{$\begin{array}{c}\text { Ativos } \\
\text { Individuais }\end{array}$} & $\alpha$ & -0.002953 & 0.0024 & -1.188 & 0.2345 & \multirow{4}{*}{7920} & \multirow{4}{*}{0.1474} & \multirow{4}{*}{0.0000} \\
\hline & $\boldsymbol{\beta}\left(R_{m L}-R_{f L}\right)$ & 0.709086 & 0.0446 & 15.885 & 0.0000 & & & \\
\hline & $s(\mathrm{SMB})$ & 0.554128 & 0.0768 & 7.211 & 0.0000 & & & \\
\hline & $h$ (HML) & -0.016452 & 0.0673 & -0.244 & 0.8069 & & & \\
\hline \multirow{4}{*}{ Carteiras } & $\alpha$ & -0.002148 & 0.0024 & -0.862 & 0.3887 & \multirow{4}{*}{3600} & \multirow{4}{*}{0.6799} & \multirow{4}{*}{0.0000} \\
\hline & $\boldsymbol{\beta}\left(R_{m L}-R_{f L}\right)$ & 0.703369 & 0.0447 & 15.710 & 0.0000 & & & \\
\hline & $s(\mathrm{SMB})$ & 0.515008 & 0.0770 & 6.683 & 0.0000 & & & \\
\hline & $\boldsymbol{h}$ (HML) & -0.044205 & 0.0675 & -0.654 & 0.5126 & & & \\
\hline
\end{tabular}

Fonte: Elaborado pela autora

A Tabela 6 apresenta os resultados das regressões para o modelo de três fatores de Fama e French (1993), bem como os coeficientes estimados e os respectivos p-valor. A regressão estimada mostrou-se significativa em termos estatísticos ao nível de significância de $1 \%$, tendo em vista que o p-valor obtido para a estatística $F$ é inferior a 0,01 , para carteiras e também ativos individuais. $\mathrm{O}$ fator prêmio de mercado também mostrou-se significativo nos dois casos e positivamente relacionado com o retorno, como esperado.

Observa-se que a inclusão dos fatores tamanho e Book-to-Market no CAPM melhorou o poder explicativo do modelo nas duas regressões. Corroborando os resultados de Málaga e Securato (2004), Dos Santos, Fama e Mussa (2007), Rogers e Securato (2008) e Veras e Reis (2014)

O fator tamanho mostrou-se significativo estatisticamente nas duas regressões. Os valores dos coeficientes $s$ apresentaram valores semelhantes para ativos individuais e para carteiras, o prêmio pelo fator tamanho foi positivo nos dois casos.

Quanto ao fator Book-to-Market, ele não se mostrou significativo em nenhum dos casos. Foi também testado o modelo sem este fator, mas em função do aumento no critério informacional de Akaike a variável foi mantida no modelo. Rogers e Securato (2008) e Noda et al (2015) também obtiveram esses resultados e apresentaram como justificativa as particularidades do mercado acionário brasileiro no que diz respeito à taxa de inflação. $\mathrm{O}$ fato de o poder explicativo do fator de risco relacionado ao índice Book-to-Market do modelo de 3 fatores ser menor, pode ser uma consequência da inflação historicamente elevada, uma vez que os valores contábeis podem ser influenciados pela idade dos ativos. Dessa forma os índices Book-to-Market tornam-se menos significativos. Esses resultados podem decorrer do impacto da inflação que reduz o conteúdo informativo do valor do patrimônio líquido. 


\subsubsection{APT}

Tabela 7 - Resumo dos resultados estatísticos do modelo APT

\begin{tabular}{|c|c|c|c|c|c|c|c|c|}
\hline & & Coeficiente & $\begin{array}{l}\text { Erro } \\
\text { padrão }\end{array}$ & $\begin{array}{c}\text { Estatística } \\
\mathrm{t}\end{array}$ & Prob. & $\begin{array}{c}\mathrm{n}^{\mathrm{o}} \text { de } \\
\text { observações }\end{array}$ & $\mathrm{R}^{2}$ & $\begin{array}{l}\text { Prob. } \\
\text { Teste F }\end{array}$ \\
\hline \multirow{6}{*}{$\begin{array}{c}\text { Ativos } \\
\text { Individuais }\end{array}$} & $\alpha$ & 0.000651 & 0.007 & 0.098 & 0.9219 & \multirow{6}{*}{7920} & \multirow{6}{*}{0.1364} & \multirow{6}{*}{0.0000} \\
\hline & $\beta_{1}\left(R_{m L}-R_{f L}\right)$ & 0.618901 & 0.054 & 11.539 & 0.0000 & & & \\
\hline & $\beta_{2}(\mathrm{PIB})$ & -0.168439 & 0.080 & -2.101 & 0.0356 & & & \\
\hline & $\beta_{3}(\mathrm{PET})$ & 0.093737 & 0.051 & 1.855 & 0.0636 & & & \\
\hline & $\beta_{4}$ (IPCA) & -1.163 .389 & 1.192 & -0.975 & 0.3294 & & & \\
\hline & $\beta_{5}(\mathrm{E})$ & 0.351608 & 0.159 & 2.206 & 0.0274 & & & \\
\hline \multirow{6}{*}{ Carteiras } & $\alpha$ & 0.001001 & 0.006 & 0.158 & 0.8743 & \multirow{6}{*}{3600} & \multirow{6}{*}{0.6209} & \multirow{6}{*}{0.0000} \\
\hline & $\beta_{1}\left(R_{m L}-R_{f L}\right)$ & 0.612114 & 0.051 & 11.985 & 0.0000 & & & \\
\hline & $\beta_{2}(\mathrm{PIB})$ & -0.151552 & 0.076 & -1.985 & 0.0471 & & & \\
\hline & $\beta_{3}(\mathrm{PET})$ & 0.094408 & 0.048 & 1.962 & 0.0498 & & & \\
\hline & $\beta_{4}$ (IPCA) & -0.991571 & 1.135 & -0.873 & 0.3827 & & & \\
\hline & $\beta_{5}(\mathrm{E})$ & 0.383156 & 0.152 & 2.524 & 0.0116 & & & \\
\hline
\end{tabular}

Fonte: Elaborado pela autora

A Tabela 7 apresenta os resultados das regressões para o modelo APT, bem como os coeficientes estimados e as respectivas probabilidades, indicando que as variáveis (PIB) e (E) são significativas a um nível de significância de 5\%. A variável (PET) é significativa a um nível de 5\% para carteiras. A variável (IPCA) não se mostrou significativa em nenhum dos casos. Adicionalmente, o fator mercado mostrou-se significativo nos dois casos e positivamente relacionado em acordo com o esperado.

Corroborando os resultados de Brandão (2013) e Milani e Ceretta (2014), significa que em acordo ao que diz a teoria referente ao modelo APT, a adição de fatores macroeconômicos foi capaz de melhorar o poder explicativo do CAPM. Entretanto percebe-se que o modelo ainda deixa de explicar uma parte das variações dos retornos, apesar da melhora em relação ao CAPM. Assim, sugere-se que outros fatores macroeconômicos ou específicos podem estar influenciando a variação dos retornos.

\subsection{Testes De Robustez}

\subsubsection{Teste de raízes unitárias}

O teste de raízes unitárias deve ser realizado para que seja possível verificar se a série é estacionária ou não. A estacionariedade é uma propriedade relevante e desejável, que 
se refere ao comportamento de uma variável em torno da sua média. Uma série que contém raiz unitária é não estacionária e, portanto, não pode ser utilizada para estimar uma regressão, pois a regressão seria espúria. Uma variável cuja série é estacionária permite que ela seja utilizada para generalização de seu comportamento para outros períodos de tempo, portanto, possível que seja utilizada em regressões e modelos de previsão (WOOLDRIDGE, 2002; GUJARATI, 2006).

A não rejeição da hipótese nula dos testes de raízes unitárias significa que a série da variável é não-estacionária, ou seja significa que a série possui comportamento crescente ou decrescente, terá uma média, variância ou ambas variando ao longo do tempo. Isso geralmente ocorre quando são utilizadas séries de preços. Entretanto, nesse estudo são utilizadas apenas séries de retornos, ou seja, as variáveis já em primeira diferença. É esperado que séries de retornos apresentem estacionariedade (BROOKS, 2008).

A literatura recente sugere uma grande eficiência dos testes de raiz unitária feitos em painel, eles são simplesmente testes de raiz unitária de várias séries que foram aplicadas às estruturas do painel de dados. Com o objetivo de verificar se as séries possuíam mais de uma raiz unitária foram utilizados três testes disponíveis no EViews, sendo eles: Levin, Lin, e Chu (LLC), Dickey-Fuller Aumentado (ADF) e Phillips-Perron (PP). Foi utilizada a configuração padrão definida automaticamente pelo EViews . Os testes de raiz unitária em painel são similares, mas não idênticos, aos testes de raízes unitárias realizadas em uma única série. $\mathrm{O}$ teste de Levin, Lin, e Chu é realizado partindo da suposição de que há um processo de raiz unitária comum, de modo que é idêntico a todas as séries, já os testes ADF e PP testam processos individuais de raiz unitária de modo que podem variar entre as séries. Todos os testes são caracterizados pela combinação de testes de raiz unitária individuais para derivar um resultado comum (WOOLDRIDGE,2002, BROOKS,2008). Tendo seus resultados apresentados na Tabela 8: 
Tabela 8 - Testes de Raiz Unitária

\begin{tabular}{|c|c|c|c|c|c|c|c|}
\hline & & \multicolumn{2}{|c|}{ Levin, Lin \& Chu } & \multicolumn{2}{|l|}{$\mathrm{ADF}$} & \multicolumn{2}{|c|}{ PP-Fisher } \\
\hline & & Estatística & Prob. & Estatística & Prob. & Estatística & Prob. \\
\hline \multirow{5}{*}{ Ativos Individuais } & CAPM & -78.9181 & $0^{*}$ & 4644.37 & $0 *$ & 4791.58 & $0^{*}$ \\
\hline & CAPM Global & -79.5546 & $0 *$ & 4662.17 & $0 *$ & 4796.79 & $0 *$ \\
\hline & CAPM Local & -78.667 & $0 *$ & 4659.12 & $0 *$ & 4793.77 & $0 *$ \\
\hline & 3 Fatores & -79.3615 & $0^{*}$ & 4696.28 & $0 *$ & 4843.16 & $0 *$ \\
\hline & $\mathrm{APT}$ & -77.1898 & $0 *$ & 4716.74 & $0 *$ & 4887.28 & $0 *$ \\
\hline \multirow{5}{*}{ Carteiras } & CAPM & -38.9561 & $0^{*}$ & 1742.63 & $0 *$ & 1796.46 & $0 *$ \\
\hline & CAPM Global & -39.8395 & $0 *$ & 1751.85 & $0 *$ & 1795.97 & $0 *$ \\
\hline & CAPM Local & -38.9034 & $0^{*}$ & 1748.79 & $0 *$ & 1792.95 & $0 *$ \\
\hline & 3 Fatores & -39.9132 & $0^{*}$ & 1794.54 & $0 *$ & 1848.03 & $0 *$ \\
\hline & APT & -37.4494 & $0^{*}$ & 1814.99 & $0 *$ & 1892.15 & $0 *$ \\
\hline
\end{tabular}

Fonte: Elaborado pela autora

De acordo com o esperado observa-se a rejeição da hipótese nula de existência de raiz unitária ao nível de significância de $1 \%$ em todos os modelos. Os testes realizados sugerem que a primeira diferença realizada eliminou a existência de possíveis raízes unitárias das séries. Desta forma é possível trabalhar com as séries de retornos das ações, do Ibovespa e demais séries. A decisão de rejeição significa que as séries são estacionárias, não incorrendo o risco de realização de regressões espúrias.

\subsubsection{Teste de autocorrelação dos resíduos}

Sob a presença de autocorrelação dos resíduos de uma regressão podem ser obtidos estimadores que são lineares e não-viesados, porém não são de variância mínima e ainda podem ser observados que os erros padrão e que as estatísticas dos testes não são válidos podendo levar a inferências errôneas, ao ignorar a existência de autocorrelação é ignorada a possibilidade de que os estimadores não sejam eficientes (WOOLDRIDGE, 2002; GUJARATI, 2006).

Dessa forma através do através do teste de Durbin-Watson buscou-se identificar a presença de correlação serial. De acordo com Brooks (2008), Durbin - Watson (DW) é um teste para a primeira ordem de autocorrelação, ou seja, ele testa a relação entre um erro e o seu valor imediatamente anterior. O teste tem dois valores críticos um valor crítico inferior $\left(\mathrm{d}_{\mathrm{L}}\right)$ e outro crítico valor superior $\left(\mathrm{d}_{\mathrm{U}}\right)$ obtidos de acordo com o número de variáveis independentes da regressão chamado de k' e o números de observações. O valor da estatística Durbin-Watson varia de 0 a 4 , sendo 2 o ideal para que não existam evidências de 
autocorrelação dos resíduos e os resultados do teste devem ser interpretados de acordo com o quadro a seguir:

Quadro 6 - Teste de Durbin-Watson

\begin{tabular}{|l|l|l|l|l|l|}
\hline 0 & Inconclusivo & Não rejeitar Ho: & Inconclusivo & Rejeitar Ho: \\
\hline $\begin{array}{l}\text { Rejeitar Ho } \\
\text { Evidências de } \\
\begin{array}{l}\text { Autocorrelação } \\
\text { Positiva }\end{array}\end{array}$ & $\begin{array}{l}\text { Sem evidências de } \\
\text { autocorrelação }\end{array}$ & & $\begin{array}{l}\text { Evidências } \\
\text { Autocorrelação } \\
\text { Negativa }\end{array}$ \\
\hline
\end{tabular}

Fonte: Adaptado de Gujarati (2006)

Considerando que os modelos CAPM e CAPM Global têm apenas uma variável independente, considera-se $\mathrm{k}^{\prime}$ igual a 1 , nos demais modelos foram identificados os $\mathrm{k}^{\prime} \mathrm{em}$ função do número de variáveis de cada modelo e fazendo uso da tabela Durbin-Watson a 5\% foram encontrados os valores de $\mathrm{d}_{\mathrm{L}}$ e $\mathrm{d}_{\mathrm{U}}$ para cada um dos modelos e foram feitas as análises como demonstrado na tabela a seguir:

Tabela 9 - Teste de Durbin-Watson

\begin{tabular}{|c|c|c|c|c|c|c|c|c|}
\hline & & Estatística & k' & $\mathrm{dl}$ & du & 4-du & 4-dl & Conclusão \\
\hline \multirow{5}{*}{$\begin{array}{c}\text { Ativos } \\
\text { Individuais }\end{array}$} & CAPM & 2.03 & 1 & 1.66 & 1.68 & 2.32 & 2.34 & $\begin{array}{l}\text { Não há evidências de } \\
\text { aucorrelação }\end{array}$ \\
\hline & $\begin{array}{l}\text { CAPM } \\
\text { Global }\end{array}$ & 1.98 & 1 & 1.66 & 1.68 & 2.32 & 2.34 & $\begin{array}{l}\text { Não há evidências de } \\
\text { aucorrelação }\end{array}$ \\
\hline & $\begin{array}{l}\text { CAPM } \\
\text { Local }\end{array}$ & 2.04 & 2 & 1.65 & 1.69 & 2.31 & 2.35 & $\begin{array}{l}\text { Não há evidências de } \\
\text { aucorrelação }\end{array}$ \\
\hline & 3 Fatores & 2.06 & 3 & 1.64 & 1.70 & 2.30 & 2.36 & $\begin{array}{l}\text { Não há evidências de } \\
\text { aucorrelação }\end{array}$ \\
\hline & APT & 2.05 & 5 & 1.62 & 1.72 & 2.28 & 2.38 & $\begin{array}{l}\text { Não há evidências de } \\
\text { aucorrelação }\end{array}$ \\
\hline \multirow{5}{*}{ Carteiras } & CAPM & 1.76 & 1 & 1.66 & 1.68 & 2.32 & 2.34 & $\begin{array}{l}\text { Não há evidências de } \\
\text { aucorrelação }\end{array}$ \\
\hline & $\begin{array}{l}\text { CAPM } \\
\text { Global }\end{array}$ & 1.45 & 1 & 1.66 & 1.68 & 2.32 & 2.34 & $\begin{array}{l}\text { Há evidências de } \\
\text { autocorrelação positiva }\end{array}$ \\
\hline & $\begin{array}{l}\text { CAPM } \\
\text { Local }\end{array}$ & 1.78 & 2 & 1.65 & 1.69 & 2.31 & 2.35 & $\begin{array}{l}\text { Não há evidências de } \\
\text { aucorrelação }\end{array}$ \\
\hline & 3 Fatores & 2.05 & 3 & 1.64 & 1.70 & 2.30 & 2.36 & $\begin{array}{l}\text { Não há evidências de } \\
\text { aucorrelação }\end{array}$ \\
\hline & APT & 1.81 & 5 & 1.62 & 1.72 & 2.28 & 2.38 & $\begin{array}{l}\text { Não há evidências de } \\
\text { aucorrelação }\end{array}$ \\
\hline
\end{tabular}

Fonte: Elaborado pela autora

Apenas o modelo CAPM Global apresentou evidências de autocorrelação positiva. Entretanto vale recordar que o problema de autocorrelação é suportado pelo método de estimação SUR (PCSE). De qualquer forma a existência de autocorrelação no modelo CAPM Global também é uma sugestão de que este modelo é mal especificado para o mercado acionário brasileiro, visto que a existência de autocorrelação pode sugerir a omissão de uma 
variável explicativa relevante. Como apresentado pela tabela, não foram constatadas evidências de correlação serial nos demais modelos de precificação de ativos.

\subsubsection{Teste de Heteroscedasticidade}

A existência de homoscedasticidade dos resíduos garante que a variância dos resíduos é constante, os estimadores são os de variância mínima e também são eficientes. Neste estudo, para verificar a existência de heteroscedasticidade nos resíduos das regressões foi utilizado o teste de Breusch-Pagan que baseia-se no teste multiplicador de Lagrange. $\mathrm{O}$ teste é comumente utilizado, e é indicado principalmente para amostras grandes e quando não há a violação na suposição de normalidade nos erros. O teste apresenta a hipótese nula de que as variâncias dos erros são iguais (homoscedasticidade) contra a hipótese alternativa de que as variâncias dos erros não são constantes e há presença de heteroscedasticidade. Se não existe heteroscedasticidade, é de se esperar que os resíduos ao quadrado não aumentem ou diminuam em função do valor das variáveis independentes e assim, a estatística do teste sendo não significante indica a homoscedasticidade dos resíduos da regressão (WOOLDRIDGE, 2010).

Por meio de uma regressão auxiliar utilizando como variável dependente o quadrado dos resíduos de cada regressão, foi obtida a estatística do teste de Breusch-Pagan através do número de observações multiplicado pelo $R^{2}$ da regressão auxiliar, a qual possui assintoticamente uma distribuição $\chi^{2}$. Como o resultado da regressão, além de gerar a estatística teste gera também seu p-valor, então se o p-valor for superior ao nível de significância adotado, no caso 5\%, não se pode rejeitar a hipótese nula. Admitindo que os resíduos são homoscedásticos a variância dos resíduos é constante.

Tabela 10 - Teste de Breusch-Pagan

\begin{tabular}{clccl}
\hline \multirow{4}{*}{$\begin{array}{c}\text { Ativos } \\
\text { Individuais }\end{array}$} & g.l. & Prob. & \multicolumn{1}{c}{ Conclusão } \\
\cline { 2 - 5 } & CAPM & 1 & 0.749 & Os resíduos são Homoscedásticos \\
\cline { 2 - 5 } & CAPM Global & 1 & 0.058 & Os resíduos são Homoscedásticos \\
\cline { 2 - 5 } & 3 Fatores & 2 & 0.001 & Há evidências de Heteroscedasticidade \\
\cline { 2 - 5 } & APT & 3 & 0.106 & Os resíduos são Homoscedásticos \\
\hline \multirow{4}{*}{ Carteiras } & 5 & 0.023 & Há evidências de Heteroscedasticidade \\
\cline { 2 - 5 } & CAPM & 1 & 0.415 & Os resíduos são Homoscedásticos \\
\cline { 2 - 5 } & CAPM Global & 1 & 0 & Há evidências de Heteroscedasticidade \\
\cline { 2 - 5 } & CAPM Local & 2 & 0.001 & Há evidências de Heteroscedasticidade \\
\cline { 2 - 5 } & APT & 3 & 0.174 & Os resíduos são Homoscedásticos \\
\hline
\end{tabular}


$\mathrm{Na}$ presença de heteroscedasticidade os intervalos de confiança e teste de hipóteses $t$ e F terão resultados inexatos em função do erro padrão e as inferências estarão incorretas, em quatro situações foram encontradas evidências de heteroscedasticidade e nesse caso os métodos de mínimos quadrados ordinários (MQO) não é adequado, visto que os estimadores não são os melhores estimadores lineares não-viesados (MELNV). Entretanto o modelo SUR suporta a presença de heteroscedasticidade e autocorrelação. Mesmo nos casos de onde não há heteroscedasticidade os modelos foram estimados utilizando o método SUR, que apresenta erros padrões robustos.

\subsubsection{Normalidade dos Resíduos}

Uma distribuição normal é simétrica em relação à sua média, trata-se de uma propriedade desejável para que seja possível realizar testes de hipóteses e inferências sobre os parâmetros da população a partir dos dados da amostra, Na modelagem financeira é comum o caso de que alguns resíduos com valores extremos causem a rejeição da suposição de normalidade. Segundo Brooks (2008) o teste mais comum para normalidade é o Bera-Jarque (BJ). O cálculo se baseia na assimetria e curtose dos resíduos da regressão. A hipótese nula do teste é que os resíduos são normalmente distribuídos.

No presente estudo foram realizados os teste de normalidade para cada série de resíduos, que totalizaram 960 testes, foram observados que em sua maior parte os resíduos apresentavam distribuição normal, menos em alguns casos onde existiam outliers, que ao serem excluídos poderia ser observada a normalidade da sua distribuição. Em função da grande quantidade de testes, foram realizados testes de normalidade dos resíduos em conjunto para cada um dos modelos. Foram excluídos os resíduos tidos como outliers que eram superiores ou inferiores a três desvios padrão em relação a média, os resultados são apresentados na tabela 11: 
Tabela 11 - Resultados dos testes de normalidade dos resíduos

\begin{tabular}{|c|c|c|c|c|c|c|c|}
\hline & & D.P. & Assimetria & Curtose & $\begin{array}{l}\text { Estatística } \\
\text { J.B. }\end{array}$ & Prob. & Conclusão \\
\hline \multirow{5}{*}{$\begin{array}{c}\text { Ativos } \\
\text { Individuais }\end{array}$} & CAPM & 0.08 & -0.00048 & 2.95 & 4.34 & 0.114 & $\begin{array}{l}\text { Evidências de } \\
\text { normalidade a 5\% }\end{array}$ \\
\hline & $\begin{array}{l}\text { CAPM } \\
\text { Global }\end{array}$ & 0.08 & 0.004798 & 2.98 & .376 & 0.828 & $\begin{array}{l}\text { Evidências de } \\
\text { normalidade a 5\% }\end{array}$ \\
\hline & $\begin{array}{l}\text { CAPM } \\
\text { Local }\end{array}$ & 0.08 & 0.008737 & 2.94 & 5.72 & 0.058 & $\begin{array}{l}\text { Evidências de } \\
\text { normalidade a } 5 \%\end{array}$ \\
\hline & APT & 0.08 & 0.00927 & 2.91 & 14.18 & 0.001 & $\begin{array}{l}\text { Não há evidências de } \\
\text { normalidade a } 5 \%\end{array}$ \\
\hline & 3 Fatores & 0.08 & 0.000249 & 2.95 & 3.62 & 0.162 & $\begin{array}{l}\text { Evidências de } \\
\text { normalidade a } 5 \%\end{array}$ \\
\hline \multirow{5}{*}{ Carteiras } & CAPM & 0.03 & -0.03181 & 3.04 & 4.57 & 0.101 & $\begin{array}{l}\text { Evidências de } \\
\text { normalidade a } 5 \%\end{array}$ \\
\hline & $\begin{array}{l}\text { CAPM } \\
\text { Global }\end{array}$ & 0.04 & -0.08436 & 2.72 & 76,16 & 0.000 & $\begin{array}{l}\text { Não há evidências de } \\
\text { normalidade a } 5 \%\end{array}$ \\
\hline & $\begin{array}{l}\text { CAPM } \\
\text { Local }\end{array}$ & 0.03 & 0.016376 & 3.09 & 7.23 & 0.027 & $\begin{array}{l}\text { Não há evidências de } \\
\text { normalidade a } 5 \%\end{array}$ \\
\hline & APT & 0.03 & -0.01854 & 2.93 & 4.19 & 0.122 & $\begin{array}{l}\text { Evidências de } \\
\text { normalidade a 5\% }\end{array}$ \\
\hline & 3 Fatores & 0.02 & 0.017586 & 2.95 & 2.43 & 0.295 & $\begin{array}{l}\text { Evidências de } \\
\text { normalidade a } 5 \%\end{array}$ \\
\hline
\end{tabular}

Fonte: Elaborado pela autora

Apenas em três casos não foram encontradas evidências de normalidade dos resíduos. Nos demais, a hipótese de normalidade não foi rejeitada. Entretanto de acordo com Brooks (2008) para amostras de tamanhos suficientemente grandes, a violação da suposição de normalidade é praticamente inconsequente, razão pela qual essa premissa pode ser relaxada apelando-se para a utilização do teorema do limite central.

\subsubsection{Teste de Multicolinearidade}

Segundo Greene (2012), deve-se verificar a existência de multicolinearidade ao considerar um modelo que contém mais de uma variável explanatória. Se duas variáveis são perfeitamente correlacionados a variância é infinita. $\mathrm{O}$ caso da existência de uma relação linear exata entre os regressores é uma falha grave dos pressupostos do modelo, mas não dos dados. O caso mais comum é aquele em que as variáveis são altamente, mas não perfeitamente, correlacionadas. Neste caso surgem problemas estatísticos. Até certo ponto a multicolinearidade sempre existirá, então busca-se identificar através do fator de inflação da variância se o nível de colinearidade entre os regressores é aceitável e não causa prejuízo ao modelo. O cálculo do fator de inflação de variância é dado por:

$$
V I F=\frac{1}{\left(1-R^{2}\right)}
$$


Onde:

$\mathrm{VIF}=$ Fator de inflação da variância

$R^{2}=$ coeficiente de correlação entre cada regressor e os demais.

De acordo com Gujarati (2006), pode-se usar o VIF como um indicador de multicolinearidade, sendo que quanto maior o valor de VIF, maior a evidência de multicolinearidade. Como regra geral, se o VIF de uma variável for superior a 10, o que acontece quando o $R^{2}$ excede 0,90 . Admite-se então a existência de alta colinearidade, então quanto menor o valor de VIF menor a evidência de colinearidade entre as variáveis, adotando como 4 o valor de limite para que a colinearidade entre as variáveis não seja prejudicial.

Os modelos CAPM e CAPM Global, são modelos de um único fator, não existindo possibilidade de haver multicolinearidade, já os outros três modelos apresentam mais de um regressor. Desta forma no intuito de identificar a existência de multicolinearidade foi executado o teste de fator de inflação da variância, cujos resultados são apresentados na tabela 12:

Tabela 12 - Resultados dos testes do Fator de inflação da variância (FIV)

\begin{tabular}{ccccccc}
\hline & & $\left(R_{m L}-R_{f L}\right)$ & $(\mathrm{SMB})$ & $(\mathrm{E})$ & $(\mathrm{PIB})$ & $(\mathrm{PET})$ \\
\hline \multirow{2}{*}{ CAPM Local } & $\left(R_{c}\right)$ & 1.260952 & - & - & - & - \\
\hline \multirow{2}{*}{ Modelo de 3 Fatores } & $(\mathrm{SMB})$ & 1.254059 & - & - & - & - \\
& $(\mathrm{HML})$ & 1.419150 & 1.111987 & - & - & - \\
\hline \multirow{2}{*}{ APT } & $(\mathrm{E})$ & 1.013754 & - & - & - & - \\
& $(\mathrm{PIB})$ & 1.050821 & - & 1.017096 & - & - \\
& (PET) & 1.371466 & - & 1.404637 & 1.085803 & - \\
& (IPCA) & 1.062705 & - & 1.176296 & 1.318928 & 1.168195 \\
\hline
\end{tabular}

Fonte: Elaborado pela autora

Através do cálculo do coeficiente de correlação $\left(R^{2}\right)$ foi obtido o fator de inflação da variância (VIF) de cada um dos regressores de cada modelo, admitindo 4 como valor de referência para que não existam evidências de multicolinearidade, pode ser observado na tabela que nenhum dos três modelos multifatoriais apresentou evidências de colinearidade entre as variáveis.

\subsection{Análise Comparativa dos Modelos}

Com o objetivo de identificar o modelo que possui o melhor desempenho no mercado acionário brasileiro, os modelos foram analisados e comparados por meio do Critério 
informacional de Akaike, obtidos através regressões. Adicionalmente, no intuito de dar mais robustez aos resultados também foram analisados os critérios de Schwarz e Hannan-Quinn.

Tabela 13- Resumo dos resultados estatísticos de todos os modelos

\begin{tabular}{clccccc}
\hline & & \multicolumn{1}{c}{$\mathrm{R}^{2}$} & $\mathrm{R}^{2}$ ajustado & $\begin{array}{c}\text { E. P. da } \\
\text { regressão }\end{array}$ & Teste F & prob. Teste F \\
\hline \multirow{4}{*}{$\begin{array}{c}\text { Ativos } \\
\text { Individuais }\end{array}$} & CAPM & 0.12717 & 0.112377 & 0.106882 & 8.595 & 0.0000 \\
\cline { 2 - 7 } & CAPM Global & 0.07057 & 0.054819 & 0.110303 & 4.479 & 0.0000 \\
\cline { 2 - 7 } & CAPM Local & 0.12892 & 0.114042 & 0.106792 & 8.664 & 0.0000 \\
\cline { 2 - 7 } & 3 Fatores & 0.14745 & 0.132779 & 0.105647 & 1.004 & 0.0000 \\
\hline \multirow{5}{*}{ Carteiras } & 0.13641 & 0.121329 & 0.106342 & 9.040 & 0.0000 \\
\cline { 2 - 7 } & CAPM & 0.56112 & 0.561003 & 0.029994 & 4.600 & 0.0000 \\
\cline { 2 - 7 } & CAPM Global & 0.21268 & 0.212466 & 0.040186 & 9.719 & 0.0000 \\
\cline { 2 - 7 } & CAPM Local & 0.57323 & 0.573001 & 0.029591 & 2.415 & 0.0000 \\
\cline { 2 - 7 } & 3 Fatores & 0.67993 & 0.674321 & 0.025834 & 1.211 & 0.0000 \\
\hline
\end{tabular}

Fonte: Elaborado pela autora

Os resultados de significância global do modelo, o teste $(\mathrm{F})$, demonstram que todos os modelos são conjuntamente significativos a 1\%. Em todos os casos é rejeitada a hipótese nula de que todos coeficientes estimados pela regressão são simultaneamente iguais a zero. Ao analisar do coeficiente de determinação $\left(\mathrm{R}^{2}\right)$ observa-se que o desempenho dos modelos com a utilização de carteiras é bem superior do que utilizando ativos individuais.

O modelo de 3 fatores de Fama e French (1993) apresentou maior poder explicativo que os demais modelos, tanto para carteiras quanto ativos individuais. Entretanto são analisados outros critérios para identificação do modelo de melhor ajuste ao mercado acionário brasileiro.

De acordo com Greene (2012), deve-se considerar que os modelos são construções teóricas que buscam as verdadeiras relações comportamentais entre as variáveis que constituem o modelo. Então existe a necessidade de critérios para análise da especificação dos modelos, onde são consideradas as implicações da omissão de variáveis importantes e a inclusão de variáveis supérfluas no modelo. $\mathrm{O} \mathrm{R}^{2}$ ajustado tem como objetivo ser uma medida apta para avaliar o ajuste de modelos, pois o $\mathrm{R}^{2}$ ajustado penaliza a perda de graus de liberdade que ocorre quando um modelo é expandido. No entanto, há dúvidas se a penalização é suficientemente grande para garantir que o critério conduzirá ao modelo correto. Assim, observam-se duas medidas alternativas sugeridas que são o critério de informacional de Akaike (AIC) e critério informacional Bayesiano ou Schwarz (BIC). O critério de Akaike é representado por: 
$\operatorname{AIC}(K)=\ln \left(\frac{e^{\prime} e}{n}\right)+\frac{2 K}{n}$

Onde:

$A I C(K)=$ é o resultado do critério de Akaike;

$K=$ número de regressores

$N=$ número de observações

$e^{\prime} e=$ soma do quadrado dos resíduos da regressão

Ambos os critérios se assemelham. Entretanto o critério de Schwarz de modo geral apresenta uma penalização mais forte em termos de graus de liberdade perdidos em modelos com um maior número de observações e sua utilização inclina-se para modelos mais simples. O critério de Schwarz é representado por:

$$
B I C(K)=\ln \left(\frac{e^{\prime} e}{n}\right)+\frac{K \ln n}{n}
$$

Onde:

$B I C(K)=$ é o resultado do critério de Schwarz;

$K=$ número de regressores

$N=$ número de observações

$e^{\prime} e=$ soma do quadrado dos resíduos da regressão

A observação para o Critério de informação de Akaike (AIC) é impor uma punição pelo acréscimo do número de regressores a cada um dos cinco modelos utilizados, por essa razão, o critério informacional de Akaike é mais consistente que o $\mathrm{R}^{2}$ e o $\mathrm{R}^{2}$ ajustado. Ao comparar os cinco modelos testados busca-se identificar o preferível, ou seja, o que melhor explica a relação entre variável dependente e independentes, sendo o de melhor ajuste aquele que apresenta o menor valor de AIC por sofrer menor impacto do fator punitivo referente ao acréscimo de regressores. Os critérios de informação de Schwarz e Hannan-Quinn são similares ao critério de Akaike, isto é quanto menor o valor obtido melhor o modelo. 
Tabela 14- Critérios de comparação dos modelos

\begin{tabular}{cllcccc}
\hline & & \multicolumn{1}{c}{$\mathrm{R}^{2}$} & prob. Teste F & Akaike & Schwarz & Hannan-Quinn \\
\hline \multirow{4}{*}{$\begin{array}{c}\text { Ativos } \\
\text { Individuais }\end{array}$} & CAPM & 0.127173 & 0.0000 & -1.617 & -1.500 & -1.577 \\
\cline { 2 - 7 } & CAPM Global & 0.070574 & 0.0000 & -1.554 & -1.437 & -1.514 \\
\cline { 2 - 7 } & CAPM Local & 0.128922 & 0.0000 & -1.619 & -1.501 & -1.578 \\
\cline { 2 - 7 } & 3 Fatores & 0.147454 & 0.0000 & -1.640 & -1.521 & -1.599 \\
\cline { 2 - 7 } & APT & 0.136419 & 0.0000 & -1.627 & -1.506 & -1.585 \\
\hline \multirow{5}{*}{ Carteiras } & CAPM & 0.561125 & 0.0000 & -4.175 & -4.171 & -4.173 \\
\cline { 2 - 7 } & CAPM Global & 0.212684 & 0.0000 & -3.590 & -3.586 & -3.588 \\
\cline { 2 - 7 } & CAPM Local & 0.573238 & 0.0000 & -4.201 & -4.196 & -4.200 \\
\cline { 2 - 7 } & 3 Fatores & 0.679931 & 0.0000 & -4.456 & -4.348 & -4.418 \\
\cline { 2 - 7 } & APT & 0.620948 & 0.0000 & -4.319 & -4.309 & -4.315 \\
\hline
\end{tabular}

Fonte: Elaborado pela autora

Através dos critérios de seleção de modelos utilizados observa-se que o modelo de 3 Fatores apresenta um desempenho superior aos demais, tanto em carteiras como em ativos individuais, visto que apresentam os menores valores para o critério de Akaike, Schwarz e também Hannan-Quinn, ressalta-se que em nenhum dos casos os critérios de seleção de modelos se contradizem. Esses resultados corroboram os resultados de Rogers e Securato (2009) e Veras e Reis (2014), que relatam a superioridade do modelo de 3 Fatores no mercado acionário brasileiro.

Observe-se que a possível comparação entre o CAPM e o CAPM Local através do R 2 ajustado tornou-se desnecessária, uma vez que o segundo não se mostrou viável ao ser aplicado ao mercado brasileiro, tendo em vista a não significância do coeficiente associado ao risco-país. 


\section{CONSIDERAÇÕES FINAIS}

A literatura de finanças tem demonstrado a importância da precificação de ativos para as decisões financeiras a nível global. Dentre os modelos de precificação de ativos, a literatura mostra que o uso do CAPM de Sharpe (1964), Lintner (1965) e Mossin (1966) ainda persiste, embora se discuta a capacidade de apenas um fator ser responsável pela explicação dos retornos dos ativos. Em decorrência dos diversos testes empíricos realizados, observam-se outros fatores que podem aprimorar o poder explicativo do CAPM, além de capturar algumas anomalias encontradas no mercado.

Este estudo teve como objetivo avaliar e comparar o próprio CAPM com alguns dos modelos alternativos propostos para a precificação de ativos. Foram estudados o modelo APT de Ross (1976), o modelo de 3 fatores de Fama e French (1993), o modelo CAPM e duas adaptações: CAPM Global e CAPM Local.

Os testes foram realizados por meio de um painel de dados composto por ativos individuais que totalizaram 132 ações de empresas e também por 60 portfólios. Dessa forma foram realizadas 2 regressões em painel para cada um dos cinco modelos escolhidos, com dados do período compreendido entre 2010 e 2014, totalizando 60 meses.

Entre os resultados encontrados pode-se observar que o fator mercado apresentou significância estatística e relação positiva com o retorno referente a todas as carteiras e ativos individuais em todos os modelos analisados, de acordo com o previsto pela teoria.

Dos modelos de precificação de ativos analisados, o CAPM Global mostrou-se o menos adequado na explicação dos retornos. Observou-se que nos ativos individuais e nos portfólios analisados o intercepto mostrou-se significativamente diferente de zero, contrariando a hipótese do mercado eficiente. Adicionalmente, foi o modelo que apresentou o menor poder explicativo, além de apresentar autocorrelação positiva, sugerindo especificação inadequada.

A inclusão do risco-país, que é amplamente sugerida pela literatura como adaptação dos modelos de precificação de ativos para os mercados emergentes, não se mostrou significativa na explicação dos retornos. Dessa forma a utilização modelo CAPM Local não se mostrou viável no mercado acionário brasileiro.

Verificou-se que os testes do APT, que flexibiliza a ideia de que apenas um único fator (beta do prêmio de mercado) é capaz de explicar o retorno de ativos no mercado, mostra que as variáveis macroeconômicas inseridas foram capazes de melhorar o poder de explicação 
do CAPM. Entretanto, ainda existe um vasto campo de pesquisa para a escolha de outras variáveis que não foram utilizadas nesse estudo.

Embora o modelo de três fatores de Fama e French tenha apresentado resultados superiores aos demais modelos, é discutível o seu uso no Brasil. Os resultados indicam a existência de um prêmio pelo fator tamanho, entretanto há dúvidas sobre a existência de uma estimativa admissível e consistente de prêmio para esse fator que seja capaz de gerar previsões plausíveis na precificação de ativos no mercado acionário brasileiro tendo em vista as particularidades deste mercado.

Já ao analisar o CAPM, o beta referente ao prêmio de mercado apresenta-se significativo em todos os testes realizados. Então, deve-se avaliar se estimativas obtidas apenas com um único fator (prêmio de risco de mercado) podem ser mais consistentes e de menor custo, visto que o modelo CAPM é mais parcimonioso que os demais modelos.

Como caráter de conclusão, de forma geral, os modelos CAPM, 3 Fatores e APT apresentaram desempenho satisfatório na precificação de carteiras e de ativos individuais no mercado brasileiro, apesar das críticas apontadas na literatura acerca da proxy do ativo livre de risco e da carteira de mercado de referência. Os modelos CAPM Global e CAPM Local não apresentaram especificações válidas.

Ao comparar o desempenho dos modelos, observou-se que alguns fatores possuem capacidade de ampliar o poder de explicação do retorno de ativos, e pode-se obter um apreçamento mais adequado ao mercado em análise. Entretanto a opção pela utilização de modelos mais complexos, apesar de seu desempenho superior, exige uma operacionalização mais criteriosa, incorrendo em maiores custos, sob pena da obtenção de estimativas imprecisas para o apreçamento de ativos.

A realização dos testes apenas no mercado acionário brasileiro constitui uma limitação do trabalho. Como sugestão para futuras pesquisas, poderiam ser incluídos na amostra outros mercados emergentes, outros modelos de precificação de ativos e também testes da capacidade preditiva dos modelos. 


\section{REFERÊNCIAS}

ALVES, Janaína da Silva. Análise comparativa e teste empírico da validade dos modelos CAPM tradicional e condicional: o caso das ações da Petrobrás. Revista Ciências

Administrativas, Fortaleza, v. 13, n. 1, p.147-157, ago. 2007.

ARAÚJO, D. L., BRESSAN, A. A., BERTUCCI, L. A., \& LAMOUNIER, W. M. O risco de mercado do agronegócio brasileiro: uma análise comparativa entre os modelos CAPM e GARCH-M. Revista eletrônica de Gestão Organizacional. 2004.

ARAÚJO, Elisson Alberto Tavares; OLIVEIRA, Victor do Carmo; SILVA, Wendel Alex. CAPM em estudos brasileiros: uma análise da pesquisa. Revista de Contabilidade e Organizações, v. 6, n. 15, p. 95-122, 2012.

ARGOLO, Érico Falcão Bittencourt; LEAL, Ricardo Pereira Câmara; ALMEIDA, Vinício de Souza e. O modelo de Fama e French é aplicável no Brasil? Relatórios COPPEAD; 40227 p. Rio de Janeiro: UFRJ /COPPEAD, 2012.

ASSAF NETO, Alexandre; LIMA, Fabiano Guasti; ARAUJO, Adriana Maria Procópio de. Uma proposta metodológica para o cálculo do custo de capital no Brasil. Revista de Administração, v. 43, n. 1, p. 72-83, 2008.

ASSAF NETO, Alexandre. Finanças corporativas e valor. 5. ed. São Paulo: Atlas, 2010.

BANZ, Rolf W. The relationship between return and market value of common stocks. Journal of Financial Economics, n. 9, p. 3-18, 1981.

BARCLAY, Richard; FLETCHER, Jonathan; MARSHALL, Andrew. Pricing emerging market stock returns: an update. Emerging markets review, v. 11, n. 1, p. 49-61, 2010.

BARROS, Aidil Jesus da Silveira; LEHFELD, Neide Aparecida de Souza. Fundamentos de Metodologia Cientifica. 3. ed. São Paulo: Prentice Hall, 2007.

BASU, Sanjoy. Investment performance of common stocks in relation to their price-earnings ratios: A test of the efficient market hypothesis. The journal of Finance, v. 32, n. 3, p. 663682, 1977.

BENSON, Karen; FAFF, Robert. $\beta$. In ABACUS, 2012.

BERENICE, K. A precificação de ativos através da Arbitrage Pricing Theory no mercado de capital brasileiro. Dissertação de mestrado. Universidade Federal do Rio Grande do Sul, Porto Alegre, RS, Brasil. 1998.

BERK, Jonathan. Finanças empresariais essencial. Porto Alegre: Bookman, 2010.

BODIE, Z., KANE, A., MARCUS, A. J.. Fundamentos de investimentos. Porto Alegre: Bookman., 2001.

BORNHOLT, Graham. Extending the capital asset pricing model: the reward beta approach. Accounting \& Finance, v. 47, n. 1, p. 69-83, 2007 
BRANDÃO, Carolina Santos. Desempenho dos Modelos APT e CAPM no Mercado Acionário Brasileiro. 2013. Tese de Doutorado. PUC-Rio.

BROOKS, C. Introductory Econometric for Finance. Cambridge University Press, 2008.

BROWN, Philip, WALTER, Terry. The CAPM: Theoretical Validity, Empirical Intractability and Practical Applications. In ABACUS, 2012.

BROWN, S. J., ELTON, E. J., GRUBER, M. J., \& GOETZMANN, W. N. Moderna teoria de carteiras e análise de investimentos. São Paulo: Atlas 2004

BURMEISTER, E., \& MCELROY, M. Joint estimation of factor sensitivities and risk premium for arbitrage pricing theory. Journal of Finance, 43(3), 721-733. 1988.

BRUNER, Robert F. et al. Market integration in developed and emerging markets: Evidence from the CAPM. Emerging Markets Review, v. 9, n. 2, p. 89-103, 2008.

CASOTTI, F. P.; MOTTA, L. F. J. Oferta pública inicial no Brasil (2004-2006): uma abordagem da avaliação através de múltiplos e do custo de capital próprio. Revista Brasileira de Finanças, v. 6, n. 2, p. 157-204, 2008.

CHAN, K. C., CHEN, N., \& HSIEH, D. An exploratory investigation of the firm size. Journal of Financial Economics, 14(3), 451-571. 1985.

CHEN, N., ROLL, R., \& ROSS, S. A. Economic forces and the stock markets. Journal of Busines, 59(3), 386-403. 1986.

CASTRO SILVA, W. A. C.; PINTO, E. A.; MELO, A. O.; CAMARGOS, M. A. Análise comparativa entre o CAPM e o C-CAPM na precificação de índices acionários: evidências de mudanças nos coeficientes estimados de 2005 à 2008. In: Encontro Brasileiro de Finanças, 9., 2009, São Leopoldo. Anais... São Paulo: SBFIN, 2009.

; MELO, A. O.; PINTO, E. A. Capital asset pricing model (CAPM) e variantes em apreçamento de índices acionários da bolsa de valores de São Paulo. In: Encontro Nacional de Engenharia de Produção, 29., 2009, Salvador. Anais... Rio de Janeiro: ABEPRO, 2009.

CONNOR, G., \& KORAJCZYK, R. Performance measurement with the arbitrage pricing theory: a new framework for analysis. Journal of Financial Economics, 15(3), 373 394.1986.

COPELAND, Tom; KOLLER, Tim; MURRIN, Jack. Avaliação de empresas - Valuation: calculando e gerenciando o valor das empresas. 3. ed. São Paulo: Makron Books, 2002.

COSTA, N. C. A., JR., \& NEVES, M. B. E. Variáveis fundamentalistas e os retornos das ações. Anais do Encontro Nacional da Associação Nacional de Pós-Graduação e Pesquisa em Administração, Foz do Iguaçu, PR, Brasil, 22. 1998.

CUNHA, Moisés Ferreira da. Avaliação de Empresas no Brasil pelo Fluxo de Caixa Descontado: Evidências Empíricas Sob o Ponto de Vista do Desempenho Econômico Financeiro. Universidade de São Paulo: Faculdade de Economia, Administração e Contabilidade. São Paulo, 2011. 
DAMODARAN, Aswath. Corporate Finance: Theory and Practice. New York: John Wiley,1997.

Investment Valuation: Tools and Techniques for

Determining the Value of Any Asset. New York: John Wiley \& Sons, 2002.

Equity risk premiums: determinants, estimation and

implications - the 2010 edition. Disponível em: <http://ssrn.com/abstract=1556382〉. Acesso em: 15 de janeiro de 2015.

Finanças corporativas teoria e prática. 2. ed. Porto Alegre:

Bookman, 2011.

DEMIR, Sezgin; KADERLI, Yasemin Coşkun. The Effects Of International Integration On Cost Of Equity: Application Of Turkey's Tourism Sector. Journal of Accounting \& Finance, 2015.

DHRYMES, P.J., IRWIN F., BULENT G. A critical reexamination of the empirical evidence on the arbitrage pricing theory. Journal of Finance: 323-346.1984.

DRANEV, Yury; FOMKINA, Sofya. An asymmetric approach to the cost of equity estimation: empirical evidence from Russia. Higher School of Economics Research Paper No. WP BPR, v. 12, 2012.

ERB, C. B., HARVEY, C., VISKANTA, T. Political risk, economic risk and financial risk. Financial Analysts Journal 52:28-46. (1996a).

ERB, C. B., HARVEY, C., VISKANTA, T. Expected returns and volatility in 135 countries. Journal of Portfolio Management Spring:46-58. (1996b).

ELTON, E. J., \& GRUBER, M. A multi-index risk model of the Japanese stock market. Japan and the Word Economy, 1(1), 21-44. 1988.

ESTRADA, Javier. The cost of equity in emerging markets, a downside risk approach.SSRN Social Science Reaserch Network, Aug 1994.

The cost of equity in emerging markets: a downside risk approach.

Emerging Marketing Quarterly, New York, v. 3, n. 1, p. 19-30, 2000.

Systematic risk in emerging marketing: the D-CAPM. Emerging

Markets Review, New York, v. 3, p.365-379, 2002.

FAMA, Eugene. Efficient Capital Markets: a review of theory and empirical work. Journal of Finance 25, p. 383-417, 1969. maio de 1970.

FAMA, E. F.; FRENCH, K. R. The cross-section of expected stock returns. Journal of Finance, v. 47, n. 2, p. 427-465, 1992.

Common risk factors in the returns on stocks e bonds. Journal of Financial Economics, 33(1), 3-56. 1993. 
Finance, 51(1), 55-84. 1996.

Multifactor explanations of asset pricing anomalies. Journal of

Kenneth R. The capital asset pricing model: Theory and

evidence. Journal of Economic Perspectives, v. 18, p. 25-46, 2004.

O Modelo de Precificação de Ativos de Capital: teoria e evidências.

Revista de Administração de Empresas, v.47, n.2, p.103-118, abr/jun, 2007.

FARIAS, T.; DE MOURA, F. R. Carteiras eficientes e ingênuas: uma análise comparativa com o uso do modelo de Markowitz. Revista de Economia Mackenzie, v. 11, n. 2, 2014.

FERNANDÉZ, Pablo. Valuation Methods and Shareholder Value Creation. USA:

Elsevier Science, 2002.

GALDI; F. C.; SECURATO, J. R. O risco idiossincrático é relevante no mercado brasileiro? Revista Brasileira de Finanças, v. 5, n. 1, p. 41-58, 2007.

GARRÁN, Felipe Turbuk; MARTELANC, Roy. Metodologias em Uso no Brasil para a Determinação do Custo de Capital Próprio. In: ENCONTRO ANUAL DA ASSOCIAÇÃO NACIONAL DOS PROGRAMAS DE PÓS-GRADUAÇÃO EM ADMINISTRAÇÃO EnANPAD, 31.,2007, Rio de Janeiro. Anais... Rio de Janeiro: ANPAD, 2007.

GIL, Antônio Carlos. Como elaborar projetos de pesquisa. 4. ed. São Paulo: Atlas, 2002.

GODFREY, Stephen; ESPINOSA, Ramon. A practical approach to calculating costs of equity for investments in emerging markets. Journal of Applied Corporate Finance, v. 9, n. 3, p. 80-89, 1996.

GRAHAM, John; HARVEY, Campbell. The theory and practice of corporate finance: Evidence from the field. Journal of Financial Economics, v. 60, p. 187-243, 2001.

GREENE, William H. Econometric Analysis. 7th ed. Upper Saddle River, NJ: Prentice Hall. 2012

GRINBLATT, Mark; TITMAN, Sheridan. Mercados Financeiros \& Estrategias Corporativas. Bookman, 2005.

GUJARATI, Damodar N.; PORTER, Dawn C. Econometria básica. 5. ed. Porto Alegre: AMGH, 2011.

HARVEY, Campbell R. Predictable risk and returns in emerging markets. SSRN - Social Science Research Network, Aug 1994. Disponível em: <http://ssrn.com/abstract=796194>. Acesso em: 04/12/2014.

HILL, R. Carter; GRIFFITHS, William E; JUDGE, George G. Econometria. 3. ed. São Paulo: Saraiva, 2010.

JAGANNATHAN, R., \& WANG, Z. The conditional CAPM and the cross-section of expected returns. Journal of Finance, 51(1), 3-53. 1996. 
LEAL, Ricardo P. C.. Revisão da literatura sobre estimativa de custo de capital aplicada ao Brasil. COPPEAD/UFRJ. Rio de Janeiro, 2002.

LINS, A. G.; SILVA, W. V.; GOMES, L.; MARQUES, S. Formulação de carteiras hipotéticas de ativos financeiros usando a técnica de análise de cluster. In: Encontro da Associação Nacional de Pós-graduação e Pesquisa em Administração, 31., 2007, Rio de Janeiro (RJ). Anais... Rio de Janeiro: ANPAD, 2007.

LINTNER, John. The valuation of risk assets and the selection of risky investments in stock portfolios and capital budgets. Review of Economics and Statistics, Cambridge, MA, USA, v.47, n.1, p.13-37, Feb. 1965.

LUCENA, P., PINTO, A. C. F. Estudo de anomalias no mercado brasileiro de ações através de uma modificação no modelo de Fama e French. Anais do Encontro Nacional da Associação Nacional de Pós-Graduação e Pesquisa em Administração, Brasília, DF, Brasil, 29. 2005.

LUCENA, E. R. F., SILVA, C. A. T., MELO, C. L. L., \& GOMES, A. M. Custo Médio Ponderado de Capital: um estudo dos erros contidos em seu cálculo nas ofertas públicas de aquisições de ações registradas na Comissão de Valores Mobiliários (CVM). Registro Contábil, 4(1), 19-32. 2013.

MACHADO, M. A. V. Modelos de precificação de ativos e o efeito liquidez: evidências empíricas no mercado acionário brasileiro. 2009. 165f. Tese de Doutorado. Braíslia: UNB, 2009.

MACHADO, M. A. V.; MEDEIROS, O. R. Modelos de precificação de ativos e o efeito liquidez: evidências empíricas no mercado acionário brasileiro. Revista Brasileira de Finanças, v. 9, n. 3, p. 383-412, 2011.

MACHADO, M. A. V.; MEDEIROS, O. R. Existe o efeito liquidez no mercado acionário brasileiro? Brazilian Business Review, v. 9, n. 4, p. 28-51, 2012.

MÁLAGA, F. K.; SECURATO, J. R. Aplicação do modelo de três fatores de Fama e French no mercado acionário brasileiro: um estudo empírico no período 1995-2003. In Encontro Anual da Associação Nacional dos Programas de Pós-Graduação em Administração, 28. Curitiba: Anpad.2004.

MARKOWITZ, H. Portfolio selection. Journal of Finance, v. 7, n.1, p. 77-99, 1952.

MARKOWITZ, H. Portfolio Selection: Efficient Diversification of Investment. Cowles Foundation Monograph, n. 16. New York: John Wiley E Sons, Inc, 1959.

MARTINS, G. Manual para elaboração de monografias e dissertações. 3 ed. São Paulo: Atlas, 2002.

MARTINS, H. C.; GAVA, A. Aplicação De Modelos De Precificação De Ativos No Mercado Acionário Brasileiro-Um Teste De CAPM, D-CAPM e APT. Encontro Nacional de Engenharia de Produção. ABEPRO. São Carlos.2010 
MELLO, Luiz Maranhão de; SAMANEZ, Carlos Patrício. Determinação e análise de desempenho do modelo APT-Arbitrage Pricing Theory-no mercado de capitais brasileiro. Anais do Encontro Nacional da Associação Nacional de Pós-Graduação e Pesquisa em Administração, 1999.

MELLONE, G., JR. Evidência empírica da relação cross-section entre o retorno e earnings to price ratio e book to market ratio no mercado de ações do Brasil no período de 1995 a 1998. Anais do Encontro Nacional da Associação Nacional de Pós-Graduação e Pesquisa em Administração,, Foz do Iguaçu, PR, Brasil, 23.1999.

MENDES DA SILVA et al. Rede de Pesquisadores de Finanças no Brasil: Um Mundo Pequeno Feito por Poucos. RAC, Rio de Janeiro, v. 17, n. 6, art. 6, pp. 739-763, Nov./Dez. 2013.

MERTON, R. C. An intertemporal capital asset pricing model. Econometrica, v. 41, n. 5, p. 867-887, Sept., 1973.

MILANI, Bruno; CERETTA, Paulo Sérgio. O modelo de precificação por arbitragem no contexto dos fundos de investimenos brasileiros. Estudos do CEPE, n. 39, p. 55-78, 2014.

MONGRUT, Samuel. Tasas de descuento em Latinoamérica: hechos y desafios. Centro de Investigación de la Universidad del Pacífico, 2006.

MOSSIN, J. Equilibrium in a capital asset market. Econometrica, Oxford, UK, v.34, n.4, p.768-783, Oct. 1966.

MUSSA, Adriano; FAMÁ, Rubens; DOS SANTOS, José Odálio. A Adição Do Fator De Risco Momento Ao Modelo De Precificação De Ativos Dos Três Fatores De Fama \& French Aplicado Ao Mercado Acionário Brasileiro. REGE Revista de Gestão, v. 19, n. 3, 2012.

MUSSA, A., ROGERS, P. e SECURATO, J. R. Modelos de retornos esperados no mercado brasileiro: testes empíricos utilizando metodologia preditiva. Revista de Ciências da Administração, 11(23), 192-216, 2009.

NEVES, A. W. A precificação de ativos de renda variável no mercado de capitais brasileiro: uma visão comparativa entre a Arbitrage Pricing Theory e o Capital Asset Pricing Model. Dissertação de mestrado. Universidade Federal de Minas Gerais, Belo Horizonte, MG, Brasil. 2001.

NODA, Rafael Falcão; MARTELANC, Roy; KAYO, Eduardo Kazuo. O Fator de Risco Lucro/Preço em Modelos de Precificação de Ativos Financeiros. Rev. contab. finanç., São Paulo, 2015. Disponível em:

$<$ http://www.scielo.br/scielo.php?script=sci_arttext\&pid=S151970772015005000060\&lng=en $\& n r m=i s o>$. Acesso em 07 out 2015.

O'BRIEN, T. J. The global CAPM and the firms cost of capital in different currencies. Journal of Applied Corporate Finance, v. 12, n. 3, 1999.

ODA, André Luiz; SENGER, Maria Carlota Morandin; CHÁRA, Alexandre Noboru. Um estudo sobre diversificação na Bolsa de Valores de São Paulo. XXII Encontro da Associação Nacional de Pós-Graduação em Administração (ENANAP). Foz do Iguaçu. Anais... Rio de Janeiro: ANPAD, 1998. 
PAIVA, F. Dias. Modelos De Precificação De Ativos Financeiros De Fator Único: Um Teste Empírico Dos Modelos Capm E D-Capm. Caderno de Pesquisas em Administração, São Paulo, v. 12, n. 2, p. 49-65, abril/junho 2005.

PEREIRO, Luis E. The valuation of closely-held companies in Latin America. Center for Entrepreneurship and Business Veturing, Universidad Torcauto Di Tella, Miñones 2177,1428 Buenos Aires Argentina. Emerging Markets Review 2, p. 330-370. Ago. 2001. Valuation of companies in emerging markets: a practical approach. New York: Editor: John Wiley \& Sons. PubDate: 2002.

The practice of investment valuation in emerging markets: Evidence from Argentina. Journal of Multinational Financial Management, Elsevier, vol. 16(2), pages 160-183, April, 2006.

PERLIN, Marcelo Scherer; CERETTA, Paulo Sérgio. O CAPM na Bolsa de São Paulo: um modelo condicional. $4^{\circ}$. Congresso USP de Contabilidade e Controladoria. São Paulo, 2004. Acesso: http://www.congressousp.fipecafi.org/artigos42004/172.pdf, em 08/05/2015.

RAYES, Ana Cristina W., ARAÚJO, Gustavo S. e BARBEDO, Claudio S. O Modelo de 3 Fatores de Fama e French Ainda Explica Os Retornos No Mercado Acionário Brasileiro? Revista Alcance, 19, 52-61. 2012.

REINGANUM, Marc R. Misspecification of capital asset pricing: Empirical Anomalies Based on Earnings' Yields and Market Values. Journal of Financial Economics, n. 9, p. 1946, 1981.

RODRIGUES, M. R. A. O efeito valor, o efeito tamanho e o modelo multifatorial: evidências do caso brasileiro. Anais do Encontro Nacional da Associação Nacional de Pós-Graduação e Pesquisa em Administração, Florianópolis, SC, Brasil, 24. 2000.

RODRIGUES, M. R. A., \& LEAL, R. P. C. The three factor Fama and French model in Brazil. Proceedings of the Annual Conference, San Antonio, Texas, USA. 2003

ROGERS, P.; SECURATO, J. R. Estudo Comparativo no Mercado Brasileiro do Reward Beta Approach, Capital Asset Princing Model (CAPM) e Modelo 3-Fatores de Fama e French. In: XXXII Encontro da Associação Nacional de Pós-Graduação e Pesquisa em Administração (EnANPAD), 2008, Rio de Janeiro, ANPAD, 2008.

ROGERS, Pablo; SECURATO, José Roberto. Estudo comparativo no mercado brasileiro do Capital Asset Pricing Model (CAPM), Modelo 3-Fatores de Fama e French e Reward Beta Approach. RAC eletronica, v. 3, n. 1, p. 159-179, 2009.

ROLL, R. A critique of the asset pricing theory's tests' part $i$ : on past and potential testability of the theory. Journal of Financial Economics, v. 4, n. 2, p. 129-176, 1977.

ROLL, R., \& ROSS, S. A. An empirical investigation of the arbitrage pricing theory. Journal of Finance, 35(5), 1073-1103. 1980.

ROSENBERG, Barr; REID, Kenneth; LANSTEIN, Ronald. Persuasive evidence of market inefficiency. The Journal of Portfolio Management, v. 11, n. 3, p. 9-16, 1985. 
ROSS, S. A. The arbitrage theory of capital asset pricing. Journal of Economic Theory, v. 13, n. 3, p. 341-360, 1976.

ROSS, Stephen A; WESTERFIELD, Randolph W; JAFFE, Jeffrey F. Corporate Finance. $8^{\mathrm{a}}$ ed. Mc Graw Hill, 2008.

SOARES, Rodrigo Oliveira; ROSTAGNO, Luciano Martin; SOARES, Karina Talamini Costa. Estudo de evento: o método e as formas de cálculo do retorno anormal. XXVI Encontro Nacional dos Programas de Pós Graduação em Administração, 2002.

SAMUELSON, Paul A. Proof that properly anticipated prices fluctuate randomly. Industrial Management Review, v. 6, n. 2, p. 41, 1965.

SANTIAGO, Diogo Carneiro; LEAL, Ricardo Pereira Câmara. Carteiras igualmente ponderadas com poucas ações e o pequeno investidor. RAC, Rio de Janeiro, v. 19, n. 5, art. 1, pp. 544-564, Set./Out. 2015.

SANVICENTE, Antônio Zoratto. Relevância de Prêmio por Risco País no Custo de Capital das Empresas. Rev. adm. contemp., Curitiba, v. 19, n. spe, p. 38-52, 2015. Disponível em: $<$ http://www.scielo.br/scielo.php?script=sci_arttext\&pid=S141565552015000700004\&lng=en $\& n r m=i s o>$. access on 29 Nov. 2015. http://dx.doi.org/10.1590/1982-7849rac2015140097.

SCHRAMM, Ronald. M.; WANG, Henry. N. Measuring the cost of capital in an international CAPM framework. Journal of Applied Corporate Finance. v.12, n. 3, Fall, p. 63-72, 1999.

SHARPE, William F. Capital asset prices: a theory of market equilibrium under conditions of risk. Journal of Finance, Oxford, UK, v.19, n.3, p.425-442, Sept. 1964.

SILVA, Wesley Vieira da et al. A EFICIÊNCIA DO MERCADO DE CAPITAIS BRASILEIROS PELA ANÁLISE DO EFEITO MOMENTO DOI - 10.5752/P.19846606.2014v14n36p113. Revista Economia \& Gestão, Belo Horizonte, v. 14, n. 36, p. 113137, out. 2014. ISSN 1984-6606. Disponível em:

<http://periodicos.pucminas.br/index.php/economiaegestao/article/view/P.19846606.2014v14n36p113/7256>. Acesso em: 07 Out. 2015.

STATMAN, Meir. Behaviorial finance: Past battles and future engagements. Financial Analysts Journal, v. 55, n. 6, p. 18-27, 1999.

TAMBOSI FILHO, Elmo; COSTA JÚNIOR, Newton C. A.; ROSSETTO, José Roberto. Testando o CAPM condicional nos mercados brasileiro e norte-americano. RAC, v. 10, n. 4, Out./Dez. 2006: 153-168.

VERAS, MACHADO, M. A.; REIS MACHADO, M. Liquidez e precificação de ativos: evidências do mercado brasileiro. BBR - Brazilian Business Review 2014.

WOOLDRIDGE, Jeffrey M. Introdução à econometria: uma abordagem moderna. São Paulo, Cengage Learning, 2010. 


\section{APÊNDICES}

Apêndice A- Empresas que fazem parte da amostra

\begin{tabular}{|c|c|c|c|c|c|c|}
\hline Nome & Classe & Liquidez & Setor Economática & Bolsa & $\begin{array}{c}\text { Data do Início da } \\
\text { Série }\end{array}$ & Código \\
\hline AES Tiete & PN & 0,242456 & Energia Elétrica & Bovespa & 26/07/1999 & GETI4 \\
\hline Alpargatas & $\mathrm{PN}$ & 0,079375 & Textil & Bovespa & 02/01/1986 & ALPA4 \\
\hline Ambev S/A & ON & 0,865272 & Alimentos e Beb & Bovespa & 03/06/1988 & ABEV3 \\
\hline Arteris & ON & 0,186563 & Transporte Serviç & Bovespa & $14 / 07 / 2005$ & ARTR3 \\
\hline B2W Digital & $\mathrm{ON}$ & 0,276001 & Comércio & Bovespa & 08/08/2007 & BTOW3 \\
\hline Battistella & $\mathrm{PN}$ & 0,003212 & Comércio & Bovespa & $30 / 08 / 2007$ & BTTL4 \\
\hline Bematech & ON & 0,023296 & Eletroeletrônicos & Bovespa & $18 / 04 / 2007$ & BEMA3 \\
\hline BR Brokers & ON & 0,110879 & Outros & Bovespa & $26 / 10 / 2007$ & BBRK3 \\
\hline BR Malls Par & ON & 0,61382 & Outros & Bovespa & 04/04/2007 & BRML3 \\
\hline Bradespar & $\mathrm{PN}$ & 0,752917 & Outros & Bovespa & $10 / 08 / 2000$ & BRAP4 \\
\hline Brasilagro & ON & 0,00538 & Agro e Pesca & Bovespa & $28 / 04 / 2006$ & AGRO3 \\
\hline Braskem & PNA & 0,617053 & Química & Bovespa & 02/01/1986 & BRKM5 \\
\hline BRF SA & $\mathrm{ON}$ & 1,033967 & Alimentos e Beb & Bovespa & 22/07/1997 & BRFS3 \\
\hline Brookfield & ON & 0,276972 & Construção & Bovespa & $20 / 10 / 2006$ & BISA3 \\
\hline CCR SA & ON & 1,065137 & Transporte Serviç & Bovespa & $31 / 01 / 2002$ & $\mathrm{CCRO} 3$ \\
\hline Celesc & $\mathrm{PN}$ & 0,046446 & Energia Elétrica & Bovespa & 19/05/1993 & CLSC4 \\
\hline Cemig & $\mathrm{PN}$ & 1,171928 & Energia Elétrica & Bovespa & 03/01/1986 & CMIG4 \\
\hline Cesp & PNB & 0,497025 & Energia Elétrica & Bovespa & $31 / 07 / 2006$ & CESP6 \\
\hline Cia Hering & ON & 0,448346 & Textil & Bovespa & 19/10/1999 & HGTX3 \\
\hline Coelce & PNA & 0,033376 & Energia Elétrica & Bovespa & 24/10/1995 & COCE5 \\
\hline Comgas & PNA & 0,05152 & Petróleo e Gas & Bovespa & 08/07/1997 & CGAS5 \\
\hline Copasa & $\mathrm{ON}$ & 0,1514 & Outros & Bovespa & 07/02/2006 & CSMG3 \\
\hline Copel & PNB & 0,450769 & Energia Elétrica & Bovespa & 17/01/1997 & CPLE6 \\
\hline Cosan & $\mathrm{ON}$ & 0,640553 & Alimentos e Beb & Bovespa & $17 / 11 / 2005$ & CSAN3 \\
\hline CPFL Energia & ON & 0,437611 & Energia Elétrica & Bovespa & 28/09/2004 & CPFE3 \\
\hline Cremer & ON & 0,011311 & Textil & Bovespa & $27 / 04 / 2007$ & CREM3 \\
\hline Csu Cardsyst & ON & 0,014226 & Outros & Bovespa & $28 / 04 / 2006$ & CARD3 \\
\hline Cyrela Realt & ON & 1,087868 & Construção & Bovespa & 01/07/2005 & CYRE3 \\
\hline Dasa & ON & 0,342111 & Outros & Bovespa & $18 / 11 / 2004$ & DASA3 \\
\hline Duratex & ON & 0,280109 & Outros & Bovespa & $20 / 09 / 2007$ & DTEX3 \\
\hline Eletrobras & PNB & 0,583559 & Energia Elétrica & Bovespa & 01/12/1989 & ELET6 \\
\hline Eletropaulo & $\mathrm{PN}$ & 0,40149 & Energia Elétrica & Bovespa & $31 / 08 / 2006$ & ELPL4 \\
\hline Embraer & ON & 0,641678 & Veículos e peças & Bovespa & $18 / 08 / 1993$ & EMBR3 \\
\hline Energias BR & ON & 0,432058 & Energia Elétrica & Bovespa & $12 / 07 / 2005$ & ENBR3 \\
\hline Eneva & ON & 0,141396 & Energia Elétrica & Bovespa & $13 / 12 / 2007$ & ENEV3 \\
\hline Estrela & $\mathrm{PN}$ & 0,006732 & Outros & Bovespa & 02/01/1986 & ESTR4 \\
\hline Eternit & ON & 0,03695 & Minerais não Met & Bovespa & 09/01/1987 & ETER3 \\
\hline Even & ON & 0,246497 & Construção & Bovespa & $30 / 03 / 2007$ & EVEN3 \\
\hline Eztec & ON & 0,112484 & Construção & Bovespa & $21 / 06 / 2007$ & EZTC3 \\
\hline Fer Heringer & ON & 0,02688 & Química & Bovespa & $11 / 04 / 2007$ & FHER3 \\
\hline
\end{tabular}




\begin{tabular}{|c|c|c|c|c|c|c|}
\hline Ferbasa & $\mathrm{PN}$ & 0,026832 & Siderur \& Metalur & Bovespa & 02/01/1986 & FESA4 \\
\hline Forja Taurus & $\mathrm{PN}$ & 0,01696 & Siderur \& Metalur & Bovespa & 03/01/1986 & FJTA4 \\
\hline Gafisa & ON & 0,841419 & Construção & Bovespa & $16 / 02 / 2006$ & GFSA3 \\
\hline Generalshopp & ON & 0,01383 & Outros & Bovespa & $27 / 07 / 2007$ & GSHP3 \\
\hline Gerdau & PN & 2,06035 & Siderur \& Metalur & Bovespa & $29 / 06 / 1988$ & GGBR4 \\
\hline Gerdau Met & PN & 0,605705 & Siderur \& Metalur & Bovespa & $14 / 07 / 1986$ & GOAU4 \\
\hline Gol & $\mathrm{PN}$ & 0,574148 & Transporte Serviç & Bovespa & $23 / 06 / 2004$ & GOLL4 \\
\hline Grendene & $\mathrm{ON}$ & 0,088521 & Textil & Bovespa & $28 / 10 / 2004$ & GRND3 \\
\hline Guararapes & $\mathrm{ON}$ & 0,026768 & Textil & Bovespa & 02/01/1986 & GUAR3 \\
\hline Haga S/A & PN & 0,005225 & Siderur \& Metalur & Bovespa & 21/01/1994 & HAGA4 \\
\hline Helbor & $\mathrm{ON}$ & 0,04236 & Construção & Bovespa & $26 / 10 / 2007$ & HBOR3 \\
\hline Ideiasnet & ON & 0,034854 & Outros & Bovespa & 08/06/2000 & IDNT3 \\
\hline Iguatemi & ON & 0,110381 & Outros & Bovespa & 06/02/2007 & IGTA3 \\
\hline Inds Romi & $\mathrm{ON}$ & 0,016249 & Máquinas Indust & Bovespa & 06/06/1988 & ROMI3 \\
\hline Inepar & $\mathrm{PN}$ & 0,023753 & Outros & Bovespa & 01/06/1988 & INEP4 \\
\hline Inepar Tel & $\mathrm{ON}$ & 0,010127 & Telecomunicações & Bovespa & 19/07/1996 & INET3 \\
\hline Iochp-Maxion & $\mathrm{ON}$ & 0,10532 & Veiculos e peças & Bovespa & 04/08/1993 & MYPK3 \\
\hline Itausa & PN & 2,091552 & Outros & Bovespa & 02/01/1986 & ITSA4 \\
\hline J B Duarte & PN & 0,007869 & Alimentos e Beb & Bovespa & 02/01/1986 & JBDU4 \\
\hline JBS & ON & 0,650901 & Alimentos e Beb & Bovespa & $28 / 03 / 2007$ & JBSS3 \\
\hline Jereissati & $\mathrm{PN}$ & 0,00743 & Outros & Bovespa & 01/06/1988 & MLFT4 \\
\hline JHSF Part & ON & 0,056511 & Construção & Bovespa & $11 / 04 / 2007$ & JHSF3 \\
\hline Kepler Weber & ON & 0,053285 & Siderur \& Metalur & Bovespa & $24 / 01 / 2001$ & KEPL3 \\
\hline Klabin S/A & PN & 0,40364 & Papel e Celulose & Bovespa & 02/01/1986 & KLBN4 \\
\hline Light S/A & $\mathrm{ON}$ & 0,35583 & Energia Elétrica & Bovespa & 07/01/1986 & LIGT3 \\
\hline Localiza & $\mathrm{ON}$ & 0,467176 & Outros & Bovespa & $20 / 05 / 2005$ & RENT3 \\
\hline Log-In & $\mathrm{ON}$ & 0,029538 & Transporte Serviç & Bovespa & 20/06/2007 & LOGN3 \\
\hline Lojas Americ & PN & 0,752805 & Comércio & Bovespa & 03/01/1986 & LAME4 \\
\hline Lojas Marisa & $\mathrm{ON}$ & 0,065144 & Comércio & Bovespa & $19 / 10 / 2007$ & AMAR3 \\
\hline Lojas Renner & ON & 0,729168 & Comércio & Bovespa & 02/08/1993 & LREN3 \\
\hline Lopes Brasil & $\mathrm{ON}$ & 0,061627 & Outros & Bovespa & $15 / 12 / 2006$ & LPSB3 \\
\hline Lupatech & ON & 0,073408 & Siderur \& Metalur & Bovespa & $12 / 05 / 2006$ & LUPA3 \\
\hline M.Diasbranco & ON & 0,079733 & Alimentos e Beb & Bovespa & $17 / 10 / 2006$ & MDIA3 \\
\hline Mangels Indl & PN & 0,003433 & Siderur \& Metalur & Bovespa & 02/01/1986 & MGEL4 \\
\hline Marcopolo & $\mathrm{PN}$ & 0,271574 & Veiculos e peças & Bovespa & 05/04/1989 & POMO4 \\
\hline Marfrig & ON & 0,3588 & Alimentos e Beb & Bovespa & $28 / 06 / 2007$ & MRFG3 \\
\hline Metal Iguacu & PN & 0,006659 & Siderur \& Metalur & Bovespa & $14 / 05 / 1997$ & MTIG4 \\
\hline Minerva & $\mathrm{ON}$ & 0,105836 & Alimentos e Beb & Bovespa & 19/07/2007 & BEEF3 \\
\hline Minupar & $\mathrm{ON}$ & 0,007584 & Alimentos e Beb & Bovespa & 13/01/1994 & MNPR3 \\
\hline MMX Miner & $\mathrm{ON}$ & 0,516806 & Mineração & Bovespa & $21 / 07 / 2006$ & MMXM3 \\
\hline MRV & $\mathrm{ON}$ & 0,694554 & Construção & Bovespa & 20/07/2007 & MRVE3 \\
\hline Multiplan & ON & 0,202631 & Outros & Bovespa & $26 / 07 / 2007$ & MULT3 \\
\hline Natura & $\mathrm{ON}$ & 0,723633 & Comércio & Bovespa & $25 / 05 / 2004$ & NATU3 \\
\hline Odontoprev & ON & 0,205639 & Outros & Bovespa & $30 / 11 / 2006$ & ODPV3 \\
\hline Oi & $\mathrm{PN}$ & 0,759102 & Telecomunicações & Bovespa & 14/07/1992 & OIBR4 \\
\hline P.Acucar-Cbd & PN & 0,675223 & Comércio & Bovespa & 13/10/1995 & PCAR4 \\
\hline Paranapanema & ON & 0,067597 & Siderur \& Metalur & Bovespa & 03/06/1988 & PMAM3 \\
\hline
\end{tabular}




\begin{tabular}{|c|c|c|c|c|c|c|}
\hline PDG Realt & ON & 1,074392 & Construção & Bovespa & 24/01/2007 & PDGR3 \\
\hline Petrobras & PN & 8,126471 & Petróleo e Gas & Bovespa & 02/01/1986 & PETR4 \\
\hline Plascar Part & ON & 0,032189 & Veiculos e peças & Bovespa & 09/05/1989 & PLAS3 \\
\hline Portobello & ON & 0,005415 & Minerais não Met & Bovespa & 06/01/1995 & PTBL3 \\
\hline Positivo Inf & ON & 0,084245 & Eletroeletrônicos & Bovespa & $08 / 12 / 2006$ & POSI3 \\
\hline Profarma & ON & 0,021919 & Comércio & Bovespa & $25 / 10 / 2006$ & PFRM3 \\
\hline Providencia & ON & 0,008764 & Química & Bovespa & $26 / 07 / 2007$ & PRVI3 \\
\hline RaiaDrogasil & ON & 0,203489 & Comércio & Bovespa & 29/04/1996 & RADL3 \\
\hline Randon Part & PN & 0,210046 & Veiculos e peças & Bovespa & 02/01/1986 & RAPT4 \\
\hline Recrusul & PN & 0,00484 & Veiculos e peças & Bovespa & 03/04/1987 & RCSL4 \\
\hline Renar & ON & 0,008731 & Agro e Pesca & Bovespa & $25 / 02 / 2005$ & RNAR3 \\
\hline Rodobensimob & ON & 0,015695 & Construção & Bovespa & $30 / 01 / 2007$ & RDNI3 \\
\hline Rossi Resid & ON & 0,669437 & Construção & Bovespa & 22/07/1997 & RSID3 \\
\hline Sabesp & ON & 0,45552 & Outros & Bovespa & $11 / 11 / 1996$ & SBSP3 \\
\hline Sanepar & PN & 0,006218 & Outros & Bovespa & $16 / 03 / 2000$ & SAPR4 \\
\hline Santos Brp & UNT N2 & 0,049341 & Transporte Serviç & Bovespa & 05/12/2007 & STBP11 \\
\hline Sao Carlos & ON & 0,01179 & Outros & Bovespa & 20/09/1999 & SCAR3 \\
\hline Sao Martinho & ON & 0,056629 & Alimentos e Beb & Bovespa & $09 / 02 / 2007$ & SMTO3 \\
\hline Saraiva Livr & PN & 0,036188 & Outros & Bovespa & $10 / 03 / 2000$ & SLED4 \\
\hline Sid Nacional & ON & 1,569225 & Siderur \& Metalur & Bovespa & 02/08/1993 & CSNA3 \\
\hline SLC Agricola & ON & 0,057731 & Agro e Pesca & Bovespa & $14 / 06 / 2007$ & SLCE3 \\
\hline Souza Cruz & ON & 0,49673 & Outros & Bovespa & 02/01/1986 & CRUZ3 \\
\hline Springs & ON & 0,005735 & Textil & Bovespa & $26 / 07 / 2007$ & SGPS3 \\
\hline Suzano Papel & PNA & 0,677157 & Papel e Celulose & Bovespa & $16 / 06 / 1986$ & SUZB5 \\
\hline Tecnisa & ON & 0,111664 & Construção & Bovespa & $31 / 01 / 2007$ & TCSA3 \\
\hline Tectoy & PN & 0,006314 & Outros & Bovespa & $16 / 07 / 1993$ & TOYB4 \\
\hline Tegma & ON & 0,042883 & Transporte Serviç & Bovespa & $02 / 07 / 2007$ & TGMA3 \\
\hline Telebras & $\mathrm{PN}$ & 0,136782 & Telecomunicações & Bovespa & 21/09/1998 & TELB4 \\
\hline Telef Brasil & PN & 0,525325 & Telecomunicações & Bovespa & $02 / 01 / 1986$ & VIVT4 \\
\hline Tempo Part & ON & 0,009984 & Outros & Bovespa & $17 / 12 / 2007$ & TEMP3 \\
\hline Tim Part S/A & $\mathrm{ON}$ & 0,645376 & Telecomunicações & Bovespa & $22 / 09 / 1998$ & TIMP3 \\
\hline Totvs & ON & 0,199731 & Software e Dados & Bovespa & 08/03/2006 & TOTS3 \\
\hline Tractebel & ON & 0,382998 & Energia Elétrica & Bovespa & 01/06/1998 & TBLE3 \\
\hline Tran Paulist & $\mathrm{PN}$ & 0,190772 & Energia Elétrica & Bovespa & 26/07/1999 & TRPL4 \\
\hline Trisul & ON & 0,005394 & Construção & Bovespa & $11 / 10 / 2007$ & TRIS3 \\
\hline Triunfo Part & ON & 0,018835 & Transporte Serviç & Bovespa & $20 / 07 / 2007$ & TPIS3 \\
\hline Tupy & ON & 0,014192 & Veiculos e peças & Bovespa & 08/10/1991 & TUPY3 \\
\hline Unipar & PNB & 0,042051 & Química & Bovespa & 02/01/1986 & UNIP6 \\
\hline Usiminas & PNA & 1,866709 & Siderur \& Metalur & Bovespa & $11 / 12 / 1991$ & USIM5 \\
\hline V-Agro & ON & 0,214566 & Outros & Bovespa & $21 / 11 / 2006$ & VAGR3 \\
\hline Vale & PNA & 6,916973 & Mineração & Bovespa & 02/01/1986 & VALE5 \\
\hline Valid & ON & 0,105244 & Outros & Bovespa & $26 / 04 / 2006$ & VLID3 \\
\hline Viver & ON & 0,040526 & Construção & Bovespa & $05 / 06 / 2007$ & VIVR3 \\
\hline Weg & ON & 0,172697 & Máquinas Indust & Bovespa & 07/10/1991 & WEGE3 \\
\hline Whirlpool & PN & 0,002884 & Eletroeletrônicos & Bovespa & 23/07/1986 & WHRL4 \\
\hline
\end{tabular}


Apêndice B - Portfólios

\begin{tabular}{|c|c|c|c|c|c|}
\hline Portfólio 1 & Portfólio 2 & Portfólio 3 & Portfólio 4 & Portfólio 5 & Portfólio 6 \\
\hline Generalshopp ON & Cosan ON & Positivo Inf ON & Tran Paulist PN & Tecnisa ON & Triunfo Part ON \\
\hline Saraiva Livr PN & Telef Brasil PN & Inepar PN & BR Brokers ON & Brookfield ON & CCR SA ON \\
\hline Duratex ON & J B Duarte PN & Oi PN & Cesp PNB & RaiaDrogasil ON & Eletropaulo PN \\
\hline Sao Carlos ON & Lojas Renner ON & Itausa PN & Unipar PNB & Bematech ON & Cemig PN \\
\hline Whirlpool PN & CPFL Energia ON & Randon Part PN & Brasilagro ON & Estrela PN & Springs ON \\
\hline Coelce PNA & Marcopolo PN & Tractebel ON & Braskem PNA & Usiminas PNA & Eletrobras PNB \\
\hline Gafisa ON & CCR SA ON & JBS ON & Marcopolo PN & Eternit ON & Lojas Marisa ON \\
\hline Celesc PN & Sid Nacional ON & Odontoprev ON & CPFL Energia ON & Sid Nacional ON & Cia Hering ON \\
\hline Lupatech ON & Ferbasa PN & Haga S/A PN & Minerva ON & Eztec ON & Inds Romi ON \\
\hline Eletropaulo PN & Dasa ON & Natura ON & Coelce PNA & Gol PN & Gerdau PN \\
\hline Cia Hering ON & Grendene ON & Vale PNA & Sanepar PN & Cosan ON & Unipar PNB \\
\hline Lojas Americ PN & Iochp-Maxion ON & Totvs ON & Gol PN & Telef Brasil PN & Localiza ON \\
\hline Suzano Papel PNA & Saraiva Livr PN & Ambev S/A ON & Mangels IndI PN & Eletropaulo PN & Lojas Americ PN \\
\hline Triunfo Part ON & Even ON & Iguatemi ON & B2W Digital ON & Minupar ON & Randon Part PN \\
\hline Eneva ON & Brookfield ON & Sid Nacional ON & SLC Agricola ON & CPFL Energia ON & JHSF Part ON \\
\hline Eternit ON & BR Brokers ON & Tecnisa ON & Helbor ON & Lojas Renner ON & Recrusul PN \\
\hline Alpargatas PN & Valid ON & Celesc PN & Souza Cruz ON & Kepler Weber ON & Even ON \\
\hline Tran Paulist PN & Petrobras PN & Tempo Part ON & Copasa ON & Valid ON & Sabesp ON \\
\hline Weg ON & Renar ON & Cia Hering ON & Lojas Renner ON & Sao Carlos ON & Light S/A ON \\
\hline Energias BR ON & BR Malls Par ON & SLC Agricola ON & Eternit ON & JHSF Part ON & SLC Agricola ON \\
\hline Inds Romi ON & Sao Carlos ON & Sao Carlos ON & Recrusul PN & Eletrobras PNB & Iguatemi ON \\
\hline Csu Cardsyst ON & Minupar ON & V-Agro ON & Brookfield ON & Tupy ON & Tim Part S/A ON \\
\hline
\end{tabular}

\begin{tabular}{|c|c|c|c|c|c|}
\hline Portfólio 7 & Portfólio 8 & Portfólio 9 & Portfólio 10 & Portfólio 11 & Portfólio 12 \\
\hline Marcopolo PN & Braskem PNA & Eletrobras PNB & Suzano Papel PNA & Ambev S/A ON & Gol PN \\
\hline Celesc PN & Cemig PN & Coelce PNA & Eneva ON & Generalshopp ON & J B Duarte PN \\
\hline BR Malls Par ON & RaiaDrogasil ON & CCR SA ON & Ideiasnet ON & Usiminas PNA & Eztec ON \\
\hline Souza Cruz ON & Localiza ON & Sao Carlos ON & CCR SA ON & Sao Carlos ON & Localiza ON \\
\hline Telef Brasi & Vale PNA & Brookfield ON & Natura ON & Cremer ON & Souza Cruz ON \\
\hline Petrobras PN & Weg ON & Klabin S/A PN & V-Agro ON & Odontoprev ON & SLC Agricola ON \\
\hline Sabesp ON & JBS ON & Itausa PN & BR Brokers ON & Eletrobras PNB & Tim Part S/A ON \\
\hline Saraiva Livr PN & Ideiasnet ON & Copasa ON & Rossi Resid ON & Unipar PNB & Telef Brasil PN \\
\hline PDG Realt ON & Itausa PN & Tecnisa ON & Helbor ON & Inepar PN & Braskem PNA \\
\hline Portobello ON & PDG Realt ON & Rossi Resid ON & Lupatech ON & Valid ON & Vale PNA \\
\hline Cemig PN & Telebras PN & Minerva ON & MRV ON & Alpargatas PN & Embraer ON \\
\hline Tegma ON & Gol PN & Tran Paulist PN & Braskem PNA & Sao Martinho ON & PDG Realt ON \\
\hline Inepar Tel ON & Brasilagro ON & Metal Iguacu PN & Bradespar PN & Grendene ON & RaiaDrogasil ON \\
\hline Battistella PN & Energias BR ON & Telef Brasil PN & Odontoprev ON & B2W Digital ON & Tecnisa ON \\
\hline CPFL Energia ON & Plascar Part ON & Iochp-Maxion ON & Guararapes ON & Vale PNA & Copel PNB \\
\hline Copel PNB & Whirlpool PN & Guararapes ON & Marfrig ON & Paranapanema ON & Telebras PN \\
\hline Grendene ON & Minupar ON & CPFL Energia ON & P.Acucar-Cbd PN & Trisul ON & Plascar Part ON \\
\hline Lojas Renner ON & Lopes Brasil ON & Tim Part S/A ON & Copel PNB & Fer Heringer ON & Springs ON \\
\hline Arteris ON & Portobello ON & RaiaDrogasil ON & Oi PN & Sabesp ON & Sao Martinho ON \\
\hline Gerdau Met PN & Totvs ON & Ferbasa PN & Celesc PN & Rossi Resid ON & AES Tiete PN \\
\hline BR Brokers ON & Marcopolo PN & Gol PN & Santos Brp UNT I & Dasa ON & Cemig PN \\
\hline Rodobensimob C & Inepar PN & Weg ON & Souza Cruz ON & Petrobras PN & Battistella PN \\
\hline
\end{tabular}




\begin{tabular}{|c|c|c|c|c|c|}
\hline Portto & lio 14 & Portfólio 15 & Portfólio 16 & Portfólio 17 & \\
\hline upy ON & Copa & Sanep & e ON & $\mathrm{Sao} \mathrm{Ma}$ & Miner \\
\hline$S O N$ & & & eber 0 & Natura ON & anco $\mathrm{O}$ \\
\hline PN & Weg & Brp UNT N2 & Localiza ON & Lojas Americ PN & Comgas PNA \\
\hline $\mathrm{AON}$ & & Natu & & Iacu PN & Indl PN \\
\hline PN & & ON & s ON & Ferba & Profar \\
\hline PN & Evel & ON & Ran & I ON & Telet \\
\hline sil ON & & Tupy & & & ON \\
\hline omg & UPN & Eletro & oes ON & Battis & ON \\
\hline RaiaL & & Arter & Tupy $C$ & Cyrela Realt ON & Usiminas PNA \\
\hline lultip & MRV & Com & Helb & UNTN & Souza Cruz ON \\
\hline $\mathrm{ON}$ & $B R B$ & $\mathrm{CiaH}$ & $J B S C$ & Mins & Santc \\
\hline guat & Das & Tele & tal ON & Tem & Vive \\
\hline Cosar & Gafis & Unip & Cem & Crem & Light $\mathrm{S} / \mathrm{f}$ \\
\hline ztec & & Klabi & Broc & Tran & J B Duar \\
\hline aus & Valid & Brask & sil PN & SLC Agricola ON & Localiza C \\
\hline Jatu & Telef & Brad & Trisul & Copa & Brasil \\
\hline ane & & Metal & Multip & Cem & Durat \\
\hline & & Marco & Even $C$ & Pro & Sara \\
\hline Eternit ON & Generalshopp O & Rossi Resid ON & Marfrig ON & Gafisa ON & lochp-Maxion ON \\
\hline Klabin S/A PN & & Mangels Indl PN & Saraiva Livr PN & Telebras PN & Celesc PN \\
\hline & & & & & \\
\hline & & & & & Sanepar PN \\
\hline
\end{tabular}

\begin{tabular}{|c|c|c|c|c|c|}
\hline Portfólio 19 & Portfólio 20 & Portfólio 21 & Portfólio 22 & Portfólio 23 & Portfólio 24 \\
\hline RaiaDrogasil ON & Copel PNB & Kepler Weber OI & Gerdau PN & Rodobensimob ON & Gafisa ON \\
\hline Paranapanema ON & PDG Realt ON & Randon Part PN & Saraiva Livr PN & Suzano Papel PNA & Tegma ON \\
\hline Tupy ON & Petrobras PN & Positivo Inf ON & Copasa ON & Guararapes ON & SLC Agricola ON \\
\hline Haga S/A PN & CPFL Energia ON & Odontoprev ON & Rodobensimob ON & Positivo Inf ON & Sid Nacional ON \\
\hline Cia Hering ON & Tractebel ON & Souza Cruz ON & Randon Part PN & Ideiasnet ON & Minerva ON \\
\hline Weg ON & BR Malls Par ON & Guararapes ON & Dasa ON & Profarma ON & Tupy ON \\
\hline Unip & P.Acucar-Cbd PN & Gerdau Met PN & JHSF Part ON & PDG Realt ON & Eletropaulo PN \\
\hline Etern & Natura ON & Souza Cruz ON & Telebras PN & Gol PN & J B Duarte PN \\
\hline Braskem PNA & Suzano Papel PNA & Gol PN & Generalshopp ON & RaiaDrogasil ON & Telebras PN \\
\hline Telebras PN & Renar ON & Oi PN & Cosan ON & Mangels Indl PN & Portobello ON \\
\hline JBS C & Inds Romi ON & Klabin S/A PN & Ferbasa PN & Cyrela Realt ON & Suzano Papel PNA \\
\hline Cesp PNB & Multiplan ON & Eztec ON & Cremer ON & Paranapanema ON & Sao Martinho ON \\
\hline Plascar Part ON & Trisul ON & Generalshopp O & Mangels Indl PN & Localiza ON & Inepar Tel ON \\
\hline Sabesp ON & Embraer ON & Natura ON & Profarma ON & Renar ON & Bematech ON \\
\hline Grendene ON & Sabesp ON & Tegma ON & Eletropaulo PN & Braskem PNA & Ambev S/A ON \\
\hline Embraer ON & Grendene ON & Forja Taurus PN & Forja Taurus PN & Eztec ON & Brookfield ON \\
\hline Renar ON & Providencia ON & Lopes Brasil ON & Log-In ON & Weg ON & CPFL Energia ON \\
\hline Marcopolo PN & Lojas Renner ON & Mangels Indl PN & Odontoprev ON & Souza Cruz ON & Even ON \\
\hline Itausa PN & Even ON & Fer Heringer ON & M.Diasbranco ON & Unipar PNB & Guararapes ON \\
\hline Generalshopp ON & Totvs ON & Braskem PNA & Celesc PN & Energias BR ON & Klabin S/A PN \\
\hline & Profarma ON & Duratex ON & Klabin S/A PN & BR Brokers ON & P.Acucar-Cbd PN \\
\hline Brasilagro ON & Log-In ON & Cosan ON & Gafisa ON & Iochp-Maxion ON & Santos Brp UNT N2 \\
\hline
\end{tabular}




\begin{tabular}{|c|c|c|c|c|c|}
\hline Portfólio 25 & Portfólio 26 & Portfólio 27 & Portfólio 28 & Portfólio 29 & Portfólio 30 \\
\hline Lojas Americ PN & Triunfo Part ON & Cremer ON & Natura ON & Viver ON & Lupatech ON \\
\hline Telebras PN & RaiaDrogasil ON & Unipar PNB & V-Agro ON & Inds Romi ON & Ambev S/A ON \\
\hline Eneva ON & Valid ON & Eneva ON & Trisul ON & Log-In ON & Multiplan ON \\
\hline Helbor ON & Telebras PN & JHSF Part ON & Suzano Papel PNA & Even ON & Ideiasnet ON \\
\hline Generalshopp $d$ & SLC Agricola ON & Braskem PNA & RaiaDrogasil ON & Kepler Weber ON & Randon Part PN \\
\hline Inepar PN & Profarma ON & Marcopolo PN & M.Diasbranco ON & Jereissati PN & Tempo Part ON \\
\hline Suzano Papel PN & Santos Brp UNT N & Minupar ON & Portobello ON & Petrobras PN & Estrela PN \\
\hline Alpargatas PN & Tecnisa ON & Copasa ON & Helbor ON & Whirlpool PN & Metal Iguacu PN \\
\hline PDG Realt ON & Bradespar PN & BR Malls Par ON & Marcopolo PN & Lojas Americ PN & Eternit ON \\
\hline Jereissati PN & Coelce PNA & Tegma ON & B2W Digital ON & Minerva ON & Cemig PN \\
\hline Cremer ON & Sao Carlos ON & Providencia ON & Sabesp ON & P.Acucar-Cbd PN & MRV ON \\
\hline Positivo Inf ON & Sid Nacional ON & Jereissati PN & Saraiva Livr PN & Marfrig ON & Eztec ON \\
\hline Log-In ON & Recrusul PN & Gol PN & Valid ON & Eletropaulo PN & Comgas PNA \\
\hline Inds Romi ON & Grendene ON & Sao Martinho ON & Cosan ON & Tegma ON & Bematech ON \\
\hline Tupy ON & Light S/A ON & B2W Digital ON & P.Acucar-Cbd PN & PDG Realt ON & Sao Carlos ON \\
\hline Randon Part PN & Paranapanema O & Csu Cardsyst ON & Multiplan ON & Guararapes ON & Tractebel ON \\
\hline Haga S/A PN & Inds Romi ON & Inds Romi ON & Dasa ON & Eternit ON & JBS ON \\
\hline Brookfield ON & Metal Iguacu PN & Fer Heringer ON & Odontoprev ON & Celesc PN & Copasa ON \\
\hline Multiplan ON & Trisul ON & Saraiva Livr PN & Inepar PN & Brookfield ON & Odontoprev ON \\
\hline Eletropaulo PN & Multiplan ON & Sanepar PN & Springs ON & Iochp-Maxion ON & Fer Heringer ON \\
\hline Minupar ON & Eternit ON & Odontoprev ON & Celesc PN & Metal Iguacu PN & Springs ON \\
\hline Arteris ON & Dasa ON & Usiminas PNA & Cia Hering ON & CPFL Energia ON & Saraiva Livr PN \\
\hline
\end{tabular}

\begin{tabular}{|c|c|c|c|c|c|}
\hline Portfólio 31 & Portfólio 32 & Portfólio 33 & Portfólio 34 & Portfólio 35 & Portfólio 36 \\
\hline Eternit ON & Valid ON & Celesc PN & Souza Cruz ON & Sao Carlos ON & Sabesp ON \\
\hline Alpargatas PN & Petrobras PN & Tempo Part ON & Copasa ON & JHSF Part ON & Light S/A ON \\
\hline Tran Paulist PN & Renar ON & Cia Hering ON & Lojas Renner ON & Eletrobras PNB & SLC Agricola ON \\
\hline Weg ON & BR Malls Par ON & SLC Agricola ON & Eternit ON & Tupy ON & Iguatemi ON \\
\hline Energias BR ON & Sao Carlos ON & Sao Carlos ON & Recrusul PN & Itausa PN & Tim Part S/A ON \\
\hline Inds Romi ON & Minupar ON & V-Agro ON & Brookfield ON & Viver ON & Minupar ON \\
\hline Csu Cardsyst ON & Gerdau Met PN & Duratex ON & Viver ON & Log-In ON & Brookfield ON \\
\hline Cosan ON & Metal Iguacu PN & Paranapanema ON & Grendene ON & Braskem PNA & Generalshopp ON \\
\hline Eletrobras PNB & Inds Romi ON & Portobello ON & Csu Cardsyst ON & Battistella PN & Eternit ON \\
\hline Copasa ON & Gerdau PN & Marfrig ON & Marfrig ON & Embraer ON & Lopes Brasil ON \\
\hline RaiaDrogas & Battistella PN & Copasa ON & Petrobras PN & Fer Heringer ON & Estrela PN \\
\hline Inepar Tel ON & Cesp PNB & Marcopolo PN & Kepler Weber ON & P.Acucar-Cbd PN & Helbor ON \\
\hline Klabin S/A PN & Braskem PNA & Light S/A ON & Providencia ON & Marcopolo PN & Portobello ON \\
\hline BR Malls Par ON & Coelce PNA & Lojas Marisa ON & Alpargatas PN & Arteris ON & CPFL Energia ON \\
\hline Viver ON & Arteris ON & Battistella PN & Cyrela Realt ON & Natura ON & Gerdau Met PN \\
\hline BRF SA ON & Localiza ON & P.Acucar-Cbd PN & Minupar ON & Celesc PN & Minerva ON \\
\hline Cemig PN & Marfrig ON & RaiaDrogasil ON & Natura ON & Tegma ON & BR Malls Par ON \\
\hline CCR SA ON & Eztec ON & Lojas Renner ON & Celesc PN & Dasa ON & Sid Nacional ON \\
\hline Bradespar PN & Profarma ON & Rossi Resid ON & Ambev S/A ON & Sanepar PN & Viver ON \\
\hline Fer Heringer $\mathrm{O}$ & Comgas PNA & Lupatech ON & Forja Taurus PN & CCR SA ON & Grendene ON \\
\hline Multiplan ON & Copel PNB & MRV ON & Alpargatas PN & Cyrela Realt ON & Cyrela Realt ON \\
\hline Light S/A ON & Rodobensimob ON & Cremer ON & Light S/A ON & Sao Martinho ON & Bradespar PN \\
\hline
\end{tabular}




\begin{tabular}{|c|c|c|c|c|c|}
\hline Portfólio 37 & Portfólio 38 & Portfólio 39 & Portfólio 40 & Portfólio 41 & Portfólio 42 \\
\hline Battistella PN & Brasilagro ON & Tim Part S/A ON & Copel PNB & Trisul ON & Copel PNB \\
\hline CPFL Energia ON & Energias BR ON & RaiaDrogasil ON & Oi PN & Fer Heringer ON & Telebras PN \\
\hline Copel PNB & Plascar Part ON & Ferbasa PN & Celesc PN & Sabesp ON & Plascar Part ON \\
\hline ne ON & Whirlpoc & Gol PN & Santos Brp UNT & id ON & Springs ON \\
\hline nner ON & Minu & & Souza Cruz ON & Das & Sao Martinho O \\
\hline Arter & Lopes Brasil ON & & Tegma ON & Petrobras PN & AES Tiete PN \\
\hline Gerdau Met PN & Portobello ON & Kepler Weber ON & Weg ON & Light S/A ON & Cemig \\
\hline okers ON & Totvs ON & Min & $\mathrm{CiaH}$ & Lojas Ma & Battistella PN \\
\hline $\mathrm{ob} O N$ & Marc & & Sabe & Klabin S & Usiminas PNA \\
\hline M.Diasbranco ON & Inepa & Brasken & Inepa & Positivo & Metal Iguacu PN \\
\hline Dasa & Sabe & ner ON & Iguate & $\mathrm{PN}$ & Unip \\
\hline isa ON & Cele & & Creme & $\mathrm{V}-\mathrm{Ag}$ & \\
\hline Ideiasnet ON & SLC Agricola ON & Paranapanema ON & Cemig PN & Celesc PN & Bematech ON \\
\hline te PN & AES Tiete & Cosar & Estrela PN & eric PN & Sid Nacional ON \\
\hline Ezte & Positivo Inf ON & Santos Brp UNT N2 & Portobello ON & Eterr & Estrela PN \\
\hline Plascar Part ON & Lojas Renner ON & V-Agro ON & Renar ON & Haga S/A PN & Eneva ON \\
\hline er ON & Log-In ON & Ambev S/A ON & Brasilagro ON & Tupy ON & AES Tiete PN \\
\hline PN & Forja Taurus PN & & Providencia ON & Oi PN & BR Brokers ON \\
\hline las PNA & Haga S/A PN & Ideiasnet ON & Telebras PN & Plascar Part ON & BRF SA ON \\
\hline Gafisa ON & Cremer ON & Whirlpool PN & Lojas Marisa ON & Lojas Renner ON & Ambev S/A ON \\
\hline Tim Part S/A ON & Metal Iguacu PN & Lojas Marisa ON & Ferbasa PN & PDG Realt ON & Rossi Resid ON \\
\hline Haga S/A PN & AES Tiete PN & Lojas Americ PN & Plascar Part ON & B2W Digital ON & Cosan ON \\
\hline
\end{tabular}

\begin{tabular}{|c|c|c|c|c|c|}
\hline Portfólio 43 & Portfólio 44 & Portfólio 45 & Portfólio 46 & Portfólio 47 & Portfólio 48 \\
\hline Iguatemi ON & Telef Brasil PN & Saraiva Livr PN & Marfrig ON & Tran Paulist PN & Viver ON \\
\hline Cosan ON & Tractebel ON & Positivo Inf ON & Saraiva Livr PN & SLC Agricola ON & Light S/A ON \\
\hline Eztec ON & Sid Nacional ON & Valid ON & Eneva ON & Copasa ON & J B Duarte PN \\
\hline Itausa PN & Generalshopp ON & Suzano Papel PNA & CCR SA ON & Cemig PN & Localiza ON \\
\hline Natura ON & Copel PNB & Ideiasnet ON & Springs ON & Profarma ON & Brasilagro ON \\
\hline Sanepar PN & Randon Part PN & Brasilagro ON & Vale PNA & Gafisa ON & Duratex ON \\
\hline Tempo Part ON & Usiminas PNA & Jereissati PN & RaiaDrogasil ON & Telebras PN & Saraiva Livr PN \\
\hline Eternit ON & BRF SA ON & Itausa PN & Tran Paulist PN & Comgas PNA & Iochp-Maxion \\
\hline Klabin S/A PN & Portobello ON & Oi PN & Iguatemi ON & Even ON & Celesc PN \\
\hline Cia Hering ON & JBS ON & Estrela PN & Profarma ON & Grendene ON & Oi PN \\
\hline Randon Part PN & Viver ON & Grendene ON & Bradespar PN & Arteris ON & Sanepar PN \\
\hline CCR SA ON & Trisul ON & Cemig PN & Telef Brasil PN & Ideiasnet ON & Jereissati PN \\
\hline Celesc PN & Cremer ON & Eztec ON & Cosan ON & Brookfield ON & Vale PNA \\
\hline Brasilagro ON & Comgas PNA & V-Agro ON & Plascar Part ON & B2W Digital ON & Bradespar PN \\
\hline Valid ON & Estrela PN & Gerdau Met PN & Paranapanema $\mathrm{O}$ & Braskem PNA & Sao Carlos ON \\
\hline Totvs ON & Cemig PN & Copel PNB & J B Duarte PN & BRF SA ON & Paranapanem \\
\hline Tran Paulist PN & Duratex ON & Eneva ON & Brasilagro ON & JHSF Part ON & CCR SA ON \\
\hline Brookfield ON & Bematech ON & Duratex ON & Lojas Marisa ON & Sanepar PN & Whirlpool PN \\
\hline Embraer ON & Gol PN & Plascar Part ON & Lojas Renner ON & Forja Taurus PN & Tegma ON \\
\hline Guararapes ON & Oi PN & Souza Cruz ON & BR Malls Par ON & Petrobras PN & Eneva ON \\
\hline Cremer ON & Braskem PNA & PDG Realt ON & Battistella PN & AES Tiete PN & Bematech ON \\
\hline Dasa ON & P.Acucar-Cbd PN & MRV ON & Rossi Resid ON & CPFL Energia O & Inepar Tel ON \\
\hline
\end{tabular}




\begin{tabular}{|c|c|c|c|c|c|}
\hline Portfólio 49 & Portfólio 50 & Portfólio 51 & Portfólio 52 & Portfólio 53 & Portfólio 54 \\
\hline Itausa PN & Grendene ON & Eztec ON & Eletropaulo PN & Eztec ON & Inepar Tel ON \\
\hline Generalshopp ON & Providencia ON & Generalshopp ON & Forja Taurus PN & Weg ON & Bematech ON \\
\hline Eletropaulo PN & Lojas Renner ON & Natura ON & Log-In ON & Souza Cruz ON & Ambev S/A ON \\
\hline Brasilagro ON & Even ON & Tegma ON & Odontoprev ON & Unipar PNB & Brookfield ON \\
\hline Bematech ON & Totvs ON & Forja Taurus PN & M.Diasbranco ON & Energias BR ON & CPFL Energia ON \\
\hline Eletrobras PNB & Profarma ON & Lopes Brasil ON & Celesc PN & BR Brokers ON & Even ON \\
\hline Positivo Inf ON & Log-In ON & Mangels Indl PN & Klabin S/A PN & Iochp-Maxion ON & Guararapes ON \\
\hline Valid ON & Generalshopp O & Fer Heringer ON & Gafisa ON & Cia Hering ON & Klabin S/A PN \\
\hline Guararapes ON & Marcopolo PN & Braskem PNA & Ambev S/A ON & Marfrig ON & P.Acucar-Cbd PN \\
\hline Lojas Marisa ON & Estrela PN & Duratex ON & Alpargatas PN & Eneva ON & Santos Brp UNT N2 \\
\hline Gerdau Met PN & Bematech ON & Cosan ON & Bematech ON & Tempo Part ON & Embraer ON \\
\hline CPFL Energia ON & Guararapes ON & PDG Realt ON & Coelce PNA & Ferbasa PN & Providencia ON \\
\hline BRF SA ON & Cemig PN & Cesp PNB & Petrobras PN & Arteris ON & Grendene ON \\
\hline Cyrela Realt ON & Mangels IndI PN & Ideiasnet ON & Itausa PN & Forja Taurus PN & Inepar PN \\
\hline Gafisa ON & Eletrobras PNB & B2W Digital ON & Tempo Part ON & Trisul ON & Gol PN \\
\hline Profarma ON & Gafisa ON & Brasilagro ON & Duratex ON & Cemig PN & Viver ON \\
\hline Duratex ON & Localiza ON & Gerdau PN & BRF SA ON & Triunfo Part ON & Light S/A ON \\
\hline Gerdau PN & Telebras PN & Weg ON & Eletrobras PNB & B2W Digital ON & Arteris ON \\
\hline Cremer ON & Dasa ON & Helbor ON & Inepar Tel ON & Embraer ON & Minupar ON \\
\hline Estrela PN & MRV ON & Celesc PN & Kepler Weber ON & P.Acucar-Cbd PN & Profarma ON \\
\hline BR Brokers ON & JHSF Part ON & Alpargatas PN & Lupatech ON & Metal Iguacu PN & M.Diasbranco ON \\
\hline Tecnisa ON & Whirlpool PN & AES Tiete PN & Usiminas PNA & CCR SA ON & Cesp PNB \\
\hline
\end{tabular}

\begin{tabular}{|c|c|c|c|c|c|}
\hline Portfólio 55 & Portfólio 56 & Portfólio 57 & Portfólio 58 & Portfólio 59 & Portfólio 60 \\
\hline Multiplan ON & Light S/A ON & Inds Romi ON & Cosan ON & PDG Realt ON & Eztec ON \\
\hline Eletropaulo PN & Paranapanema OI & Fer Heringer ON & P.Acucar-Cbd PN & Guararapes ON & Comgas PNA \\
\hline Minupar ON & Inds Romi ON & Saraiva Livr PN & Multiplan ON & Eternit ON & Bematech ON \\
\hline Arteris ON & Metal Iguacu PN & Sanepar PN & Dasa ON & Celesc PN & Sao Carlos ON \\
\hline Bradespar PN & Trisul ON & Odontoprev ON & Odontoprev ON & Brookfield ON & Tractebel ON \\
\hline Braskem PNA & Multiplan ON & Usiminas PNA & Inepar PN & lochp-Maxion ON & JBS ON \\
\hline Providencia ON & Eternit ON & Renar ON & Springs ON & Metal Iguacu PN & Copasa ON \\
\hline MRV ON & Dasa ON & AES Tiete PN & Celesc PN & CPFL Energia ON & Odontoprev ON \\
\hline Lopes Brasil ON & Totvs ON & Valid ON & Cia Hering ON & Estrela PN & Fer Heringer ON \\
\hline Klabin S/A PN & Odontoprev ON & Localiza ON & Csu Cardsyst ON & Battistella PN & Springs ON \\
\hline Weg ON & Lojas Renner ON & Telef Brasil PN & Inepar Tel ON & Light S/A ON & Saraiva Livr PN \\
\hline M.Diasbranco ON & Lojas Marisa ON & Whirlpool PN & Cremer ON & B2W Digital ON & Natura ON \\
\hline Marfrig ON & Celesc PN & Tecnisa ON & Light S/A ON & Recrusul PN & Lojas Marisa ON \\
\hline Totvs ON & BRF SA ON & Minerva ON & Vale PNA & Multiplan ON & Trisul ON \\
\hline Localiza ON & Jereissati PN & Light S/A ON & Braskem PNA & BRF SA ON & Usiminas PNA \\
\hline Cesp PNB & Helbor ON & Brasilagro ON & Mangels IndI PN & Mangels Indl PN & Tim Part S/A ON \\
\hline Eletrobras PNB & Gafisa ON & Oi PN & Tran Paulist PN & Haga S/A PN & Souza Cruz ON \\
\hline B2W Digital ON & Positivo Inf ON & Iguatemi ON & Alpargatas PN & J B Duarte PN & Ferbasa PN \\
\hline Cosan ON & Cemig PN & Ferbasa PN & Itausa PN & Copel PNB & Providencia ON \\
\hline Sid Nacional ON & Log-In ON & Inepar Tel ON & Bradespar PN & Ferbasa PN & Triunfo Part ON \\
\hline Embraer ON & Copel PNB & Gerdau PN & Estrela PN & Rodobensimob ON & Tecnisa ON \\
\hline Alpargatas PN & Tim Part S/A ON & Gerdau Met PN & Gafisa ON & Lojas Marisa ON & Telebras PN \\
\hline
\end{tabular}


Apêndice C - Resultado das Regressões

MODELO DE 3 FATORES (ATIVOS INDIVIDUAIS)

Dependent Variable: R?-RF

Method: Pooled Least Squares

Date: 12/06/15 Time: 15:38

Sample: 2010M01 2014M12

Included observations: 60

Cross-sections included: 132

Total pool (balanced) observations: 7920

Cross-section SUR (PCSE) standard errors \& covariance (d.f. corrected)

\begin{tabular}{crrrr}
\hline \hline Variable & Coefficient & Std. Error & t-Statistic & Prob. \\
\hline \hline C & -0.002953 & 0.002484 & -1.188903 & 0.2345 \\
RM-RF & 0.709086 & 0.044637 & 15.88552 & 0.0000 \\
SMB & 0.554128 & 0.076835 & 7.211935 & 0.0000 \\
HML & -0.016452 & 0.067301 & -0.244447 & 0.8069 \\
Fixed Effects (Cross) & & & & \\
A1--C & 0.014200 & & & \\
A132--C & 0.017686 & & & \\
\hline \hline
\end{tabular}

Effects Specification

Cross-section fixed (dummy variables)

\begin{tabular}{lllr}
\hline \hline R-squared & 0.147454 & Mean dependent var & -0.014225 \\
Adjusted R-squared & 0.132779 & S.D. dependent var & 0.113446 \\
S.E. of regression & 0.105647 & Akaike info criterion & -1.640534 \\
Sum squared resid & 86.89012 & Schwarz criterion & -1.521606 \\
Log likelihood & 6631.515 & Hannan-Quinn criter. & -1.599806 \\
F-statistic & 10.04829 & Durbin-Watson stat & 2.059377 \\
Prob(F-statistic) & 0.000000 & &
\end{tabular}

MODELO DE 3 FATORES (CARTEIRAS)

Dependent Variable: R?-CDI

Method: Pooled Least Squares

Date: 12/06/15 Time: 15:39

Sample: 2010M01 2014M12

Included observations: 60

Cross-sections included: 60

Total pool (balanced) observations: 3600

Cross-section SUR (PCSE) standard errors \& covariance (d.f. corrected)

\begin{tabular}{crrrr}
\hline \hline Variable & Coefficient & Std. Error & t-Statistic & Prob. \\
\hline \hline C & -0.002148 & 0.002491 & -0.862091 & 0.3887 \\
IBOV-CDI & 0.703369 & 0.044769 & 15.71092 & 0.0000 \\
SMB & 0.515008 & 0.077062 & 6.683000 & 0.0000 \\
HML & -0.044205 & 0.067500 & -0.654882 & 0.5126 \\
Fixed Effects (Cross) & & & & \\
PORT_1-C & 0.001432 & & & \\
PORT_60--C & 0.003651 & & & \\
\hline \hline
\end{tabular}


Effects Specification

Cross-section fixed (dummy variables)

\begin{tabular}{lllr}
\hline \hline R-squared & 0.679931 & Mean dependent var & -0.012777 \\
Adjusted R-squared & 0.674321 & S.D. dependent var & 0.045269 \\
S.E. of regression & 0.025834 & Akaike info criterion & -4.456878 \\
Sum squared resid & 2.360642 & Schwarz criterion & -4.348576 \\
Log likelihood & 8085.381 & Hannan-Quinn criter. & -4.418282 \\
F-statistic & 121.1896 & Durbin-Watson stat & 2.049071 \\
Prob(F-statistic) & 0.000000 & &
\end{tabular}

\section{CAPM TRADICIONAL (ATIVOS INDIVIDUAIS)}

Dependent Variable: R?-CDI

Method: Pooled Least Squares

Date: 12/06/15 Time: 18:07

Sample: 2010M01 2014M12

Included observations: 60

Cross-sections included: 132

Total pool (balanced) observations: 7920

Cross-section SUR (PCSE) standard errors \& covariance (d.f. corrected)

\begin{tabular}{cclrr}
\hline \hline Variable & Coefficient & Std. Error & t-Statistic & Prob. \\
\hline C & -0.005862 & 0.003158 & -1.856341 & 0.0634 \\
IBOV-CDI & 0.643287 & 0.057601 & 11.16797 & 0.0000 \\
Fixed Effects (Cross) & & & \\
A1--C & 0.014200 & & \\
A132--C & 0.017686 & & \\
\hline \hline & Effects Specification & \\
\hline \hline Cross-section fixed (dummy variables) & & \\
\hline \hline & & & \\
R-squared & 0.127173 & Mean dependent var & -0.014225 \\
Adjusted R-squared & 0.112377 & S.D. dependent var & 0.113446 \\
S.E. of regression & 0.106882 & Akaike info criterion & -1.617529 \\
Sum squared resid & 88.95715 & Schwarz criterion & -1.500362 \\
Log likelihood & 6538.414 & Hannan-Quinn criter. & -1.577404 \\
F-statistic & 8.595308 & Durbin-Watson stat & 2.037296 \\
Prob(F-statistic) & 0.000000 & & \\
\hline \hline
\end{tabular}

\section{CAPM TRADICIONAL (CARTEIRAS)}

Dependent Variable: R?-CDI

Method: Pooled Least Squares

Date: 12/06/15 Time: 15:32

Sample: 2010M01 2014M12

Included observations: 60

Cross-sections included: 60

Total pool (balanced) observations: 3600

Cross-section SUR (PCSE) standard errors \& covariance (d.f. corrected)

\begin{tabular}{lllll}
\hline \hline Variable & Coefficient & Std. Error & t-Statistic & Prob.
\end{tabular}




\begin{tabular}{lrlrr}
\hline \hline \multicolumn{1}{c}{ C } & -0.004500 & 0.003044 & -1.478268 & 0.1394 \\
\multicolumn{1}{c}{ IBOV-CDI } & 0.636641 & 0.055525 & 11.46592 & 0.0000 \\
\hline \hline R-squared & 0.561125 & Mean dependent var & -0.012777 \\
Adjusted R-squared & 0.561003 & S.D. dependent var & 0.045269 \\
S.E. of regression & 0.029994 & Akaike info criterion & -4.175089 \\
Sum squared resid & 3.236887 & Schwarz criterion & -4.171651 \\
Log likelihood & 7517.160 & Hannan-Quinn criter. & -4.173864 \\
F-statistic & 4600.240 & Durbin-Watson stat & 1.756172 \\
Prob(F-statistic) & 0.000000 & & \\
\hline \hline
\end{tabular}

\section{APT (ATIVOS INDIVIDUAIS)}

Dependent Variable: R?-CDI

Method: Pooled Least Squares

Date: 12/06/15 Time: 15:26

Sample: 2010M01 2014M12

Included observations: 60

Cross-sections included: 132

Total pool (balanced) observations: 7920

Cross-section SUR (PCSE) standard errors \& covariance (d.f. corrected)

\begin{tabular}{cccrr}
\hline \hline Variable & Coefficient & Std. Error & t-Statistic & Prob. \\
\hline C & 0.000651 & 0.006639 & 0.098070 & 0.9219 \\
IBOV-CDI & 0.618901 & 0.053634 & 11.53943 & 0.0000 \\
PIB & -0.168439 & 0.080138 & -2.101860 & 0.0356 \\
PET & 0.093737 & 0.050529 & 1.855128 & 0.0636 \\
IPCA & -1.163389 & 1.192742 & -0.975390 & 0.3294 \\
E & 0.351608 & 0.159356 & 2.206434 & 0.0274 \\
Fixed Effects (Cross) & & & & \\
A1--C & 0.014200 & & \\
A132--C & 0.017686 & & \\
& & & \\
\hline \hline & Effects Specification & \\
\hline \hline Cross-section fixed (dummy variables) & & \\
\hline \hline & \multirow{2}{*}{ R-squared } & 0.136419 & Mean dependent var & -0.014225 \\
Adjusted R-squared & 0.121329 & S.D. dependent var & 0.113446 \\
S.E. of regression & 0.106342 & Akaike info criterion & -1.627169 \\
Sum squared resid & 88.01479 & Schwarz criterion & -1.506478 \\
Log likelihood & 6580.587 & Hannan-Quinn criter. & -1.585837 \\
F-statistic & 9.040224 & Durbin-Watson stat & 2.043693 \\
Prob(F-statistic) & 0.000000 & & \\
\hline \hline
\end{tabular}

APT (CARTEIRAS)

Dependent Variable: R?-CDI

Method: Pooled Least Squares

Date: 12/06/15 Time: 15:28

Sample: 2010M01 2014M12

Included observations: 60

Cross-sections included: 60

Total pool (balanced) observations: 3600 
Cross-section SUR (PCSE) standard errors \& covariance (d.f. corrected)

\begin{tabular}{crlrr}
\hline \multicolumn{1}{c}{ Variable } & Coefficient & Std. Error & t-Statistic & Prob. \\
\hline \hline C & 0.001001 & 0.006322 & 0.158258 & 0.8743 \\
IBOV-CDI & 0.612114 & 0.051073 & 11.98507 & 0.0000 \\
PIB & -0.151552 & 0.076312 & -1.985940 & 0.0471 \\
PET & 0.094408 & 0.048116 & 1.962084 & 0.0498 \\
IPCA & -0.991571 & 1.135799 & -0.873016 & 0.3827 \\
E & 0.383156 & 0.151748 & 2.524945 & 0.0116 \\
\hline \hline & & & & \\
R-squared & 0.620948 & Mean dependent var & -0.012777 \\
Adjusted R-squared & 0.620421 & S.D. dependent var & 0.045269 \\
S.E. of regression & 0.027890 & Akaike info criterion & -4.319407 \\
Sum squared resid & 2.795671 & Schwarz criterion & -4.309092 \\
Log likelihood & 7780.932 & Hannan-Quinn criter. & -4.315731 \\
F-statistic & 1177.509 & Durbin-Watson stat & 1.814105 \\
Prob(F-statistic) & 0.000000 & & \\
\hline
\end{tabular}

\section{CAPM GLOBAL (ATIVOS INDIVIDUAIS)}

Dependent Variable: R?-TB10

Method: Pooled Least Squares

Date: 12/06/15 Time: 15:33

Sample: 2010M01 2014M12

Included observations: 60

Cross-sections included: 132

Total pool (balanced) observations: 7920

Cross-section SUR (PCSE) standard errors \& covariance (d.f. corrected)

\begin{tabular}{cccrr}
\hline \hline Variable & Coefficient & Std. Error & t-Statistic & Prob. \\
\hline C & -0.015596 & 0.004742 & -3.288999 & 0.0010 \\
SP500-TB10 & 0.560229 & 0.123903 & 4.521525 & 0.0000 \\
Fixed Effects (Cross) & & & \\
A1--C & 0.014200 & & \\
A132--C & 0.017686 & & \\
\hline \hline & \multirow{2}{*}{ Effects Specification } & \\
\hline \hline & & & \\
Cross-section fixed (dummy variables) & & -0.011838 \\
\hline \hline & & & \\
R-squared & 0.070574 & Mean dependent var & \\
Adjusted R-squared & 0.054819 & S.D. dependent var & -1.554519 \\
S.E. of regression & 0.110303 & Akaike info criterion & -1.437352 \\
Sum squared resid & 94.74267 & Schwarz criterion & -1.514395 \\
Log likelihood & 6288.896 & Hannan-Quinn criter. & 1.979276 \\
F-statistic & 4.479475 & Durbin-Watson stat & \\
Prob(F-statistic) & 0.000000 & & \\
\hline \hline
\end{tabular}

\section{CAPM GLOBAL (CARTEIRAS)}

Dependent Variable: R?-TB10

Method: Pooled Least Squares 
Date: 12/06/15 Time: 15:34

Sample: 2010M01 2014M12

Included observations: 60

Cross-sections included: 60

Total pool (balanced) observations: 3600

Cross-section SUR (PCSE) standard errors \& covariance (d.f. corrected)

\begin{tabular}{lrlrr}
\hline \multicolumn{1}{c}{ Variable } & Coefficient & Std. Error & t-Statistic & Prob. \\
\hline \multicolumn{1}{c}{ C } & -0.014107 & 0.004617 & -3.055052 & 0.0023 \\
\multicolumn{1}{c}{ SP500-TB10 } & 0.554203 & 0.120655 & 4.593269 & 0.0000 \\
\hline \hline R-squared & 0.212684 & Mean dependent var & -0.010390 \\
Adjusted R-squared & 0.212466 & S.D. dependent var & 0.045284 \\
S.E. of regression & 0.040186 & Akaike info criterion & -3.590025 \\
Sum squared resid & 5.810556 & Schwarz criterion & -3.586586 \\
Log likelihood & 6464.044 & Hannan-Quinn criter. & -3.588799 \\
F-statistic & 971.9593 & Durbin-Watson stat & 1.451489 \\
Prob(F-statistic) & 0.000000 & & \\
\hline \hline
\end{tabular}

\section{CAPM LOCAL (ATIVOS INDIVIDUAIS)}

Dependent Variable: R?-TB10

Method: Pooled Least Squares

Date: 12/06/15 Time: 15:36

Sample: 2010M01 2014M12

Included observations: 60

Cross-sections included: 132

Total pool (balanced) observations: 7920

Cross-section SUR (PCSE) standard errors \& covariance (d.f. corrected)

\begin{tabular}{crrrr}
\hline \hline Variable & Coefficient & Std. Error & t-Statistic & Prob. \\
\hline \hline C & 0.023407 & 0.020259 & 1.155368 & 0.2480 \\
IBOV-CDI & 0.629024 & 0.057783 & 10.88605 & 0.0000 \\
RC & -15.91133 & 11.86064 & -1.341523 & 0.1798 \\
Fixed Effects (Cross) & & & & \\
A1--C & 0.014200 & & & \\
A132--C & 0.017686 & & & \\
\hline \hline
\end{tabular}

Effects Specification

Cross-section fixed (dummy variables)

\begin{tabular}{lllr}
\hline \hline R-squared & 0.128922 & Mean dependent var & -0.011838 \\
Adjusted R-squared & 0.114042 & S.D. dependent var & 0.113457 \\
S.E. of regression & 0.106792 & Akaike info criterion & -1.619102 \\
Sum squared resid & 88.79486 & Schwarz criterion & -1.501055 \\
Log likelihood & 6545.645 & Hannan-Quinn criter. & -1.578676 \\
F-statistic & 8.664296 & Durbin-Watson stat & 2.038798 \\
Prob(F-statistic) & 0.000000 & & \\
\hline
\end{tabular}


CAPM LOCAL (CARTEIRAS)

Dependent Variable: R?-TB10

Method: Pooled Least Squares

Date: 12/06/15 Time: 15:37

Sample: 2010M01 2014M12

Included observations: 60

Cross-sections included: 60

Total pool (balanced) observations: 3600

Cross-section SUR (PCSE) standard errors \& covariance (d.f. corrected)

\begin{tabular}{lrlrr}
\hline \hline \multicolumn{1}{c}{ Variable } & Coefficient & Std. Error & t-Statistic & Prob. \\
\hline \hline C & 0.027008 & 0.019436 & 1.389602 & 0.1647 \\
\multicolumn{1}{c}{ IBOV-CDI } & 0.621040 & 0.055433 & 11.20341 & 0.0000 \\
RC & -17.23752 & 11.37840 & -1.514934 & 0.1299 \\
\hline \hline R-squared & 0.573238 & Mean dependent var & -0.010390 \\
Adjusted R-squared & 0.573001 & S.D. dependent var & 0.045284 \\
S.E. of regression & 0.029591 & Akaike info criterion & -4.201872 \\
Sum squared resid & 3.149592 & Schwarz criterion & -4.196715 \\
Log likelihood & 7566.370 & Hannan-Quinn criter. & -4.200035 \\
F-statistic & 2415.796 & Durbin-Watson stat & 1.777517 \\
Prob(F-statistic) & 0.000000 & & \\
\hline \hline
\end{tabular}

